University of Tennessee Health Science Center

UTHSC Digital Commons

$12-2013$

\title{
The Relationship between Health Literacy and Health Outcomes: A Mixed-Methods Study of African-American Adult Patients with Asthma
}

Courtnee Erin Melton

University of Tennessee Health Science Center

Follow this and additional works at: https://dc.uthsc.edu/dissertations

Part of the Public Health Education and Promotion Commons

\section{Recommended Citation}

Melton, Courtnee Erin, "The Relationship between Health Literacy and Health Outcomes: A MixedMethods Study of African-American Adult Patients with Asthma" (2013). Theses and Dissertations (ETD). Paper 171. http://dx.doi.org/10.21007/etd.cghs.2013.0210.

This Dissertation is brought to you for free and open access by the College of Graduate Health Sciences at UTHSC Digital Commons. It has been accepted for inclusion in Theses and Dissertations (ETD) by an authorized administrator of UTHSC Digital Commons. For more information, please contact jwelch30@uthsc.edu. 


\title{
The Relationship between Health Literacy and Health Outcomes: A Mixed- Methods Study of African-American Adult Patients with Asthma
}

\begin{abstract}
Introduction: Asthma affects 24.6 million people in the United States, and AfricanAmericans share a disproportionate burden of the disease. African-Americans have a higher prevalence of asthma, worse asthma control, higher hospitalization rates, and higher asthma mortality rates African-Americans are also more likely to have low health literacy. Low health literacy has been linked to increased use of emergency care, increased hospitalization, decreased use of preventive services, poorer medication adherence, poorer interpretation of prescription labels, nutrition labels, and health messages, and poorer health outcomes. Consequently, health literacy is one of the modifiable individual factors that contributes to asthma disparities among African-Americans.

Methods: This study was a sub-study of a larger clinical trial. An explanatory sequential mixed methods approach was used in this study. In the initial quantitative phase, 99 participants completed crosssectional surveys. Numeracy and health literacy (print literacy) were evaluated, and participants were dichotomized into having adequate or limited numeracy and adequate or low print literacy. Primary outcomes were asthma control (ACQ) and asthma related quality of life (AQLQ-S). Mediating factors examined were asthma self-efficacy and asthma selfmanagement knowledge. Following the quantitative phase, four participants were chosen to complete semi-structured interviews. Interview questions focused on information seeking behaviors, patient-provider communication, and self-management behaviors. Chi-square, t-tests, and Wilcoxon Mann-Whitney test were used to compare participants across health literacy levels. The Preacher and Hayes method of bootstrapping multiple mediator analysis was used in this study. Both total and specific indirect effects were examined using 5,000 bootstrap samples to calculate $95 \%$ bias corrected confidence intervals. SAS 9.3 was used to analyze quantitative data. QDA Miner was used to perform Interpretative Phenomenological Analysis of the interview data.
\end{abstract}

Results: Bivariate analysis indicated that adequate numeracy but not adequate print literacy was significantly associated with increased quality of life and asthma control. Mediation analysis found that print literacy was not associated with asthma outcomes, and self-efficacy and knowledge did not mediate the relationship. Numeracy was associated with quality of life, and this relationship was partially mediated by self-efficacy and knowledge. Numeracy was not associated with asthma control. Three themes emerged from qualitative analysis including "information received vs. information desired," "trial and error," and "expectations of the patient-provider relationship." Lastly, quantitative and qualitative results were integrated to make meta-inferences.

Discussion/Conclusion: Results indicate that numeracy, but not print literacy, is associated with asthma outcomes. This finding is consistent with previous literature in this area. Self-efficacy and asthma knowledge are not primary mediators between health literacy and asthma outcomes, and other mediators (i.e., patient-provider communication and patient activation) may have a larger impact. Culture plays an important role in health literacy and patient-provider communication. Future research should examine other mediators besides selfefficacy and asthma knowledge, the role of numeracy in asthma selfmanagement, and the intersection of culture and health literacy in relation to health outcomes.

\section{Document Type}

Dissertation

Degree Name

Doctor of Philosophy (PhD) 


\section{Program}

Health Outcomes and Policy Research

Research Advisor

James E. Bailey, MD

\section{Keywords}

African-American, asthma, health literacy

\section{Subject Categories}

Medicine and Health Sciences | Public Health | Public Health Education and Promotion

\section{Comments}

One year embargo expired December 2014 
The Relationship between Health Literacy and Health Outcomes: A Mixed-Methods Study of African-American Adult Patients with Asthma

\author{
A Dissertation \\ Presented for \\ The Graduate Studies Council \\ The University of Tennessee \\ Health Science Center
}

\begin{abstract}
In Partial Fulfillment
Of the Requirements for the Degree

Doctor of Philosophy

From The University of Tennessee
\end{abstract}

By

Courtnee Erin Melton

December 2013 
Copyright (C) 2013 by Courtnee Erin Melton. All rights reserved. 


\section{DEDICATION}

This dissertation is dedicated to the loving memory of AJ Beard, the man who started it all. I love you and always carry you in my heart. This dissertation is also dedicated to my parents. This accomplishment is as much yours as it is mine. I could not have done it without y'all.

I Samuel 18:14 


\section{ACKNOWLEDGEMENTS}

I would like to thank Dr. Graff and Dr. Holmes for their support, edits, and encouraging words throughout this process. You both have helped me more than you know and I would not have made it without you. I am forever grateful.

I would like to thank George Relyea, Dr. Bailey, and Dr. Brown for their time and for serving on my committee. Thank you to Dr. Elliot Israel and Harvard Clinical Research Institute for allowing me to use their data and participants. Thank you Brian Manning and Dr. Wilson Pace for supporting my sub-study and helping me collect data at other sites.

I would also like to thank my parents who convinced me I could do anything I put my mind to, supported me in all my endeavors, prayed for me, assured me of my sanity, and listened to me complain about grad school. Also, shout out to all the musicians who provided the soundtrack to my dissertation. None of this would have been possible without music.

Most importantly, a huge thank you to all the participants of this study who shared their time, thoughts, and stories. They helped me more than I helped them. 


\begin{abstract}
Introduction: Asthma affects 24.6 million people in the United States, and African-Americans share a disproportionate burden of the disease. African-Americans have a higher prevalence of asthma, worse asthma control, higher hospitalization rates, and higher asthma mortality rates African-Americans are also more likely to have low health literacy. Low health literacy has been linked to increased use of emergency care, increased hospitalization, decreased use of preventive services, poorer medication adherence, poorer interpretation of prescription labels, nutrition labels, and health messages, and poorer health outcomes. Consequently, health literacy is one of the modifiable individual factors that contributes to asthma disparities among AfricanAmericans.
\end{abstract}

Methods: This study was a sub-study of a larger clinical trial. An explanatory sequential mixed methods approach was used in this study. In the initial quantitative phase, 99 participants completed cross-sectional surveys. Numeracy and health literacy (print literacy) were evaluated, and participants were dichotomized into having adequate or limited numeracy and adequate or low print literacy. Primary outcomes were asthma control (ACQ) and asthma related quality of life (AQLQ-S). Mediating factors examined were asthma self-efficacy and asthma self-management knowledge. Following the quantitative phase, four participants were chosen to complete semi-structured interviews. Interview questions focused on information seeking behaviors, patient-provider communication, and self-management behaviors. Chi-square, t-tests, and Wilcoxon Mann-Whitney test were used to compare participants across health literacy levels. The Preacher and Hayes method of bootstrapping multiple mediator analysis was used in this study. Both total and specific indirect effects were examined using 5,000 bootstrap samples to calculate $95 \%$ bias corrected confidence intervals. SAS 9.3 was used to analyze quantitative data. QDA Miner was used to perform Interpretative Phenomenological Analysis of the interview data.

Results: Bivariate analysis indicated that adequate numeracy but not adequate print literacy was significantly associated with increased quality of life and asthma control. Mediation analysis found that print literacy was not associated with asthma outcomes, and self-efficacy and knowledge did not mediate the relationship. Numeracy was associated with quality of life, and this relationship was partially mediated by selfefficacy and knowledge. Numeracy was not associated with asthma control. Three themes emerged from qualitative analysis including "information received vs. information desired," "trial and error," and "expectations of the patient-provider relationship." Lastly, quantitative and qualitative results were integrated to make metainferences.

Discussion/Conclusion: Results indicate that numeracy, but not print literacy, is associated with asthma outcomes. This finding is consistent with previous literature in this area. Self-efficacy and asthma knowledge are not primary mediators between health literacy and asthma outcomes, and other mediators (i.e., patient-provider communication 
and patient activation) may have a larger impact. Culture plays an important role in health literacy and patient-provider communication. Future research should examine other mediators besides self-efficacy and asthma knowledge, the role of numeracy in asthma self-management, and the intersection of culture and health literacy in relation to health outcomes. 


\section{TABLE OF CONTENTS}

CHAPTER 1. INTRODUCTION ......................................................................................1

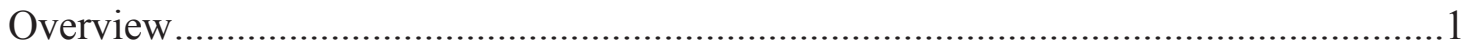

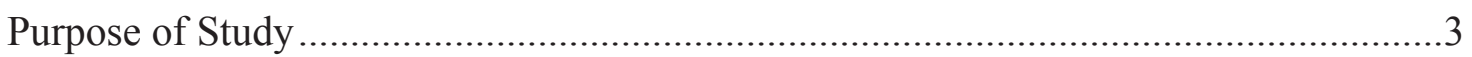

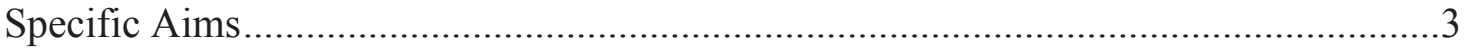

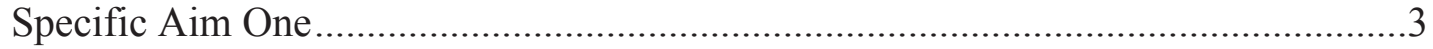

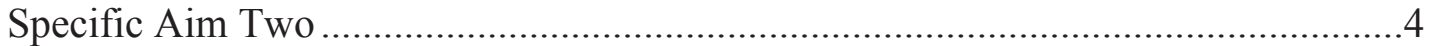

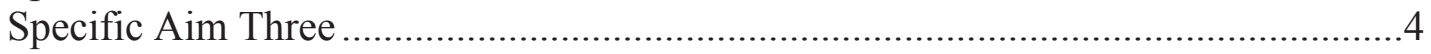

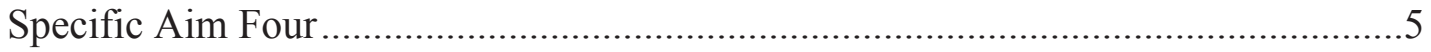

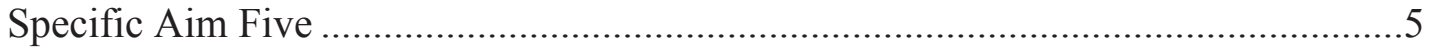

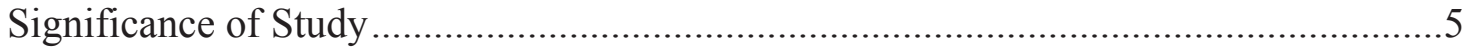

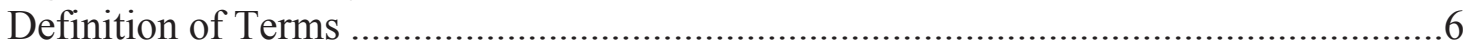

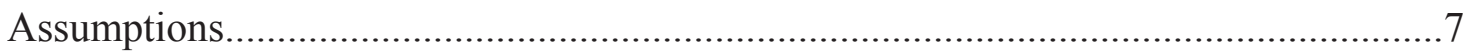

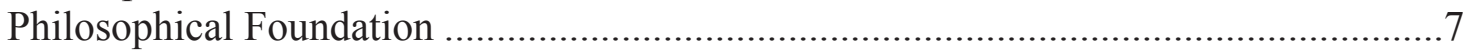

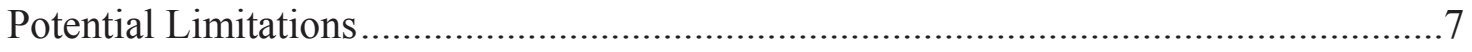

CHAPTER 2. REVIEW OF LITERATURE ...........................................................9

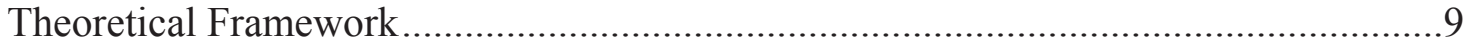

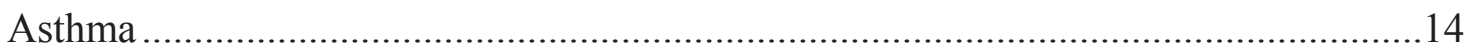

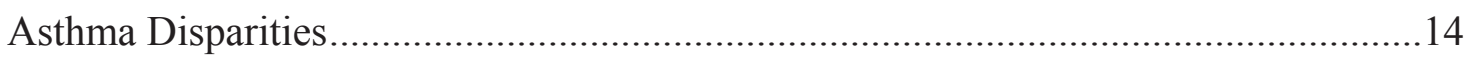

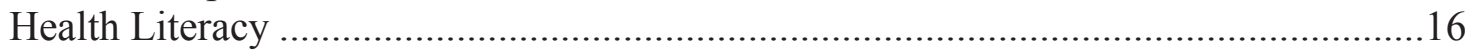

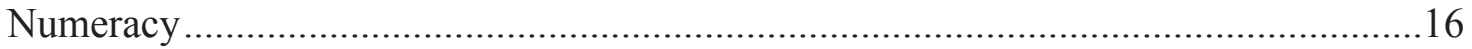

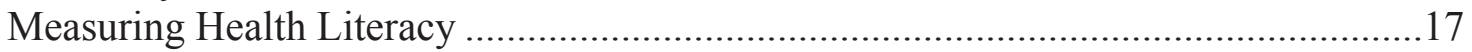

Health Literacy and Asthma Outcomes ................................................................. 19

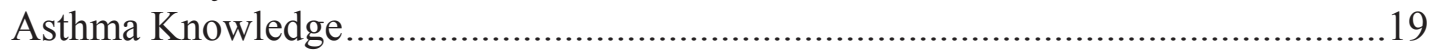

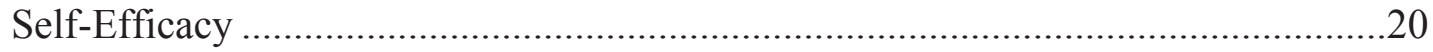

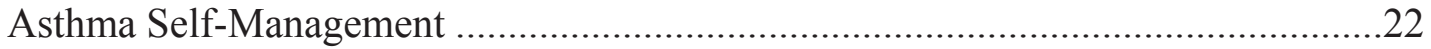

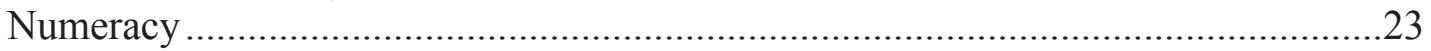

Interventions Addressing Low Health Literacy ....................................................24

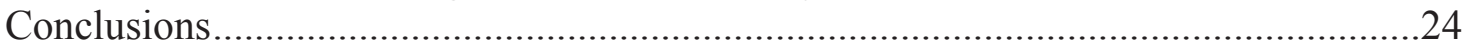

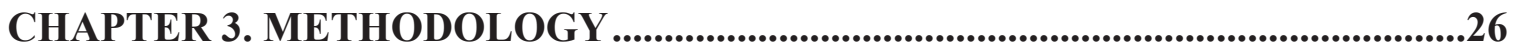

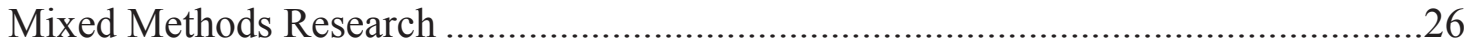

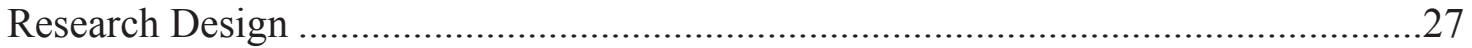

Phase One: Quantitative......................................................................................... 28

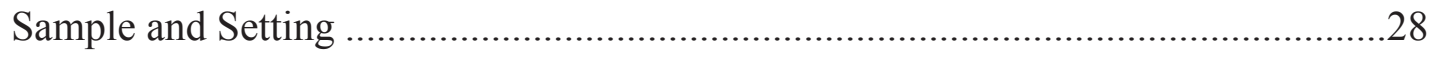

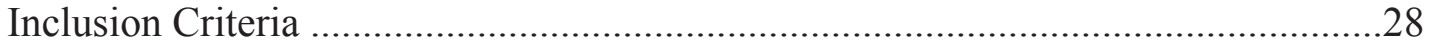

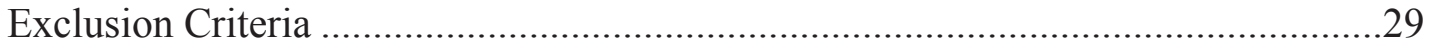

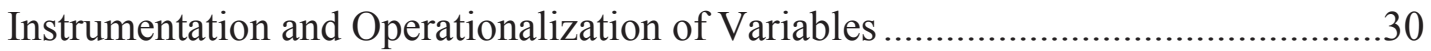

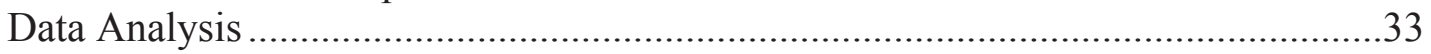

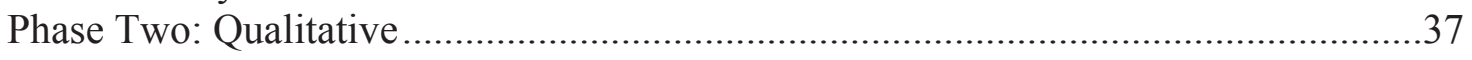

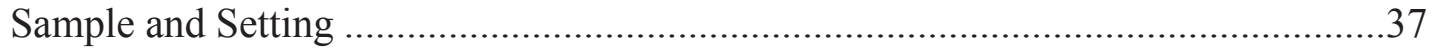

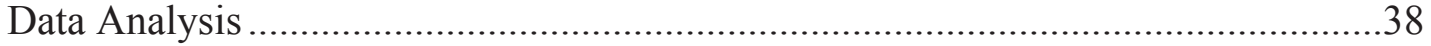

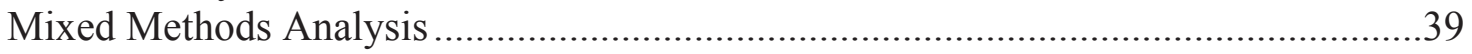


Consideration of Human Subjects

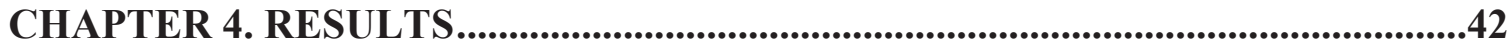

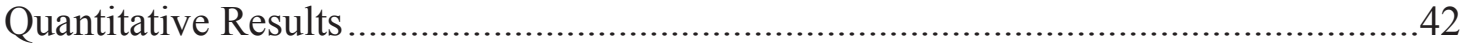

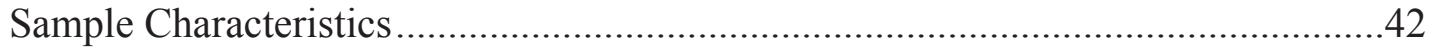

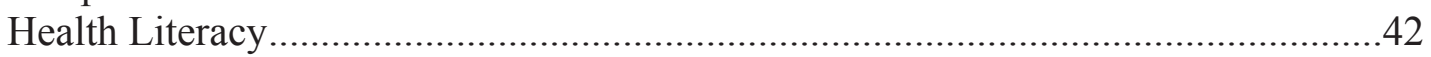

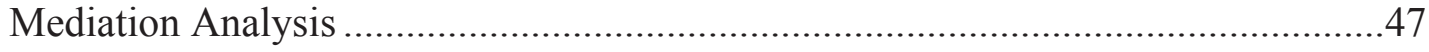

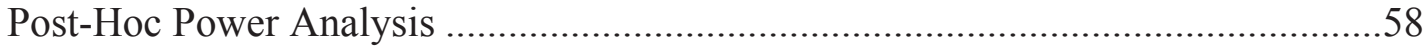

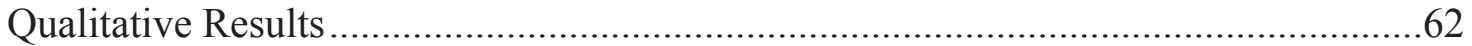

Information Desired vs. Information Received................................................6. 63

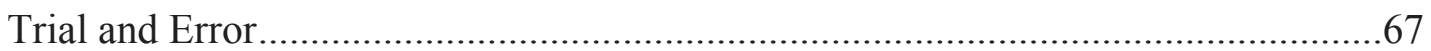

Expectations of the Patient-Provider Relationship ..............................................68

Integration of Qualitative and Quantitative Results ................................................71

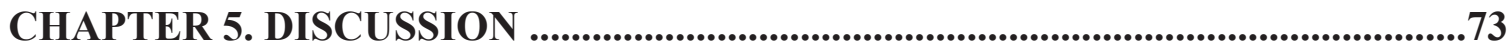

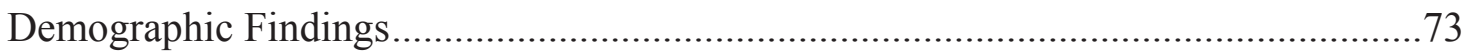

Relationship between Health Literacy and Health Outcomes .....................................73

Self-Efficacy and Asthma Knowledge as Mediators ............................................. 74

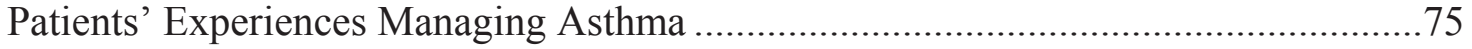

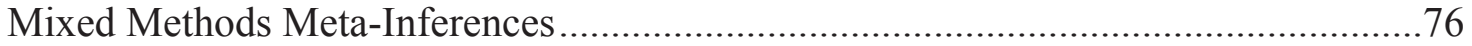

Implication of Findings..................................................................................... 78

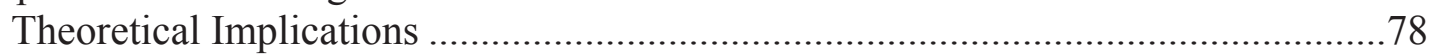

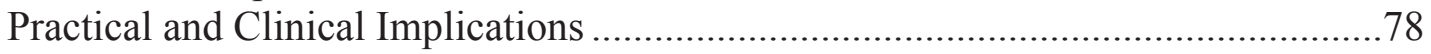

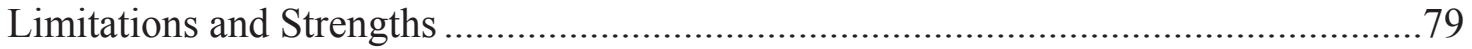

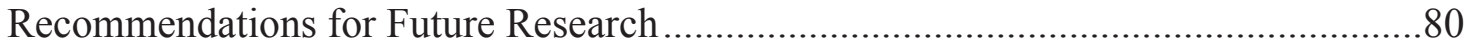

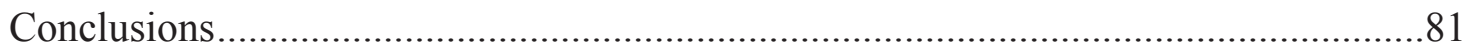

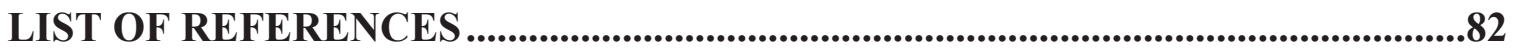

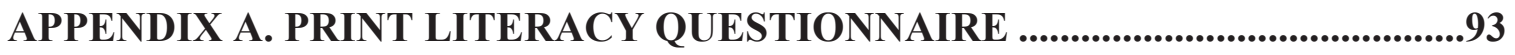

APPENDIX B. QUALITATIVE INTERVIEW SCHEDULE .....................................94

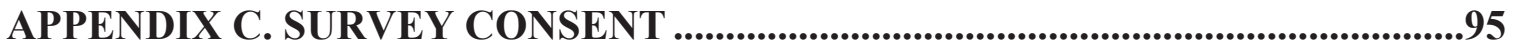

VITA 


\section{LIST OF TABLES}

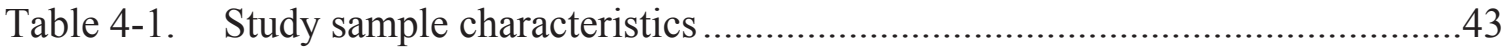

Table 4-2. Characteristics of population stratified by print literacy...........................44

Table 4-3. Characteristics of population stratified by numeracy ...............................45

Table 4-4. Model 1: Partial effect of control variables on asthma control....................49

Table 4-5. Indirect effects of print literacy on asthma control through self-efficacy

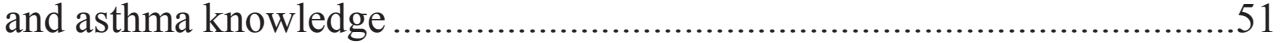

Table 4-6. Model 2: Partial effect of control variables on asthma related quality of life

Table 4-7. Indirect effects of print literacy on asthma related quality of life through self-efficacy and asthma knowledge ..................................................54

Table 4-8. Model 3: Partial effect of control variables on asthma control....................56

Table 4-9. Indirect effects of numeracy on asthma control through self-efficacy and

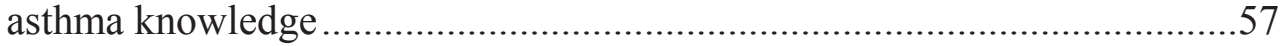

Table 4-10. Model 4: Partial effect of control variables on asthma related quality of

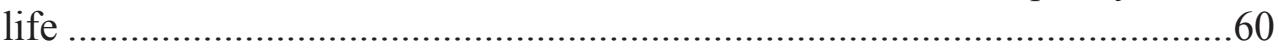

Table 4-11. Indirect effects of numeracy on asthma related quality of life through self-efficacy and asthma knowledge

Table 4-12. Characteristics of interview participants............................................64

Table 4-13. Individual participant clusters and emerging themes...............................65

Table 4-14. Linking survey results to interview results ..........................................72 


\section{LIST OF FIGURES}

Figure 2-1. Institute of medicine health literacy framework .......................................

Figure 2-2. Conceptual model of the relationship between individual capacities, health-related print and oral literacy, and health outcomes ........................11

Figure 2-3. Causal pathways between limited health literacy and health outcomes .......12

Figure 2-4. Conceptual model of the relationship between health literacy, mediators,

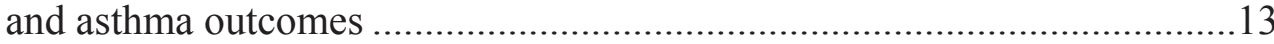

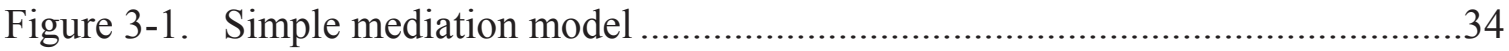

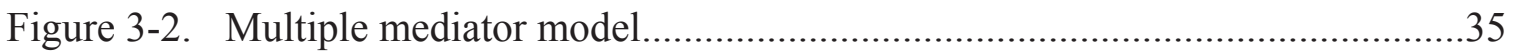

Figure $3-3$. Visual model of explanatory sequential design .....................................40

Figure 4-1. Associations among print literacy, self-efficacy, asthma knowledge, and

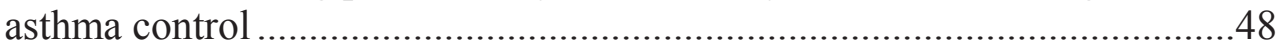

Figure 4-2. Associations among print literacy, self-efficacy, asthma knowledge, and asthma related quality of life

Figure 4-3. Associations among numeracy, self-efficacy, asthma knowledge, and asthma control

Figure 4-4. Associations among numeracy, self-efficacy, asthma knowledge, and quality of life 


\section{LIST OF ABBREVIATIONS}

ACQ

ANQ

AQLQ

ASE

$\mathrm{BC}$

$\mathrm{BCa}$

BELT

BP

ED

ICS

IOM

IPA

LABA

MDI

MDM

NVS

QOL

REALM

$\mathrm{SAS}^{\circledR}$

SES

S-TOFHLA

TOFHLA
Asthma Control Questionnaire

Asthma Numeracy Questionnaire

Asthma Quality of Life Questionnaire

Asthma Self-Efficacy Scale

Bias Corrected Confidence Intervals

Accelerated Bias Corrected Confidence Intervals

Blacks and Exacerbations on LABA vs. Tiotropium

Percentile Based Confidence Intervals

Emergency Department

Inhaled Corticosteroid

Institute of Medicine

Interpretative Phenomenological Analysis

Long Acting Beta Agonist

Metered Dose Inhaler

Multivariate Delta Method

Newest Vital Sign

Quality of Life

Rapid Estimate of Adult Literacy in Medicine

Statistical Analysis System

Socioeconomic Status

Short form Test of Functional Health Literacy in Adults

Test of Functional Health Literacy in Adults 


\section{CHAPTER 1. INTRODUCTION}

\section{Overview}

Asthma affects 24.6 million people in the United States, is responsible for 14.2 million days of missed work (Akinbami, Moorman, \& Xiang, 2011), and costs $\$ 30$ billion dollars in direct expenses annually (Kamble \& Bharmal, 2009). Certain groups share a disproportionate burden of the disease. African-Americans, American Indians, and Puerto Rican populations have a higher prevalence of asthma and worse asthma control compared to non-Latino whites. In addition to increased asthma morbidity and mortality, African-Americans are also more likely to have low health literacy. Health literacy is a national issue that has become increasingly recognized as an important factor for improving the quality of care and the health of the population. Health care consumers receive information from a variety of sources and are expected to be able to understand and synthesize the information to make informed decisions. These expectations place a heavy burden on patients, and most health information is not understood by the target audience (Nielsen-Bohlman, Panzer, \& Kindig, 2004).

The Institute of Medicine(IOM) defines health literacy as "the degree to which individuals have the capacity to obtain, process, and understand basic health information and services needed to make appropriate health decisions" (Nielsen-Bohlman et al., 2004, p.2). Researchers have identified three major dimensions of health literacy including: print literacy, oral literacy, and numeracy. Print literacy refers to the ability to read and comprehend written materials. Print literacy skills are needed for understanding written patient education materials, understanding informed consents, and being able to understand and follow hospital discharge instructions. Oral literacy encompasses speaking and listening skills (Baker, 2006). Much of the information exchanged during a health visit relies on oral health literacy skills. Individuals must be able to understand explanations and instructions from health professionals as well as effectively communicate their symptoms, needs, or concerns to their health care provider. Numeracy is the quantitative aspect of health literacy. Medication dosing and applying numerical risk information to make decisions about treatment require quantitative skills. Adequate health literacy is required to navigate the health care system, follow directions, and make informed decisions regarding health.

Approximately 90 million U.S. adults have limited health literacy. It is estimated that low health literacy results in an additional $\$ 69$ billion dollars in health expenditures yearly (Nielsen-Bohlman et al., 2004). Health literacy trends are seen among certain demographics. Women tend to have higher health literacy than men. White and Asian/Pacific Islander adults have higher health literacy than Blacks, Hispanics, Indian/Alaska Native, and Multiracial adults. Adults ages 65 and older have lower health literacy than adults in younger age groups. Adults who graduate from high school or have a GED have higher health literacy than adults who do not. Once adults surpass a high school education, health literacy increases with each level of higher educational completion. Adults living below the poverty level have lower health literacy than adults 
living above the poverty level. Adults who have health insurance through their employer, a family member's employer, military insurance, or privately purchased insurance have higher health literacy than uninsured adults and adults who have Medicaid or Medicare (Kutner, Greenberg, Jin, Paulsen, \& White, 2006).

Research has shown other correlates of low health literacy. Low health literacy is associated with increased comorbidities and disease complications in diabetes and chronic heart failure (Morrow et al., 2006; Schillinger et al., 2002). Individuals with low health literacy are also more likely to have lower self-reported poorer health status and are more likely to have a chronic disease (Nielsen-Bohlman et al, 2004). It has been suggested that individuals with low health literacy may have increased disease severity. However, there is not strong evidence to support that hypothesis, and the nature of relationship between disease severity and health literacy is inconclusive (Berkman, Sheridan, Donahue, Halpern, \& Crotty, 2011).

Low health literacy has been linked to increased use of emergency care and hospital services, but decreased use of preventive services. This pattern of health care utilization is expensive and negatively effects continuity of care and health outcomes. Poor medication adherence and interpretation of prescription labels and health messages are also associated with low health literacy. The impact of low health literacy on multiple facets of care contributes to poorer health outcomes (Berkman et al., 2011; Zarcadoolas, Pleasant, \& Greer, 2006).

The causal relationship between health literacy and health outcomes has not been well established, either, but there are a variety of possible mediating factors including self-efficacy, disease and self-management knowledge, and compliance (Berkman et al., 2011). All of these factors are at the individual level and may help explain the relationship between health literacy and health outcomes. Non-individual factors such as social support and social environment may also play a role (Lee, Arozullah, \& Cho, 2004).

The 2010 National Action Plan to Improve Health Literacy (United States Department of Health and Human Services [DHHS], 2010) issued a call for basic health literacy research to understand the primary mechanisms through which limited health literacy affects health outcomes. This fundamental knowledge is needed to create reliable and effective interventions. This research project is an answer to the call and examines individual factors influencing the relationship between health literacy and health outcomes in a vulnerable population using both quantitative and qualitative data to develop a more complete understanding.

African-American patients exhibit greater difficulty communicating with providers compared to Whites. They are less likely to engage in shared decision making, have greater distrust of the health care system, and are more passive during medical encounters (Cegala \& Post, 2006; Schoenthaer et al., 2009). Patients with low health literacy have more difficulty understanding medical jargon, accurately reporting their medical history, and understanding instructions from providers (Williams, Davis, Parker, 
$\&$ Weiss, 2002). They are also more passive when interacting with providers, less likely to engage in shared decision making, and less likely to ask questions (Paasche-Orlow \& Wolf, 2007). Knowledge gained from this study will help identify ways to empower patients to be more informed and engaged partners in their health. Understanding specific mediating factors among African-Americans will aid in the creation of culturally appropriate, evidence-based interventions to improve the patient's contribution to patientprovider communication. Health literacy's contribution to patient-provider communication is important because effective communication is associated with more patient satisfaction, increased adherence to treatment, and better health outcomes (Ferguson \& Candib, 2002).

\section{Purpose of Study}

This study addressed health literacy and health outcomes among AfricanAmerican adults with asthma. An explanatory sequential mixed methods approach was used to obtain quantitative results from a sample and then further explain those results using qualitative methods. In the first phase, survey data were used to determine if health literacy is associated with asthma outcomes and what factors mediate this relationship. In the second phase, qualitative semi-structured interviews were conducted to explore the experiences of individuals with varying levels of health literacy (from the quantitative results) to offer insight into relationship between health literacy and asthma outcomes. A mixed methods approach was then used to integrate the findings from phase one and phase two. This design was used to guide purposeful sampling for the qualitative interviews and to use the qualitative interviews to help explain the quantitative results.

\section{Specific Aims}

The specific aims of this study were designed to determine the factors that mediate the relationship between health literacy and health outcomes and to explore the individual perspective of managing asthma for greater insight into the connection between health literacy and asthma outcomes. Associated hypotheses or research questions follow each aim.

\section{Specific Aim One}

To determine the relationship between health literacy and health outcomes

- Individuals with low print literacy will have poorer asthma quality of life than individuals with adequate print literacy.

- Individuals with low print literacy will have poorer asthma control than individuals with adequate print literacy. 
- Individuals with limited numeracy will have poorer asthma quality of life than individuals with adequate numeracy.

- Individuals with limited numeracy will have poorer asthma control than individuals with adequate numeracy.

\section{Specific Aim Two}

To determine whether self-efficacy mediates the relationship between health literacy and health outcomes

- Self-efficacy will mediate the relationship between print literacy and asthma quality of life.

- Self-efficacy will mediate the relationship between print literacy and asthma control.

- Self-efficacy will mediate the relationship between numeracy and asthma quality of life.

- Self-efficacy will mediate the relationship between numeracy and asthma control.

\section{Specific Aim Three}

To determine whether asthma knowledge mediates the relationship between health literacy and health outcomes

- Asthma knowledge will mediate the relationship between print literacy and asthma quality of life.

- Asthma knowledge will mediate the relationship between print literacy and asthma control.

- Asthma knowledge will mediate the relationship between numeracy and asthma quality of life.

- Asthma knowledge will mediate the relationship between numeracy and asthma control. 


\section{Specific Aim Four}

To use the experiences of individuals with asthma to better understand the relationship between health literacy and asthma outcomes

- How do individuals with varying levels of print use health information to manage their asthma?

- How do individuals with varying levels of print literacy interact with health care providers to manage their asthma?

- What do individuals with varying levels of print literacy desire to manage their asthma?

\section{Specific Aim Five}

To examine the extent to which patient experiences of self-management enhance the understanding of the relationship between health literacy skills and asthma outcomes

- How do the interview data exploring the experiences of adults with asthma help explain the quantitative results about the relationship between health literacy and asthma outcomes?

- How does convergence and divergence among the qualitative and quantitative data offer insight the relationship between health literacy and health outcomes?

\section{Significance of Study}

There is limited research on the prevalence of low health literacy among AfricanAmericans with asthma, and the degree to which low health literacy contributes to poor health outcomes (Diette \& Rand, 2007). This study built on the previous literature in numerous ways. First, this study used measurement tools (Chew, Bradley, \& Bokyo, 2004; Weiss et al., 2005) that are practical for use in a clinical setting but have not been widely used with African-American populations. After assessing health literacy, the relationship between health literacy and asthma outcomes (asthma quality of life and asthma control) was examined. The study also investigated asthma knowledge and selfefficacy as mediating factors between health literacy and outcomes. There has been limited research exploration of the mediating factors between health literacy and asthma outcomes (Rosas-Salazar, Apter, Canino, \& Celedón, 2012). Lastly, to the investigator's knowledge, no studies to date have employed qualitative methods to explore health literacy and asthma. Understanding the patient perspective may elucidate factors influencing the health literacy-health outcomes relationship that are absent using quantitative inquiry. 
Documenting the prevalence of low health literacy and its effect on health outcomes may make health care providers more aware of the communication needs of their patients. If self-efficacy and asthma knowledge are found to be important mediating factors, interventions and patient education in this population may be more focused on these aspects of disease management. This study also demonstrated that the Newest Vital Sign (NVS) and/or three brief screening questions can be used to quickly identify individuals who may be at risk for adverse outcomes in a clinical setting. AfricanAmericans have poorer asthma outcomes, share a disproportionate burden of the disease, and also are more likely to have low health literacy. The patient perspective has not been included in the previous literature, yet it is vital that this population is included in research to gain better understanding and to ultimately inform clinical practice and decrease disparities. The majority of chronic disease management takes place outside of health providers' care. Individuals make daily decisions about their health and are indeed experts about their disease. Efforts to improve patient outcomes should include the patient perspective of disease management.

\section{Definition of Terms}

- Asthma: Asthma is a chronic inflammatory disease of the airways (U.S. Department of Health and Human Services [DHHS] \& National Institutes of Health [NIH], 2007).

- Asthma Knowledge: Asthma knowledge is the factual information concerning the pathophysiology of the disease, asthma symptoms and triggers, drug therapies, and appropriate behaviors to self-manage the disease (Wigal et al., 1993).

- Health Literacy: The degree to which individuals have the capacity to obtain, process, and understand basic health information and services needed to make appropriate health decisions (Nielsen-Bohlman et al., 2004).

- Health Outcome: A short or long term effect on the health of an individual, group, or population.

- Numeracy: The degree to which individuals have the capacity to access, process, interpret, communicate, and act on numerical, quantitative, graphical, bio statistical, and probabilistic health information needed to make effective health decisions (Golbeck, Ahlers-Schmidt, Paschal, \& Dismuke, 2005).

- Self-efficacy: Perceived ability to control something (Wigal et al., 1993).

- Self-management: Day-to-day decisions and activities patients engage in to live with and control their disease (Paasche-Orlow \& Wolf, 2007). 


\section{Assumptions}

The assumptions of the study included the following:

- Individuals with asthma are experts on their health and self-management practices

- Print literacy and numeracy are distinct aspects of health literacy with unique contributions to health outcomes

- All questionnaires used are valid and reliable instruments for measuring the intended construct

- Participant responded to questionnaires and interviews honestly

\section{Philosophical Foundation}

Mixed methods research combines qualitative and quantitative inquiry. This approach to research is often contentious because of differing paradigms. Quantitative research is based on positivism. Positivism postulates that there is a single objective truth, and all phenomena can be reduced to observed indicators which represent that single truth. This method emphasizes numerical data and hypotheses testing (Teddlie \& Tashakkori, 2009). Qualitative research is based on constructivism and interpretivism where multiple truths and multiple realities exist that are based on an individual's perception. Qualitative inquiry values narrative data and analysis usually results in themes. Mixed methods research is driven by the research question and uses all available and appropriate methodologies for answering the questions of interest (Teddlie \& Tashakkori, 2009).

This study used different assumptions for each phase of research. The initial phase of quantitative research was guided by positivism; while, constructivism guided the qualitative phase of the study. This study was built on the belief that methods from different paradigms can be combined and complement each other.

\section{Potential Limitations}

This study had several limitations. The data were collected during a single time period. Causal relationships and the effect of health literacy and health outcomes over time cannot be assessed. Secondly, this study was a sub-study of a larger study. Individuals who agreed to participate in the larger study may be different from individuals who chose not to participate. Individuals interested in participating in research may be more active participants in their health care and be more informed patients than those who chose not to participate. The larger study is testing the effectiveness of asthma medications with a follow-up period between 6 and 18 months. The nature of the main study may contribute to intrinsic bias and influence asthma 
outcomes (i.e., patients have better asthma outcomes due to participation in the study and/or study medications may be more effective than usually prescribed medications). Also, the study only included individuals with moderate to severe asthma. This population may not be reflective or representative of all African-Americans with asthma. The generalizability of the results to other populations (i.e., mild asthma, non-AfricanAmerican, etc.) should be made with caution. Lastly, this study only collected data from the perspective of individuals with asthma. However, the relationship between health literacy and health outcomes includes multiple factors beyond individual capacity that this study did not address. 


\section{CHAPTER 2. REVIEW OF LITERATURE}

Asthma is a chronic disease that disproportionately affects African-Americans, and health literacy contributes to that disparity. This section will begin with a discussion of theories explaining the relationship between health literacy and health outcomes. Next, an overview of asthma, asthma disparities, health literacy, self-efficacy, disease knowledge, and self-management is given to provide foundational knowledge. Next, literature discussing the relationship between health literacy and asthma outcomes will be presented to provide a context for the current study.

\section{Theoretical Framework}

Several models have been developed to frame the relationship between health literacy and health outcomes. The model developed by the Institute of Medicine (2004) presents health literacy as a mediator between literacy and health outcomes (Figure 2-1). Literacy is the set of basic reading, writing, mathematical, and speech skills. Literacy enables individuals to comprehend and convey health information. Health literacy is influenced by individual factors such as intellectual ability, social skills, and physical conditions and by the health context that health literacy skills are needed and used.

Baker (2006) expounded on the model presented in the IOM (Nielsen-Bohlman et

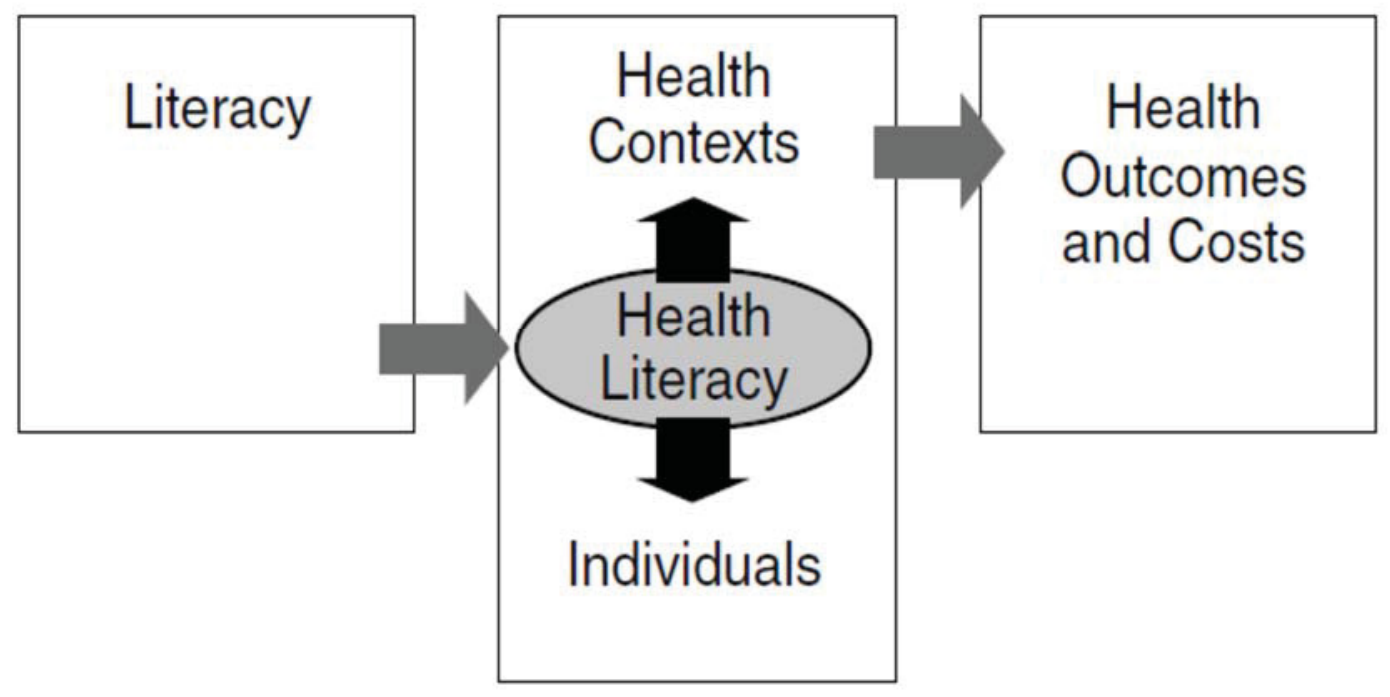

Figure 2-1. Institute of medicine health literacy framework

Reprinted with permission. Institute of Medicine (2004). Health Literacy: A Prescription to End Confusion. Washington D.C.: The National Academies Press, 34. 
al., 2004) report by providing more specific language to describe the different domains of health literacy and including other factors that are involved in the relationship. The model (Figure 2-2) consists of two major domains, individual capacity and health literacy. Individual capacity involves a person's reading fluency and their prior knowledge. Health literacy is divided into two sub domains, print literacy and oral literacy. A person's health literacy is influenced by a combination of their individual capacity and the complexity of the written and spoken messages they receive from the health care system. In this framework, health literacy is then one of many factors that lead to selfefficacy, positive attitudes, and behavior change and ultimately affects health outcomes.

Paasche-Orlow and Wolf (2007) developed a conceptual model (Figure 2-3) based on a review of previous health literacy research. This model is more detailed than Baker's (2006) model and includes three major domains (i.e. health care system, patientprovider interaction, and self-care behaviors) that connect health literacy and health outcomes. All three of the domains are influenced by both patient factors and extrinsic factors unrelated to the patient.

All three models demonstrate the complexity of the relationship, but no model is inclusive of all factors involved linking health literacy and health outcomes. There are many gaps in understanding the mechanisms linking health literacy and health outcomes, and basic research is needed (Johnson, Baur, \& Meissner, 2011). The current models are used as guidelines and should be refined through continued research (Paasche-Orlow \& Wolf, 2007).

The proposed framework for the current study (Figure 2-4) is a simplified version of the Baker (2006) model and was designed to supplement previous health literacy models. The current study is focused on individual capacity, and the Baker (2006) model is more focused on individual capacity than other frameworks. Consequently, the Baker model was appropriate. The proposed model specifies numeracy as a distinct aspect of health literacy as opposed to putting numeracy under the umbrella of print literacy. Numeracy encompasses quantitative skills that go beyond reading and understanding written materials. Evidence suggests that numeracy has a unique contribution to health outcomes (Thai \& George, 2010), and only two studies have focused on numeracy and asthma outcomes (Apter et al., 2006; Apter et al., 2009). Apter et al. (2009) found that numeracy was independently and significantly associated with asthma related quality of life. Osborn, Cavanaugh, Wallston, and Rothman (2010) also found that numeracy was independently associated with glycemic control. Also, the "other factors" in the Baker model are referred to as mediators in the proposed model, and individual capacity components of the Baker model are referred to as individual factors. These individual factors contribute to individual capacity and have been shown to influence health literacy (Lee et al., 2004). Currently, there are no measurement tools that address oral health literacy skills of patients (Nielsen-Bohlman et al., 2004). Because of the inability to accurately and reliably measure oral health literacy, it was not included in the proposed model. The exclusion of oral health literacy is due to measurement issues alone and is not indicative of oral health literacy's relative impact on health outcomes compared to other domains of health literacy. Lastly, the complexity and difficulty of written 


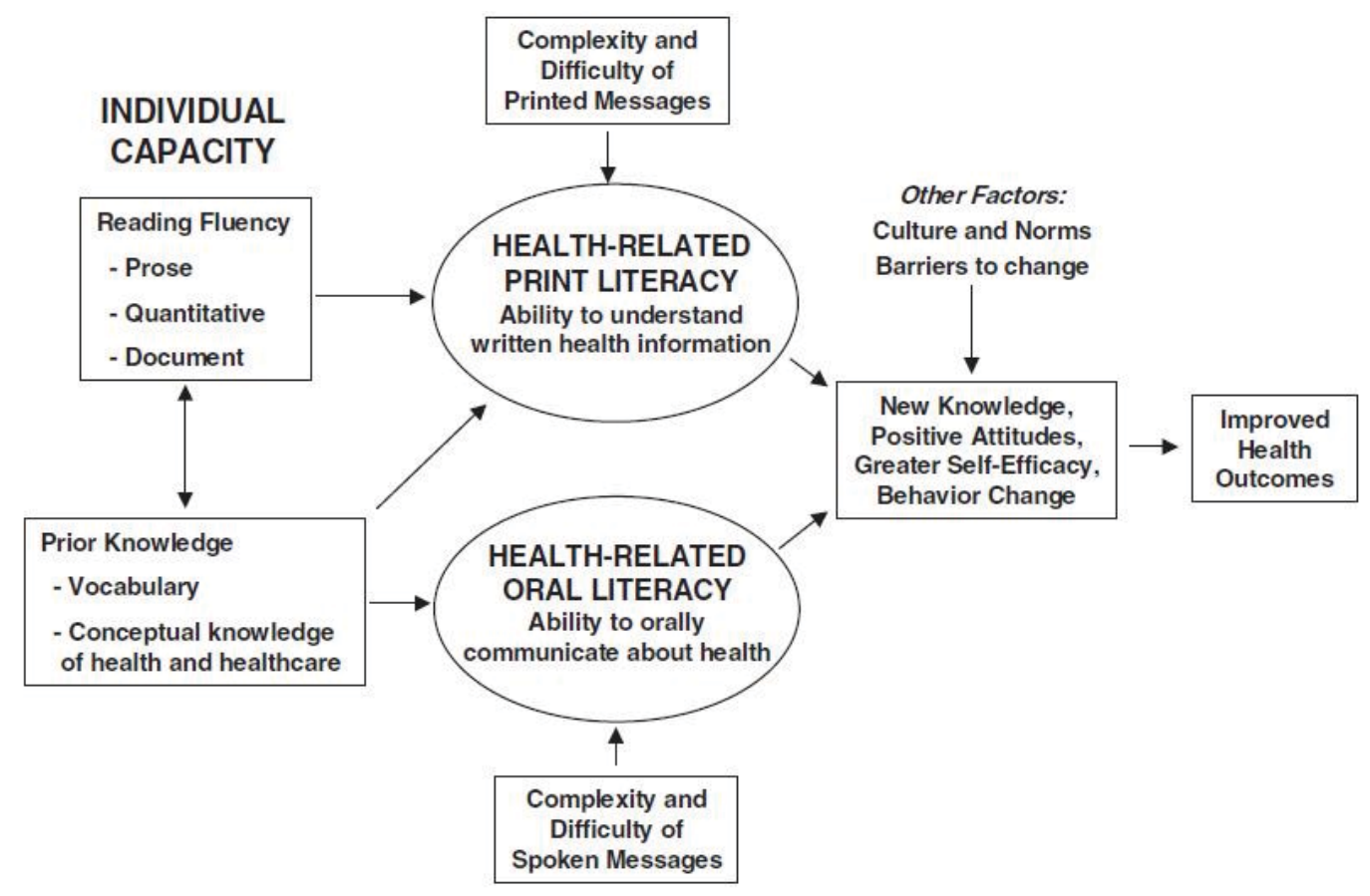

Figure 2-2. Conceptual model of the relationship between individual capacities, health-related print and oral literacy, and health outcomes

Reprinted with permission. Baker, D.W. (2006). The meaning and the measure of health literacy. Journal of General Internal Medicine, 21, 878-883. doi: 10.111/j.15251497.2006.00540.x. 


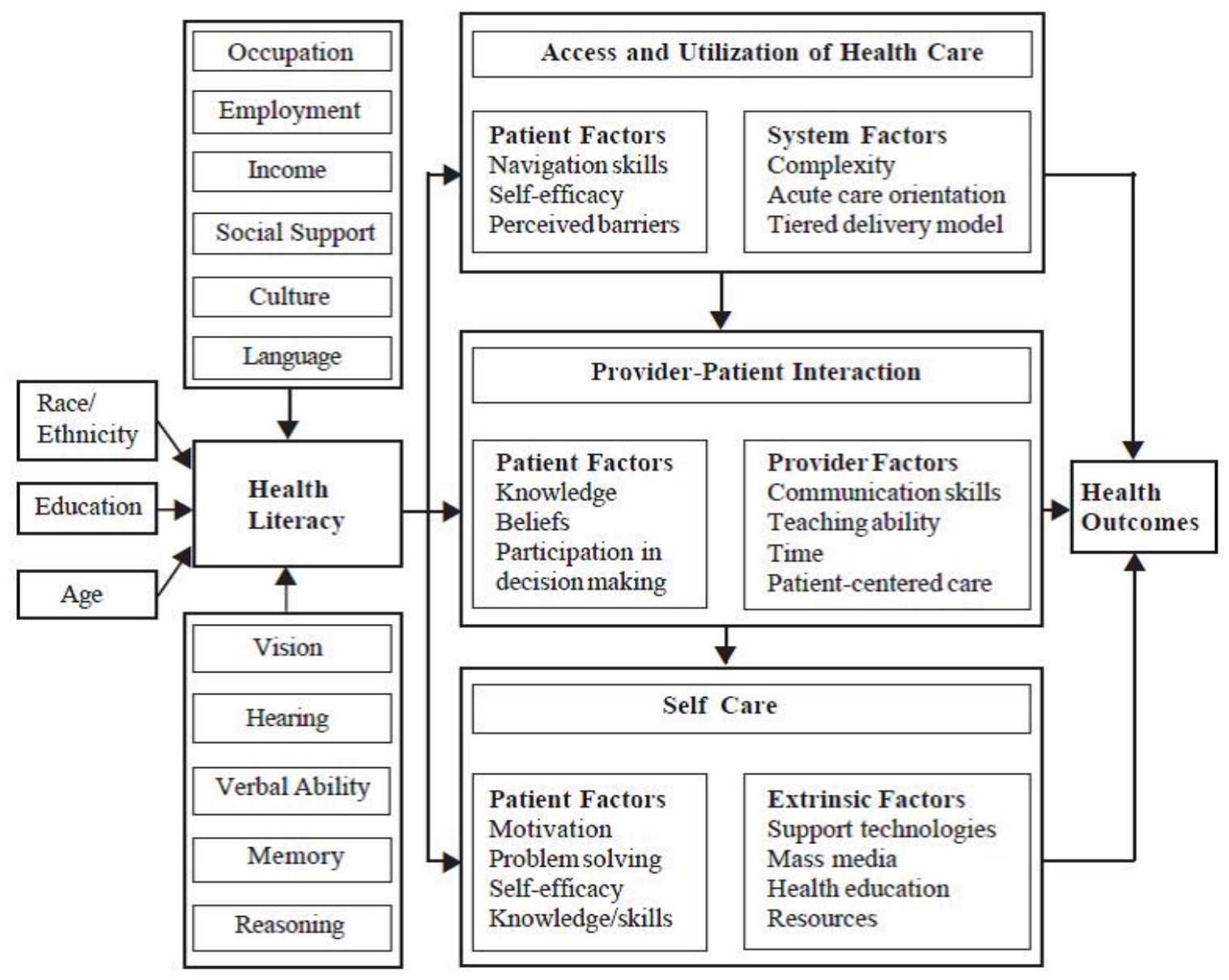

Figure 2-3. Causal pathways between limited health literacy and health outcomes Reprinted with permission. Paashe-Orlow, M., \& Wolf, M. (2007). The causal pathways linking health literacy to health outcomes. American Journal of Health Behavior, 31(suppl 1), S19-S26. 


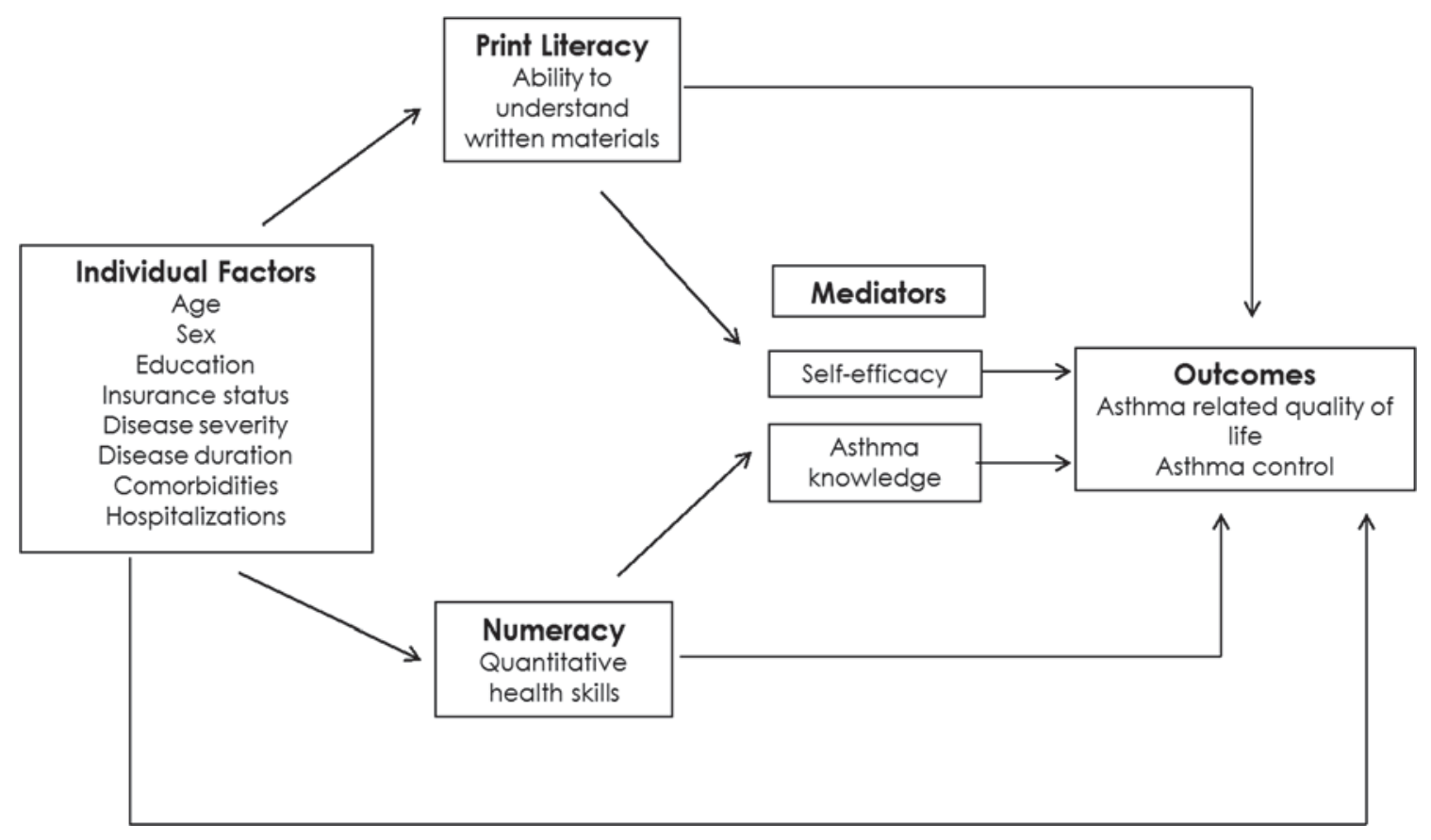

Figure 2-4. Conceptual model of the relationship between health literacy, mediators, and asthma outcomes 
and oral messages is not the focus of this study; as such, they were removed from the model as well.

\begin{abstract}
Asthma
Asthma is a chronic disease characterized by inflammation of the airways and obstructed airflow (DHHS \& NIH, 2007). Common symptoms include wheezing, shortness of breath, coughing, and chest pain with varying disease severity ranging from persistent to occasional symptoms (Akinbami et al., 2011). Prevalence varies by demographic factors. Women have a higher prevalence of asthma than men. AfricanAmericans have higher prevalence than Whites. Individuals living below the poverty line have a higher prevalence than the poor and near poor. In 2007, adults made 7.2 million office visits, 1.11 million ED visits, and 299,000 hospitalizations due to asthma (Akinbami et al., 2011). Asthma is an ambulatory care sensitive condition; consequently, ED visits and hospitalizations are indicative of poor asthma control and are considered adverse health outcomes (DHHS \& NIH, 2007).
\end{abstract}

\title{
Asthma Disparities
}

In addition to a higher prevalence of asthma, African-Americans have higher asthma hospitalization rates and higher asthma-specific mortality rates (Akinbami et al., 2011; Diette \& Rand, 2007). These disparities result in more days missed from school and work for African-Americans (Canino, McQuaid, \& Rand, 2009), and a variety of factors contribute to these disparities.

Low-income African-Americans have greater asthma morbidity and mortality compared to the general African-American population (Silvers \& Lang, 2012). Low SES individuals often live in urban neighborhoods with greater exposure to environmental triggers, violence, and stress (Canino et al., 2009). Urban areas have poorer outdoor air quality compared to non-urban areas. Individuals living in these neighborhoods are exposed to an increased amount of air pollutants like ozone, sulfur dioxide, dust, soot, smoke, and dirt. Poor outdoor air quality is associated with increased asthma morbidity (Silvers \& Lang, 2012). Another environmental stressor is crime. A study by Williams and colleagues (2007) found that residential crime rates were associated with decreased medication adherence among African-Americans. This relationship remained after controlling for other socioeconomic factors and neighborhood characteristics.

Low-income African-Americans have a high prevalence of smoking. Active smoking is associated with poorer asthma control, and increased mortality risk. Individuals with low-incomes and minorities are also less likely to quit smoking (McLeish \& Zvolensky, 2010; Silvers \& Lang, 2012). The high prevalence of smoking and lower likelihood of smoking cessation also contributes to asthma morbidity and mortality. 
Health system factors are also a contributor to asthma disparities. AfricanAmericans are disproportionately enrolled in public insurance health plans. These plans may allow decreased access to specialists and preventive care and formulary restrictions. African-Americans are less likely to see an asthma specialist, and specialist care is associated with improved asthma outcomes (Krishnan et al., 2001). Inhaled corticosteroids (ICS) are the recommended medication for individuals with moderate to severe asthma. Not only are African-Americans less likely to receive a prescription for ICS; they are more likely to be prescribed an inappropriately low dose of ICS (Halm, Wisnivesky, \& Leventhal, 2005; Krishnan et al., 2001). Factors associated with differences in receipt of recommended care are unknown, but may be linked to physician prescribing patterns and decreased patient-provider collaboration among AfricanAmericans (Canino et al., 2009; Silver \& Lang, 2012).

Individual level factors also contribute to disparities. Providers rely on selfreported symptoms for determining disease severity and medication prescribing. Hardie, Janson, Gold, Carrieri-Kohlman, and Boushey (2000) examined ethnic differences in words used to describe breathlessness and found that African-Americans used different words compared to Whites. African-Americans were more likely to report upper respiratory symptoms (i.e., tight throat, voice tight, and itchy throat) whereas Whites were more likely to report lower respiratory symptoms (out of air, aware of breathing, and hurts to breath). Phrases such as "itchy and tight throat" are not commonly used to describe asthma symptoms. Trochtenerg and BeLue (2007) explored self-reported symptoms of African-Americans and also found atypical self-reported symptoms among African-Americans. African-Americans proclivity to using less common symptom descriptors and health providers' reliance on self-reported symptoms may result in improper diagnosis or inadequate treatment; and consequently, greater asthma morbidity and mortality.

Individual health beliefs also influence asthma outcomes. Apter and colleagues (2003) found that African-Americans had greater fear of taking ICS and less knowledge about asthma compared to other groups. Le and colleagues (2008) also examined African-Americans beliefs about ICS. They found that African-Americans were more likely to have negative beliefs about asthma medications such as not believing that they required as much medication as their physician prescribed or that regular use of medications would decrease their tolerance to the medications. These negative beliefs partially mediated the relationship between minority status and medication adherence.

Environmental and socioeconomic contributors to disparities cannot be addressed through the health care system. However, patient-provider communication can be addressed through health care system interventions. Adequate patient-provider communication is necessary to manage asthma (DHHS \& NIH, 2007). Patients must be able to effectively communicate their asthma symptoms as well as understand provider given directives regarding appropriate self-management behaviors (Diette \& Rand, 2007). Health literacy is needed for individuals to manage their asthma and is a modifiable contributor to asthma health disparities (Canino et al., 2009). Many factors contribute to asthma disparities among African-Americans. Health literacy is one aspect 
of a broad issue. The remainder of this chapter will focus on health literacy's contribution to asthma outcomes.

\section{Health Literacy}

Health literacy is not only the ability to understand health information, but also to apply that information correctly in order to make informed health decisions (NielsenBohlman et al., 2004). The majority of printed materials are written above recommended reading levels. Consequently, individuals that share the greatest burden of the disease have the most difficulty understanding these educational materials (DHHS \& NIH, 2007).

Patient education is an essential component of asthma care and should be tailored to the literacy needs of the patient (DHHS \& NIH, 2007). Patients are able to conceal

their low health literacy skills, and providers tend to overestimate the health literacy skills of their patients (Cornett, 2009). Therefore, assessing the health literacy skills of patients is needed.

Low health literacy not only impacts the health outcomes of individuals; it is costly for the healthcare system as a whole. Compared to individuals with adequate health literacy, individuals with inadequate health literacy have higher emergency room costs and were more likely to use inpatient services and less likely to use outpatient services. This results in increased utilization of high cost services, decreased use of less expensive outpatient and preventive services, and ultimately unnecessary medical costs (Howard, Gazmararian, \& Parker, 2005). Improving health literacy may not only improve health outcomes, but has the potential to reduce health care costs.

\section{Numeracy}

Numeracy is defined as "the degree to which individuals have the capacity to access, process, interpret, communicate, and act on numerical, quantitative, graphical, bio statistical, and probabilistic health information needed to make effective health decisions" (Golbeck et al., 2005, p. 375). Health literacy research has primarily focused on reading comprehension, yet much of the information provided to patients is quantitative in nature (Ancker \& Kaufman, 2007; Apter et al., 2008). Individuals with adequate print literacy often have difficulty with numerical information. Consequently, numeracy should be studied and evaluated independently of print literacy (Apter et al., 2008; Donelle, Hoffman-Goetx, \& Arocha, 2007). Numeracy skills are needed for medication dosing, understanding lab values, scheduling appointments, and understanding the risks and benefits of treatment options.

The 2003 National Assessment of Adult Literacy (NAAL) found that 22\% of U.S. adults had difficulty locating numbers and using them to perform simple calculations, and $33 \%$ of U.S. adults are only able to locate easily recognizable numbers and perform one step calculations (Kutner et al., 2006). Smaller studies show great variation in the 
prevalence of inadequate numeracy skills with data from clinical studies showing that $26 \%$ to $71 \%$ of individuals have inadequate numeracy skills (Donelle et al., 2007). Being male, White, and having more education are also associated with better quantitative skills (Apter et al., 2008; Kutner et al., 2006). Racial gaps in quantitative skills are more pronounced than gaps in reading, and these differences may drive health disparities. More research is needed to understand pathways linking numeracy to health outcomes and health disparities (Apter et al., 2008).

Numeracy is crucial for individuals with asthma because they use numbers to monitor their asthma and predict asthma episodes. Individuals with asthma are often given peak flow meters to monitor their airway obstruction. Peak flow meters can detect progressive narrowing of airways and allow patients to avoid an asthma exacerbation (DHHS \& NIH, 2007). Patients have a personal best peak flow meter score that serves as the comparison number. They must be able to take readings and compare their readings to their baseline peak flow. They then must take action based on the degree to which their numbers change. Numbers may indicate that they need to use their short acting inhaler or discuss their numbers with their provider. Health care providers also depend on accurate readings and interpretation to discuss symptoms with asthma patients. Individuals with low numeracy may have difficulty using a peak flow meter and correctly interpreting readings. Numeracy is not only important for asthma but also for other diseases as well.

\section{Measuring Health Literacy}

Health care providers are often not aware of the health literacy status of their patients. Valid, reliable, and practical tools for clinical settings may encourage routine screening for health literacy. The two most common tools for measuring health literacy

are the TOFHLA and the REALM. The TOFHLA measures reading comprehension and numeracy. Reading passages are from a variety of health-care settings that include an informed consent form, a section of a Medicaid application, and preparation instructions for a medical procedure. The TOFHLA takes about 22 minutes to administer, and an abbreviated version, STOFHLA, takes about 12 minutes to administer. The REALM is a word recognition and pronunciation test that measures reading ability pertinent to medical settings and can be administered in three minutes. Although commonly used, these tests only measure basic print literacy and are not able to measure the other skills and knowledge associated with the comprehensive definition of health literacy (NielsenBohlman et al., 2004).

In addition to the lack of comprehensiveness, there are also other concerns with these tests. Low literate patients are often ashamed of their status, and formal assessments, like the TOFHLA and REALM, may invoke feelings of shame or embarrassment. Also, the TOFHLA is a lengthy test and may not be practical for the clinical setting. Two screening instruments have been specifically developed for use in the clinical setting. 
Weiss and colleagues (2005) developed the Newest Vital Sign (NVS). The NVS measures numeracy and is comprised of a nutrition label and six questions about the label. The test takes about 3 minutes to administer and is available in English and Spanish. The NVS correlates well with the TOFHLA. The test is highly sensitive and may over classify patients as having limited literacy. In spite of this, the NVS is still a good tool to signal physicians to be more thoughtful in their communication with particular patients. Osborn and colleagues (2007) compared the NVS to the REALM and the S-TOFHLA. They found that the NVS had high correlation with both the REALM and the S-TOFHLA, and it accurately identified patients with inadequate literacy. However, after adjusting for other covariates, only the S-TOFHLA (not NVS scores) were predictive of adverse health outcomes. Shah, West, Bremmeyr, and Savoy-Moore (2010) tested the NVS in rural, urban, and suburban primary care settings. The NVS was found to be an accurate measurement of health literacy and was well received by patients in a clinical setting. A study by Vangeest, Welch, and Weiner (2010) further examined patients' perspectives of the NVS. The NVS was used during routine intake in primary care clinics. Patients were also given a reaction survey about taking the NVS. None of the patients thought the test was a waste of their time. The majority (95\%) of patients had no problem with being screened for health literacy, and $96 \%$ of them were not upset by having to take the assessment. Also, $98.6 \%$ of the patients did not feel shameful about having to take the NVS. The NVS is an accurate tool for identifying individuals with low literacy and also avoids invoking feelings of shame and embarrassment for patients.

Chew et al. (2004) developed three brief screening questions to identify patients with low literacy. The questions are: "How often do you have problems learning about your medical condition because of difficulty understanding written information?" "How confident are you filling out medical forms by yourself?" and "How often do you have do you have someone help you read hospital materials?" The questions use a 5-point Likert scale. The three questions were tested along with the S-TOFHLA, and were found to accurately identify patients with inadequate health literacy. The single question, "How often do you have someone help you read hospital materials," accurately identified $80 \%$ of patients with inadequate literacy. Wallace, Rogers, Roskos, Holiday and Weiss (2006) tested the three brief questions in a demographically different population than Chew et al. (2004), and the findings were consistent with Chew et al. (2004).

Most health literacy measurement tools are focused on print literacy, and there is not a standard tool to measure numeracy. Many instruments are self-administered and rely on reading comprehension to measure numeracy. This combination makes it difficult to independently determine numeracy skill (Apter et al., 2008). Numeracy tools also assess a variety of skills including calculating medication schedules, identifying numerical patterns, converting percentages to proportions, differentiating between magnitudes of risk, and understanding basic probabilities and risk (Donelle et al., 2007).

It is agreed that low health literacy is a serious issue, but not all agree with routine clinical screening for health literacy. Lack of support for clinical screening stems from concerns that testing will elicit feelings of shame among individuals with literacy issues (Paasche-Orlow \& Wolf, 2008). Parikh, Parker, Nurss, Baker, and Williams (1996) 
examined shame among patients screened for low health literacy. Following health literacy screening, patients were asked their perception of their reading skills and about the shame associated with having low literacy skills. Approximately $40 \%$ of patients with self-admitted low literacy skills admitted shame associated with their reading abilities. These patients also admitted to hiding their reading difficulties from family and friends and to not bringing a surrogate reader with them to medical encounters. Wolf et al. (2007) also examined shame associated with literacy screening. The majority of patients with low literacy thought that it would be helpful for providers to know that they had low literacy. However, they were also significantly more likely to report feeling ashamed of revealing their literacy issues. While some studies have demonstrated an association between shame and health literacy screening, others have not. The two instruments (i.e., NVS and three screening questions) being used in this study were evaluated and no associations between these screening instruments and shame were found (Shah et al., 2010; Vangeest et al., 2010) Opponents of routine screening note that screening patients may further stigmatize patients who are already ashamed of their low literacy skills and discourage them from seeking medical care (Paassche-Orlow \& Wolf, 2007). They argue that screening for health literacy is done with the assumption that low literate patients have different needs than patients with adequate health literacy, yet suggested communication strategies for low literate patients benefit all patients, regardless of health literacy level. They believe it is best to use recommended communication strategies for all patients instead of screening for low health literacy. Although clear communication strategies benefit all patients, screening may make health care providers more mindful of how they communicate with their patients as providers are often unaware and overestimate the literacy skills of their patients (Powers, Trinh, \& Bosworth, 2010).

\section{Health Literacy and Asthma Outcomes}

Health literacy is important for the management of chronic diseases like asthma. Previous research in the area has examined the relationship between health literacy and various aspects of asthma disease management and health outcomes including asthma knowledge, self-efficacy, and self-management.

\section{Asthma Knowledge}

Having knowledge about asthma is necessary for successful asthma control. Increased asthma knowledge is associated with enhanced self-management and outcomes; and consequently, decreased hospitalizations and emergency department visits (Garg, Bidani, Rich, Hershey, \& Hershey, 2005). Williams, Baker, Honig, Lee, and Nowlan (1998) examined the relationship between health literacy and asthma knowledge and self-care. A cross-sectional survey of patients from an emergency department and asthma clinic located in an urban hospital was performed. Health literacy was measured using the Rapid Estimate of Adult Literacy (REALM) which estimates reading grade level. Self-care was defined as the ability to properly use a metered dose inhaler (MDI). 
Only $27 \%$ of the participants read at the high school level, and $13 \%$ of the participants were functionally illiterate. Low literacy levels were significantly correlated with poor asthma knowledge, and literacy level was the strongest predictor of asthma knowledge.

Gazmararian, Williams, Peel, and Baker (2003) examined the relationship between health literacy and chronic disease knowledge among Medicare enrollees. Health literacy was measured using the S-TOFHLA and a 15 minute telephone interview was completed to assess enrollees' asthma knowledge. Patients with inadequate health literacy were significantly less likely to correctly answer asthma knowledge questions, and health literacy was found to be an independent predictor of asthma knowledge.

Manusco and Rincon (2006) explored the relationship between health literacy and longitudinal asthma outcomes. The outcomes included asthma-related quality of life as measured by the Asthma Quality of Life Questionnaire (AQLQ), Medical Outcomes Study SF-36 (a measure of functional status), and emergency department visits. Patients also completed the Check Your Asthma IQ, a survey of asthma knowledge, and were followed for two years. There was a statistically significant association between low health literacy and decreased quality of life, decreased physical function, and increased emergency department visits. Because patients with low health literacy had less knowledge about asthma, researchers concluded that low health literacy hinders the ability to gain asthma knowledge. Low health literacy impacts health outcomes through the patient's ability to acquire knowledge about their disease. Patient education materials are often written beyond the reading level of patients with low health literacy resulting in difficulty obtaining asthma knowledge. Knowledge alone is not enough. Successful selfmanagement requires knowledge being translated into positive behaviors.

\section{Self-Efficacy}

Self-efficacy, the belief that one can execute behaviors to produce intended outcomes (Bandura, 1977), influences health behaviors and may be a mediating factor between health literacy and asthma outcomes (Baker, 2006). Specifically, individuals with asthma are confident that they can successfully carry out self-management behaviors to control their asthma and prevent asthma exacerbations (Lavoie et al., 2008).

Lavoie et al. (2008) examined self-efficacy in asthma patients. Participants completed the Asthma Self-Efficacy Scale (ASE), Asthma Control Questionnaire (ACQ), and the Asthma Quality of Life Questionnaire (AQLQ) and underwent pulmonary function testing via spirometry. Patients with lower ASE scores had worse asthma control and asthma quality of life. Williams et al. (1998) also found a relationship between perceived self-efficacy and health literacy. Individuals who read at high school level or better were less likely to report that they visit the ED when they had an asthma attack compared to individuals who read at or below a sixth grade level. Individuals with lower reading levels were also more likely to report that there was nothing they can do to prevent an asthma attack compared to individuals who read at higher reading levels.

These researchers demonstrated that health literacy was associated with self-efficacy, and 
self-efficacy was associated with health care utilization patterns which points to selfefficacy as a possible mediator. Federman, Wisnivesky, Wolf, Leventhal, and Halm (2010) examined the relationship between health beliefs and health literacy among older asthmatics. Adults with inadequate health literacy were more likely to believe that asthma could be cured, that medications worked better when they were not used all the time, and that asthma was only present when they experienced actual symptoms. Low health literate patients also had poorer asthma control and poorer medication adherence than patients with adequate health literacy. Unfavorable asthma beliefs may be a mediator in the relationship between health literacy and health outcomes.

Manusco and Rincon (2006) examined the impact of health literacy on longitudinal asthma outcomes. Health literacy was measured using the Test of Functional Health Literacy in Adult (TOFHLA). In contrast to previous results, they found no association between health literacy and self-efficacy. Conflicting results may have been due to different instruments used for measuring self-efficacy and changes in self-efficacy over time. Previous studies were cross-sectional, while Manusco and Rincon (2006) followed individuals for two years. They noted self-efficacy is experience based and best acquired through learned experiences rather than instruction. Self-efficacy is not static, and the nature of the relationship between health literacy and self-efficacy may change over time. Future research should examine the longitudinal relationships between health literacy and self-efficacy. Scherer and Bruce (2001) examined the relationship between self-efficacy and adherence to treatment regimens. Higher self-efficacy was significantly associated with positive attitude towards asthma, decreased number of ED visits and hospitalizations, and greater adherence to treatment regimens, and having mild asthma. Manusco, Sayles, and Allengrante (2010) evaluated the relationship between selfefficacy, asthma self-management and quality of life. Higher levels of self-efficacy (measured by the Knowledge, Attitude, and Self-Efficacy Asthma Questionnaire (KASE)) were associated with greater asthma knowledge (measured by the KASE), positive attitudes about asthma(measured by the KASE), and satisfaction with asthma status (measured by the KASE).

The previous studies have examined associations between self-efficacy, health literacy, and asthma outcomes. A few studies have explored self-efficacy as a mediator between health literacy and asthma outcomes. Apter et al. (2009) examined self-efficacy as a mediator between numeracy and quality of life and found that self-efficacy partially mediated the relationship. Diabetes research provides more evidence for self-efficacy as a mediator. Osborn et al. (2010) examined self-efficacy as a link between health literacy and numeracy to glycemic control. Health literacy and numeracy did not have a direct effect on glycemic control when controlling for covariates. However, health literacy and numeracy were associated with increased diabetes self-efficacy, and increased selfefficacy was associated with better glycemic control. Findings indicated that health literacy and numeracy have an effect on glycemic control through self-efficacy. 


\section{Asthma Self-Management}

As previously mentioned, asthma knowledge and self-efficacy affect the ability of patients to manage their disease. The following studies focus on the relationship between health literacy and self-management. Rosenfeld et al. (2011) focused on oral language skills and disease management. Oral literacy was assessed using the Woodcock Johnson Achievement Tests. Asthma management was defined by the number of nights with asthma symptoms in the last 30 days (coughing, wheezing, and shortness of breath, chest tightness, and phlegm production). A significant relationship between lower oral literacy skills and increased number of nights with asthma symptoms was found. This relationship was independent of race and income. It is important to note that this is the only study that has examined oral literacy's impact on asthma outcomes.

Manusco and Rincon (2006) focused on patients' desire to participate in the decision making process about their care. Patients were also asked about their willingness to participate in the decision making process and their satisfaction with quality of care, access to care, and their asthma status. Patients with low literacy were less willing to participate in the decision making process. This relationship remained after adjusting for age, sex, race/ethnicity, language, and asthma severity.

George, Campbell, and Rand (2009) conducted a qualitative study that examined the scope of asthma self-management training received by low-income adults and found that the majority of patients did not receive any asthma self-management training. George et al. (2009) also mentioned that poor patient provider communication and a lack of culturally appropriate patient education may also result in poor asthma outcomes. Health literacy has a great impact on patient provider communication as well as the usefulness and comprehension of patient education materials. Apter, Reisine, Affleck, Barrows, and ZuWallack (1998) examined the relationship between adherence and patient characteristics that may influence adherence. Aside from socioeconomic status, patient-clinician communication was the strongest predictor of adherence. Health literacy may influence adherence through the quality of communication between patients and providers.

Patient-provider communication is a partnership. Both parties contribute to the effectiveness of the interaction, and adequate communication skills are needed. Patients must be able to ask questions, accurately describe their symptoms, and recount their medical history (Cegala \& Post, 2006). Physicians must be able to describe illness and treatments in plain language, develop rapport with the patient and be willing to listen and negotiate. Communication is most successful when both parties have the aforementioned skills. The patient also has the ability to influence how the physician communicates. Physicians respond positively to patients who actively participate in the interaction. If a patient gives details about their symptoms, concerns, medical history, and asks questions, the physician is more likely to treat the patient as partner in the decision making process (Cegala \& Post, 2009). Arnold et al. (2012) examined what communication skills providers would like for their patients to possess. Providers said patients should be able to ask questions, give detailed medical history, provide a list of concerns to be addressed 
at each visit, and the ability to listen and negotiate treatment options. A symbiotic relationship exists between patients and providers, and both patients and providers enter medical encounters with expectations of the other party.

African-American patients exhibit greater difficulty communicating with providers compared to Whites. They are less likely to engage in shared decision making, have greater distrust of the health care system, and are more passive in interactions (Cegala \& Post, 2006; Schoenthaer et al., 2009). African-Americans assign more negative ratings to interactions with health care providers. Objective analysis of interactions showed that physicians are more verbally dominant and less patient-centered when interacting with African-American patients (Johnson et al., 2004). AfricanAmericans are also more likely to have low health literacy compared to Whites making this group more vulnerable to difficulties with patient-provider interactions.

Self-management requires disease knowledge, confidence in one's ability to care for their disease, and collaboration between patients and providers. All of these aspects are particularly important for African-Americans who face unique issues when interacting with the health care system. The body of literature on the effect of health literacy on asthma self-management clearly shows that health literacy is essential to successful asthma self-management.

\section{Numeracy}

The majority of health literacy literature has focused on print literacy. Yet quantitative skills are necessary for health care consumers as well. Numeracy encompasses a different set of skills needed for asthma self-management (Thai \& George, 2010). Asthma patients often receive peak flow meters to monitor their asthma. Reading peak flow meters requires an understanding of percentages and risk associated with those percentages. Apter et al. (2006) examined the relationship between numeracy skills and history of hospitalization and emergency department visits. Numeracy was measured using the Asthma Numeracy Questionnaire (ANQ). The REALM and the Short Test of Functional Health Literacy (S-TOFHLA) were also administered. Low numeracy was significantly associated with an increased number of hospitalizations and emergency department visits. This relationship was independent of age, sex, education, and income.

A later study by Apter et al. (2009) examined the relationship between numeracy and asthma quality of life. Subjects completed the mini Asthma Quality of Life Questionnaire (miniAQLQ) and a self-efficacy assessment. The ANQ was used to measure numeracy. Low numeracy skills were associated with decreased quality of life. Income and self-efficacy partially mediated this relationship. Both studies by Apter et al. (2006, 2009) included predominately African-American populations. Adams, Appleton, Hill, Ruffin, and Wilson (2009) examined the relationship between health literacy and asthma outcomes using the Newest Vital Sign (NVS). They found that low health 
literacy was associated with an increased risk of hospitalization, days lost from usual activities, and nocturnal asthma symptoms.

\section{Interventions Addressing Low Health Literacy}

Several interventions have been done to mitigate the impact of low health literacy on health outcomes. Sobel et al. (2009) developed a video to increase African-American adults' understanding of asthma. The video was catered to a low health literate population. Asthma knowledge was assessed pre and post intervention. At baseline, individuals with low literacy were less able to identify asthma symptoms and parts of the body affected by asthma compared to individuals with adequate or marginal literacy. Following the intervention, asthma knowledge increased by $60 \%$, but individuals with low literacy had the smallest improvements in asthma knowledge. Also, health literacy levels were still independent predictors of asthma knowledge post intervention.

Paasche-Orlow et al. (2005) provided a 30 minute intervention that provided written and oral instructions about asthma discharge directions and MDI technique to asthma patients who had been hospitalized. Prior to the intervention, inadequate health literacy was associated with lower asthma medication knowledge and poorer MDI technique. Following the intervention, $69 \%$ of subjects with inadequate health literacy and $68 \%$ of subjects with adequate health literacy demonstrated sufficient knowledge of discharge instructions and proper MDI technique. Improvements in MDI technique remained two weeks post intervention, and the intervention had the greatest impact on patients with inadequate health literacy. Notably, low health literacy was not a barrier to learning proper self-management techniques. Education modified for low health literate patients can benefit all patients. The long term effectiveness of these interventions is unknown.

\section{Conclusions}

African-Americans have a higher prevalence of asthma in addition to higher asthma morbidity and mortality compare to non-Hispanic Whites (Akinbami et al., 2011; Diette \& Rand, 2007). African-Americans are also more likely to have low health literacy which is also associated with adverse health outcomes (Kutner et al., 2006). Conceptual models explaining the relationship between health literacy and health outcomes indicate that the relationship is complex and individual, health care system, and environmental factors are involved (Baker, 2006; Nielsen-Bohlman et al., 2004; PaascheOrlow \& Wolf, 2007). A connection between health literacy and health outcomes has been established, but the underlying mechanisms are unclear. Basic health literacy research that identifies these mechanisms is needed to create effective interventions (Johnson et al., 2011).

Health literacy has multiple domains including print literacy, oral literacy, and numeracy (Nielsen-Bohlman et al., 2004). The majority of health literacy research has 
focused on print literacy, and the asthma health literacy research is no different. Previous research has primarily examined print literacy and shown that low health literacy is associated with decreased asthma knowledge, poorer medication adherence, and poorer asthma outcomes resulting in increased burden for individuals, families, and the health care system.

Future research in this area should include other domains of health literacy; as numeracy has been shown to be a distinct domain with independent effects on health outcomes (Apter et al., 2009; Osborn et al., 2010). Future research should also examine pathways linking health literacy and asthma outcomes. Multiple methods of inquiry could increase understanding of this phenomenon. Previous literature has only used quantitative methods and neglected the contextual detail, rich data, and expert knowledge of participants. The health literacy literature will benefit from both qualitative and quantitative methodologies. 


\section{CHAPTER 3. METHODOLOGY}

This section will detail the methods used for this study. It will begin with a discussion of mixed methods research, rationale for using mixed methods, and the specific research design used in this study. Next, specific methods for the quantitative phase of the study will be presented followed by methods used for the qualitative phase of the study.

\section{Mixed Methods Research}

Mixed method research emerged in the late 1980s (Creswell \& Plano Clark, 2011) and is considered a third research paradigm that is an alternative to qualitative and quantitative research (Teddlie \& Tashakkori, 2009). The mixed methods researcher collects and analyzes both qualitative and quantitative data and integrates both forms of data within a single study or multiphase research (Creswell \& Plano Clark, 2011).

Researchers have different reasons for using mixed methods to answer research questions. Green, Caracelli, and Graham (1989) identified five purposes for conducting mixed methods research. Triangulation uses different methods to assess the same phenomenon and looks for convergence among results to enhance the validity of the findings. Complementarity measures overlapping and different aspects of the same phenomenon to get a deepened understanding. Development uses the first method of inquiry to inform the development of the second method. Initiation uses different methods to discover paradoxes and contradictions to gain new perspectives. Expansion is concerned with increasing the scope of inquiry by using different methods for different aspects of phenomenon. Mixed methods studies can have one or more of these purposes. Bryman (2006) expounded on the work by Green et al. (1989) and developed sixteen reasons for conducting mixed methods research including triangulation, offset, completeness, process, different research questions, explanation, unexpected results, instrument development, sampling, credibility, context, illustration, utility, confirm and discover, diversity of views, enhancement, other/unclear, or not stated. Bryman's (2006) categories were used to provide rationale for the current study which was conducted for completeness, diversity of views, and enhancement.

Completeness is the belief that a more comprehensive understanding of the phenomenon can be reached by using both qualitative and quantitative than using either method alone. An objective and subjective view of health literacy will provide better understanding than either view alone. Diversity of views entails including both the researchers' and participants' views to understand relationships between variables. Asthma is a chronic disease with a large self-management burden. Including both the researcher's and participant's perspective can offer insight into how health literacy impacts asthma outcomes. Understanding the underlying mechanisms will aid in the development of interventions to mitigate the impact of low health literacy. The perspective of the target population is necessary when developing successful 
interventions. Enhancement involves using one form of inquiry to supplement the findings of the other. Only two mediators are being examined in the quantitative analysis, yet we know that other factors are mediating the relationship. Qualitative interviews will help explain the findings from the quantitative study and may provide insight about mediators that were not included in the quantitative phase.

There are multiple mixed methods research designs, and each design includes at least one quantitative component and one qualitative component. Research designs are influenced by: the study's purpose, the level of interaction between each component, the relative importance of each component, timing of implementation of each component, and the approach used for integrating both components (Creswell \& Plano Clark, 2011). The following section will discuss the mixed methods research design that was used for this study.

\section{Research Design}

An explanatory sequential mixed methods design was used for this study. In this design a researcher begins with a quantitative phase that is followed by a qualitative phase. The qualitative phase is used to explain the initial quantitative results. This design can also be used to form groups based on qualitative results for qualitative followup (Creswell \& Plano Clark, 2011). Quantitative data are collected and analyzed in order to use the results to inform the qualitative phase. Then, the qualitative data are collected and analyzed. Quantitative and qualitative data are interpreted separately, and then both strands are interpreted together to determine how the qualitative results help explain the quantitative results.

In the current study, cross sectional surveys were used to determine health literacy skills, and determine if self-efficacy and asthma knowledge mediated the relationship between the assessed health literacy skills and health outcomes. The health literacy skills determined during the quantitative phase were used to purposefully sample individuals to complete semi-structured interviews. Interviews were conducted to further explain mediating factors as well as the information seeking behaviors, self-management, and patient-provider communication among individuals with asthma.

This study was an emergent mixed methods design. The study was originally designed as quantitative only. During the interview process for collecting quantitative data, patients began discussing other issues related to asthma self-management and encounters with the health care system. These anecdotal conversations resulted in the development of a qualitative component to explore the issues that patients were introducing.

The study was a sub-study of the BELT: Blacks and Exacerbations on LABA vs. Tiotropium study (Brigham and Women's Hospital, 2013). BELT was a multi-site, randomized study that compared the effectiveness of two medications, long acting beta agonists (LABA)/inhaled corticosteroids (ICS) vs. tiotropium/ICS in Black patients with 
asthma. The study enrolled Blacks between $18-75$ years old with moderate to severe asthma. Subjects were followed between 6 to 18 months and completed three to five follow-up visits. Because BELT was designed to be a real-world, comparative effectiveness trial, inclusion and exclusion criteria were kept to a minimum, and outside of the month one visit, follow up was in accordance with regularly scheduled physician visits for patients with asthma.

All subjects enrolled in the BELT study were eligible to participate in the health literacy sub-study. During a BELT study visit, subjects were asked if they would like to participate in the sub-study. If subjects agreed to participate, they answered additional questionnaires related to health literacy, asthma knowledge, and self-efficacy.

\section{Phase One: Quantitative}

Quantitative data were collected via cross-sectional surveys. Subjects who participated in the sub-study answered an additional set of questions that included the NVS, three health literacy screening questions, the Asthma Self-Efficacy scale (ASE), and the Asthma Self-Management Knowledge questionnaire. The health literacy questionnaires were matched with the outcome data, ACQ and AQLQ-S, from the corresponding visit. The ACQ and AQLQ-S were collected as part of the BELT study. For example, if a participant completed health literacy surveys at their first visit, outcome data collected at the first visit was used for sub-study. An effort was made to collect data at either visit one (baseline) or visit two (one month) of the BELT study to reduce the effect of improved asthma outcomes due to study participation.

\section{Sample and Setting}

The data were collected at primary care clinics in Memphis, TN; Decatur, Georgia; Miami, Florida; and Kansas City, Missouri. All patients enrolled in the BELT study were eligible for the sub-study. Individuals with asthma who were not enrolled in the BELT study were not eligible for participation because outcome data were collected as part of the BELT study. Because the study was a sub-study, inclusion and exclusion criteria were based on eligibility for the BELT study.

\section{Inclusion Criteria}

The inclusion criteria for the study were:

- Black (self-identified, with at least one biological parent identified as Black)

- 18-75 years of age

- Ability to provide informed consent 
- Clinical history consistent with asthma for $>1$ year

- Ability to perform pulmonary function tests

- $\mathrm{FEV} 1>40 \%$ of predicted

- Receiving ICS/LABA combination therapy or ICS moderate dose monotherapy and baseline ACQ $>1.25$

- Non-smoker for past year (total lifetime smoking history $<10$ pack years)

\section{Exclusion Criteria}

The exclusion criteria for the study were:

- Use of greater than the equivalent of $1000 \mathrm{mcg}$ inhaled fluticasone daily

- Chronic use of oral corticosteroids or Anti IgE for asthma

- Lung disease other than asthma or diagnosis of vocal cord dysfunction

- Significant medical illness (other than asthma) that is not stable

- Pregnancy or lactation or an unwillingness to maintain effective birth control

- History of a significant exacerbation of asthma or respiratory tract infection in the prior 4 weeks

- History of life-threatening asthma requiring treatment with intubation and mechanical ventilation within 5 years

- Hypo sensitization therapy other than an established maintenance regimen

- Use of inhaled anticholinergic therapy (ipratropium, tiotropium) in prior month

- Known contraindication to inhaled tiotropium e.g., narrow angle glaucoma, history of bladder neck obstruction or significant symptoms related to prostatic hypertrophy

- Inability to speak and read English 


\section{Instrumentation and Operationalization of Variables}

\section{Newest Vital Sign}

The NVS was used to measure numeracy and was developed by Weiss et al. (2005). The NVS has an alpha of 0.76. The area under the ROC curve for predicting the TOFHLA was $0.88(\mathrm{p}<.001)$ indicating good correlation with the TOFHLA. It consists of a nutrition label and six accompanying questions. Each question is worth one point, and scores can range from zero to six. A score of one or zero indicates a high likelihood ( $50 \%$ or more) of limited literacy. A score of two or three indicates the possibility of limited literacy, and a score of four to six almost always indicates adequate literacy. The test takes approximately three minutes to administer.

\section{Print Literacy}

The brief screening questions (Appendix A) were developed by Chew et al. (2004) and are measured using a 5-point Likert scale and were used to assess print literacy. To test the ability of the three questions to detect inadequate literacy, ROC curves of the questions as both single items and combinations of two or all three questions have been previously evaluated (Chew et al., 2004; Powers, Trinh, \& Bosworth, 2010). Combining questions had no effect on screening ability, and a single question was deemed adequate for detecting inadequate literacy. Chew et al. (2004) found that "How often do you have someone help you read hospital materials?" adequately predicts inaccurate literacy with an AUROC of 0.87 (0.78-0.96). The authors recommended using the answer of "somewhat" to this question as the threshold for inadequate literacy. Wallace et al. (2006) found that the question "How confident are you filling out medical forms by yourself?" had an AUROC of $0.82(0.77-0.86)$ and concluded that this single question alone was sufficient for detecting inadequate literacy. They also recommend using the answer of "somewhat" as the threshold for inadequate literacy. The majority of subjects in the Chew et al. (2004) study were middle aged white men; while subjects in the Wallace et al. (2006) study were primarily women and included a larger number of African-Americans subjects than Chew et al. (2004). The present study population more closely resembled the Wallace at al. (2006) subjects. Based on the population of interest, the question "How confident are you filling out medical forms by yourself?" was used as the single item screening question.

\section{Asthma Self-Efficacy Scale}

Self-efficacy was measured using the Asthma Self-Efficacy (ASE) tool, an asthma-specific efficacy scale developed by Apter et al. (2009). The ASE has an alpha of 0.81. The questionnaire is comprised of 14 questions using a 5-point Likert scale and is specific to circumstances around taking inhaled corticosteroids. ASE scores can range between fourteen and seventy with higher scores indicating greater self-efficacy. 


\section{Asthma Self-Management Knowledge}

Asthma knowledge was measured using the Asthma Self-Management Questionnaire. This tool measures patient knowledge about asthma self-management and was developed for use in clinical settings (Schaffer \& Yarandi, 2007). Then internal consistency of the tool is 0.69 . The questionnaire is comprised of twenty four true and false questions. Scores range from zero to twenty four with higher scores indicating greater asthma knowledge.

\section{Asthma Quality of Life}

Asthma related quality of life (QOL) refers to the impact of asthma on patients as perceived by the patient (Wilson et al., 2012). Quality of life includes the psychological, social, emotional, and physical welfare of patients that is not captured in clinical outcome measurements (Apter, Reisine, Affleck, Barrows, \& ZuWullack, 1999; Ford et al., 2003). The combination of clinical measures and quality of life measures offers health care providers a better measurement of asthma management than clinical outcomes alone (Wilson et al., 2012).

Quality of life is a distinct and essential aspect of asthma outcomes. Multiple instruments have been developed to measure asthma related quality of life including the Asthma Bother Profile, the Asthma Impact Survey, the Airways Questionnaire-20, the Asthma Quality of Life Questionnaire, the Asthma Quality of Life QuestionnaireStandardized, the Asthma Short Form, the Modified Asthma Quality of Life, the MiniAsthma Quality of Life Questionnaire, the Living with Asthma Questionnaire and St. George's Respiratory Questionnaire. Although there is not a standard instrument, it is beneficial to use quality of life when assessing asthma outcomes (Wilson et al., 2012).

Asthma quality of life was measured using the standardized version of the Asthma Quality of Life scale (AQLQ-S) developed by Juniper, Buist, Cox, Ferrie, and King (1999). The AQLQ-S was developed based on the original AQLQ developed by Juniper et al. (1992). The AQLQ allows patients to select five of the eleven activities that are used for the activity limitation questions. In contrast, the AQLQ-S chooses five generic activities (strenuous exercise, moderate exercise, work-related activities, social activities, and sleep) as opposed to patient specific activities. The AQLQ-S is comprised of thirty two questions and four domains (activity limitations, symptoms, emotional function, and exposure to environmental stimuli). Questions are on 7-point Likert scale with higher scores indicating better quality of life. Reliability, responsiveness, and construct validity are similar for both the AQLQ and the AQLQ-S. The AQLQ-S has an intraclass correlation coefficient of 0.96 compared to 0.95 for the AQLQ (Juniper, Buist, et al., 1999). The AQLQ was also found to be a useful tool in low-income adults and across all racial groups (Leidy et al., 1998). 


\section{Asthma Control Questionnaire}

Asthma guidelines recommend the assessment of a patient's asthma control. Asthma control scores are recommended as an outcome measure for clinical trials and observational studies of individuals twelve years of age and older (Cloutier et al., 2012). Well controlled asthma is classified by minimal day and night time symptoms, activity limitations, airway inflammation, and rescue inhaler use ( Juniper, Bousquet, Abetz, Bateman, \& The GOAL Committee, 2006). About seventeen asthma control composite score instruments exist. The Asthma Control Questionnaire or the Asthma Control Test is the recommended instrument. Asthma control is a goal of asthma treatment and is used to guide therapy decisions (Cloutier et al., 2012).

Asthma control was measured using the Asthma Control Questionnaire (ACQ) developed by Juniper, O'Byrne, Guyatt, Ferrie, and King (1999). The instrument has an interclass correlation coefficient of 0.90 . The ACQ is comprised of seven questions on a seven point scale. Questions are scored from 0 to 7 with lower numbers indicating better control. A shortened, six item version of the ACQ was used for this study. The Cronbach's alpha for the six item version of the ACQ is 0.98. The shortened ACQ also has high concordance with the original ACQ demonstrated by an intraclass correlation coefficient of 0.94 (Juniper, Svensson, Mörk, \& Ståhl, 2005). An ACQ score of 0.75 or less indicates an $85 \%$ chance that the individual has well-controlled asthma. A score of 1.50 or higher indicates an $88 \%$ percent chance that asthma is not well-controlled. A cross-over point of 1.00 can also be used to determine the level of control. Patients with sores of 1.00 or less are more likely to have well-controlled asthma, and patients with scores greater than 1.00 are more likely to not have well-controlled asthma (Juniper et al., 2006).

\section{Operational Definitions}

\section{Independent Variables}

The independent variables for the study were numeracy and print literacy. The NVS scores were dichotomized into either adequate or possibility of limited numeracy. Scores ranging from zero to three were classified as possibility of limited numeracy, and scores between four and six were classified as adequate.

Based on the previous literature, this study used the "somewhat" response to "How confident are you filling out medical forms by yourself?" as the threshold for inadequate literacy. The screening question was dichotomized into adequate or inadequate literacy using the "somewhat" response to the aforementioned question as the threshold. 


\section{Mediating Variables}

Self-efficacy and asthma knowledge were included as mediators in this study. Both were operationalized as continuous variables with higher scores representing greater self-efficacy and asthma knowledge.

\section{Outcome Variables}

The AQLQ-S and ACQ were included as outcome variables. The overall mean of the AQLQ-S was calculated with higher scores indicating better asthma related quality of life. The ACQ was scored as the mean of the six questions with higher scores indicating poorer asthma control.

\section{Covariates}

Age was self-reported by subjects and was operationalized as a continuous variable. Sex was operationalized as a two category variable, male and female. Education was operationalized as a four category variable, less than high school, high school graduate or equivalent, some college, and college graduate. Insurance status was operationalized as a three category variable, private insurance, public insurance, and uninsured. Disease severity was operationalized as a continuous variable, and FEV1 \% of predicted was used to determine disease severity. A lower FEV1 \% indicated greater disease severity. Disease duration was operationalized as a continuous variable and was calculated by subtracting the participant's current age minus age of asthma diagnosis. Number of comorbidities, hospitalizations in the last twelve months, and number of ED visits in the last twelve months were all self-reported and were operationalized as continuous variables.

\section{Data Analysis}

Health outcomes and health services researchers examine the relationships between variables. Some relationships are fairly uncomplicated and investigate the relationship between an independent $(X)$ and dependent $(Y)$ variable. However, relationships are not always that simple, and there may be a mediating variable $(M)$ that influences the relationship between $X$ and $Y$. Mediation analysis was developed to examine these more complex relationships. Figure 3-1 presents a simple mediation model.

Path $a$ represents the effect of $X$ on $M$. Path $b$ represents the effect of $M$ on $Y$. The product of $a$ and $b$ is known as the mediated or indirect effect. Path c represents the total effect of $X$ on $Y$. Path $c$ ' represents the effect of $X$ on $Y$ when accounting for the indirect effect. Regression coefficients quantify each path. The causal order of $X, M$, and $Y$ are informed by theory and previous research. 
A.

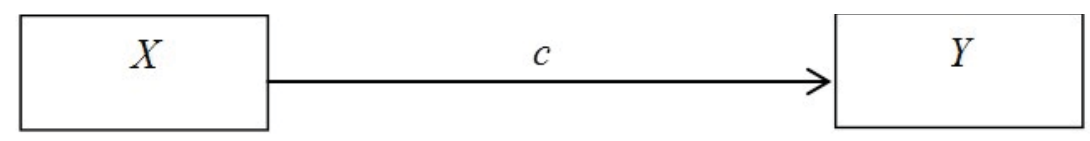

B.

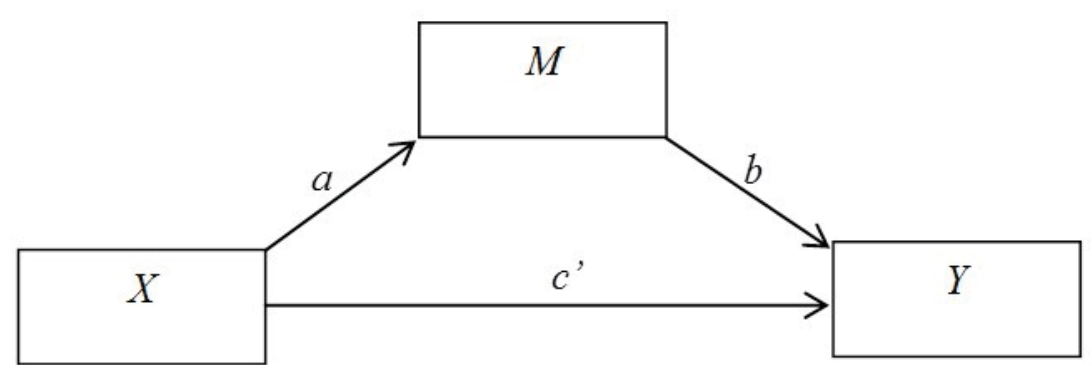

\section{Figure 3-1. Simple mediation model}

\section{Causal Steps Approach}

There are multiple approaches to mediation analysis. The causal steps approach is the most commonly used method for mediation analysis (Briggs, 2006; MacKinnon, Lockwood, Hoffman, West, \& Sheets, 2002; Preacher \& Hayes, 2008). Four conditions must be satisfied for mediation to occur. First, there must be a significant relationship between $X$ and $Y$. Next, there must be significant relationship between $X$ and $M$. The relationship between $M$ and $Y$ must be significant as well. Complete mediation occurs if $c$ ' is not significantly different from zero, and partial mediation occurred if $c$ ' is smaller than c, but still statistically significant (Baron \& Kenny, 1986).

The causal steps approach is simple and straightforward, but is problematic under some circumstances. This approach is not a statistical test and cannot test for the significance of the indirect effect, and does not produce point estimates or standard errors for the mediated effect. It has also been criticized for not being rigorous enough or a sufficient test for mediation. The causal steps approach was also developed for large sample sizes, assumes normality, and is difficult to use with multiple mediator models.

This method has low power for smaller sample sizes due to the testing of individual coefficients, $a$ and $b$, as opposed to testing the indirect effect, $a b$ (Briggs, 2006; MacKinnon et al., 2002). Lastly, this method requires a significant relationship between $X$ and $Y$ for mediation to exist. Sometimes, $c$ ' may be positive while $a b$ is negative causing the net influence to be zero and the mediated effect would not be detected (Briggs, 2006). Due to the shortcomings of this method, the Sobel test was developed. 


\section{Sobel Test}

The Sobel Test, also known as the product-of-coefficients, is an alternative to the causal steps approach (Sobel, 1982). This approach creates a standard error for $a b$, and tests the significance of the mediated effect by dividing the mediated effect by the standard error and comparing this value to the standard normal distribution (Briggs, 2006; MacKinnon et al., 2002). The Sobel test assumes normality and was developed to test the product of only two coefficients. Consequently, it is not appropriate for multiple mediator models with more than two coefficients.

\section{Multiple Mediator Models}

It is rare that one mediator accounts for all the variation between $X$ and $Y$, and it is advantageous to include multiple mediators in a model. Figure 3-2 illustrates a multiple mediator model.

The earlier approaches to mediation analysis were not developed with multiple mediators in mind. Using these methods for multiple mediator models is challenging. The Multivariate Delta Method (MDM) is an extension of the Sobel Test for multiple mediator models and produces standard errors for indirect effects for models with more than one mediator. MDM assumes multivariate normality. Not only must $a b$ be normal; the sampling distributions of the total and specific mediated effects must be normal as well (Preacher \& Hayes, 2008). If the assumption of normality is violated; confidence intervals are too wide, standard errors are too large, and Type 1 error rates are biased (Briggs, 2006).

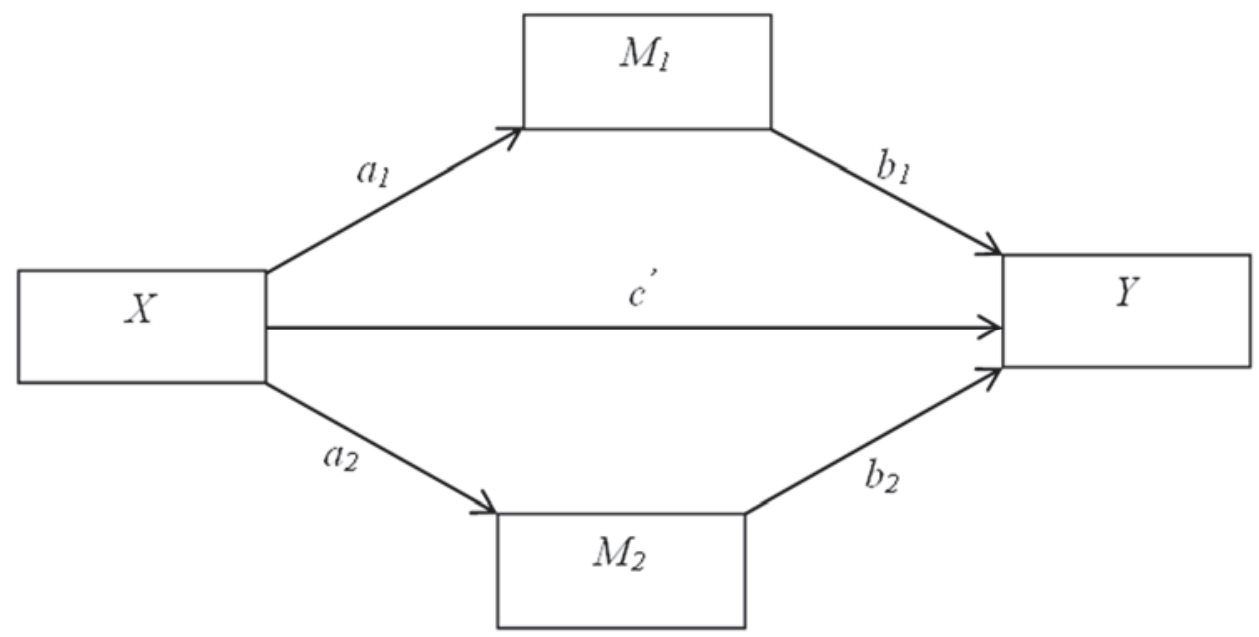

Figure 3-2. Multiple mediator model 
Bootstrapping is another approach to multiple mediator analysis that addresses the shortcomings of the MDM and makes no assumptions about the distribution of the sample. A sample of $\mathrm{n}$ cases with replacement is taken from the original sample. This process is repeated at least 1,000 times, and a sampling distribution of the specific indirect effects $\left(a_{1} b_{1}, a_{2} b_{2}\right)$ and the total indirect effect $\left(a_{1} b_{1}+a_{2} b_{2}\right)$ is created. The sampling distribution of the mediated effect is used to construct percentile based (BP) confidence intervals for the mediated effect. Unlike MDM confidence intervals, BP confidence intervals can be asymmetric because they are based on the sampling distribution (Briggs, 2006; Preacher \& Hayes, 2008). Because the percentile based confidence intervals tend to over or estimate the population value, bias-corrected (BC) and accelerated bias corrected (BCa) confidence intervals that are created by transforming the distribution of the estimate (Effron \& Tibshirani, 1993).

Williams and MacKinnon (2008) examined different methods for testing significance in multiple mediation models. The causal steps approach had the lowest power and Type 1 error rates compared to all other methods. The bias corrected bootstrap method was found to have the best power, confidence interval placement, and Type 1 error rate. The authors recommend using alternative methods as opposed to the causal steps approach to analyze multiple mediator models and models with smaller sample sizes. Briggs (2006) also examined different methods for multiple mediator models. Compared to MDM methods, bootstrap percentile methods had better power and confidence intervals. $\mathrm{BC}$ and $\mathrm{BCa}$ methods had more power and overall performance with smaller sample sizes compared to MDM and BP methods. BC bootstrapping is recommended when analyzing multiple mediator models (Briggs, 2006; Preacher \& Hayes, 2008; Williams \& MacKinnon, 2008). The BC bootstrapping method was chosen for this study because it accommodated the small sample size, has the greatest power compared to other methods, allowed the calculation of asymmetrical confidence intervals, and for more favorable type 1 error rates. The following sections will describe the specific procedures used to analyze the quantitative data.

\section{Descriptive Statistics}

Descriptive statistics of the demographic variables and health literacy levels were calculated including means, standard deviations, and frequencies. Associations between individual factors found in the conceptual model across health literacy and numeracy levels were examined using $\chi 2$ test. Bivariate associations between health literacy/numeracy and asthma outcomes were tested using t-tests for the ACQ and Wilcoxon-Mann-Whitney tests for the AQLQ-s. Analysis was also done to determine if the length of time in the main study or the effectiveness of tiotropium vs. long acting beta agonists influenced asthma outcomes. 


\section{Mediation Analysis}

The Preacher and Hayes (2008) recommended method of bootstrapping multiple mediator analysis with bias corrected confidence intervals was used in this study. Both total and specific indirect effects were examined using 5,000 bootstrap samples to calculate $95 \%$ bias corrected confidence intervals. Four main models were run, and all models included both asthma knowledge and self-efficacy as mediators. In model 1, print literacy (Chew et al. 2004 screening question) was the independent variable and asthma quality of life (AQLQ-S) was the outcome variable. In model 2, print literacy (Chew et al. 2004 screening question) was the independent variable and asthma control (ACQ) was the outcome variable. In model 3, numeracy (NVS) was the independent variable and asthma quality of life (AQLQ-S) was the outcome variable. In model 4, numeracy (NVS) was the independent variable and asthma control (ACQ) was the outcome variable. All models were controlled for age, sex, education, insurance status, disease severity, disease duration, number of comorbidities, number of hospitalizations in the last 12 months, and number of ED visits in the last 12 months. Alpha was set at .05, and all tests were two tailed. A post-hoc power analysis for each model was done to determine the power of detecting mediating effects.

\section{Phase Two: Qualitative}

The qualitative portion of the study was exploratory in nature and focused on the patient experience. The qualitative data also illuminated different topic areas related to health literacy (i.e., information seeking behaviors, patient-provider communication, and self-management behaviors). The qualitative and quantitative arms of research were not focused on identical concepts, but similar concepts of the same phenomenon, i.e., health literacy.

During the quantitative data collection, an interview schedule (Appendix B) for the semi-structured interviews was developed. Previous heath literacy literature and anecdotal conversations that occurred with participants during quantitative data collection were used to inform the questions. Participants were asked questions regarding their information seeking behaviors, self-management, and patient-provider communication.

\section{Sample and Setting}

Semi-structured interviews were conducted for the qualitative portion of the study. Quantitative data were used to identify subjects with adequate and low print literacy, and two subjects with low print literacy and two subjects with adequate print literacy completed interviews. A list of participants with adequate print literacy and a list of participants with low print literacy were generated. Participants from each list were then called to see if they would be willing to complete and interview. The first participants who agreed to participate and had transportation to come to the office to complete the interviews were selected. The small sample size of four was appropriate for 
an interpretative phenomenological analysis (IPA) study (Smith \& Osborn, 2003).

Interviews lasted between 45 and 60 minutes. Interviews were recorded and transcribed verbatim.

\section{Data Analysis}

Qualitative data were analyzed using interpretative phenomenological analysis. This qualitative approach originated in the field of psychology and is exploratory in nature (Fade, 2004; Larkin, Watts, \& Clifton, 2006; Smith, 1996). IPA is a combination of phenomenological theory and symbolic interactionism. Phenomenology is concerned with the individual's perception and experience and does not aim for objectivity. Symbolic interactionism is also focused on subjectivity, but believes that the meaning of the individual's experience is interpreted through the researcher. IPA is focused on the individual but embraces the interpretative and analytical role of the researcher (Smith, 1996; Smith \& Osborn, 2003).

Semi-structured interviews are the ideal method for collecting data for IPA studies (Smith \& Osborn, 2003). The researcher has preset questions to guide the interview, but the interview is dictated by the responses of the participant. Semistructured interviews are particularly useful when the researcher does not have the opportunity to interview the participant more than once. Using an interview guide helps ensure that the same topics are covered in each interview which allows for more reliable and comparable data (Bernard, 2006).

There are basic guidelines for analyzing data using IPA. The first stage of analysis involves becoming familiar with the data by reading the transcript multiple times. During this stage, the researcher notes anything they find interesting or significant in the participant's responses. The second stage involves turning initial thoughts and comments into emerging themes. These emerging themes are phrases that embody what was found in the initial notes. Next, the researcher looks for connections between the emerging themes which involves a theoretical or analytical ordering of the emerging themes. These connections must be supported by the respondent's actual words. Finally, the emerging themes are put into clusters, and the clusters are given a name that represents the emergent themes. Again, the clustering is supported by the transcript (Smith \& Osborn, 2003).

This process is repeated for each case. Each case can be analyzed from the very beginning or themes from the initial case can be used to orient subsequent analyses. For small sample sizes, it is recommended to analyze each case separately and then look for convergent and divergent themes among cases. Once all of the cases are analyzed, final superordinate themes from all cases are determined. These themes are chosen based on

prevalence in the data, the richness of transcript data that supports themes, and the ability of the themes to inform the cases overall (Smith \& Osborn, 2003). The researcher engages in an iterative process which involves close interaction between the researcher and the data. 
IPA is appropriate when trying to understand how an individual perceives and makes sense of a situation (Smith \& Osborn, 2003). This makes IPA applicable to health research where understanding the patient perception of illness is necessary to treat an illness. IPA is used to go beyond describing the patient experience, but also aims to make sense of the experience in a larger societal or theoretical context. IPA should ultimately result in greater insight into the phenomenon of interest through an individual's experience with the phenomenon of interest (Brocki \& Wearden, 2006; Larkin et al., 2006). This method was appropriate for this study because the participant's experience managing asthma and using health information was used to help make sense of the underlying processes that connect health literacy and asthma outcomes. Interviews were recorded and transcribed verbatim. Following transcription, data were analyzed using the four previously steps outlined by Smith and Osborn (2003). After the initial coding, a second reviewer examined the transcripts to examine the validity of the results.

\section{Mixed Methods Analysis}

This aim of this analysis was to examine the extent to which patient experiences of self-management enhance the understanding of self-reported health literacy skills and asthma outcomes. This study used an explanatory sequential mixed methods approach in which both qualitative and quantitative data were used for completeness, diversity of views, and enhancement (Bryman, 2006). Creswell and Plano Clark (2011) note that sequential approaches engage in connected data analysis. The analysis of the first phase of data was used to guide the selection of participants for the second phase of data collection. Interviewees were chosen based on health literacy skills that were determined through quantitative phase of the study. Interview questions included topics such as information seeking, self-efficacy, and patient-provider communication to ensure that the researcher was able to use the results to answer both the qualitative and mixed methods research questions (Creswell and Plano Clark, 2011). Figure 3-3 presents the multiple stages of data analysis.

Onwuegbuzie and Teddlie's (2003) steps for mixed methods analysis were followed to analyze data. These seven steps include: data reduction, data display, data transformation, data correlation, data consolidation, data comparison, and data integration. Data reduction involved the separate analysis of the qualitative (i.e., interpretative phenomenological analysis) and quantitative (i.e., descriptive statistics, bivariate analysis, mediation analysis) data. Next, data was displayed using tables, figures, and charts. Data transformation, an optional step that involves converting qualitative data into quantitative data or vice versa, was not a part of this study. Following data display, the quantitative and qualitative data were correlated. For example, results of the bivariate and mediational analysis regarding self-efficacy were correlated with participant interview data regarding how confident participants felt taking care of their asthma. Following correlation, qualitative and quantitative data were compared. The researcher explored whether qualitative results supported the quantitative results regarding self-efficacy or asthma knowledge and whether the qualitative and 
Phase

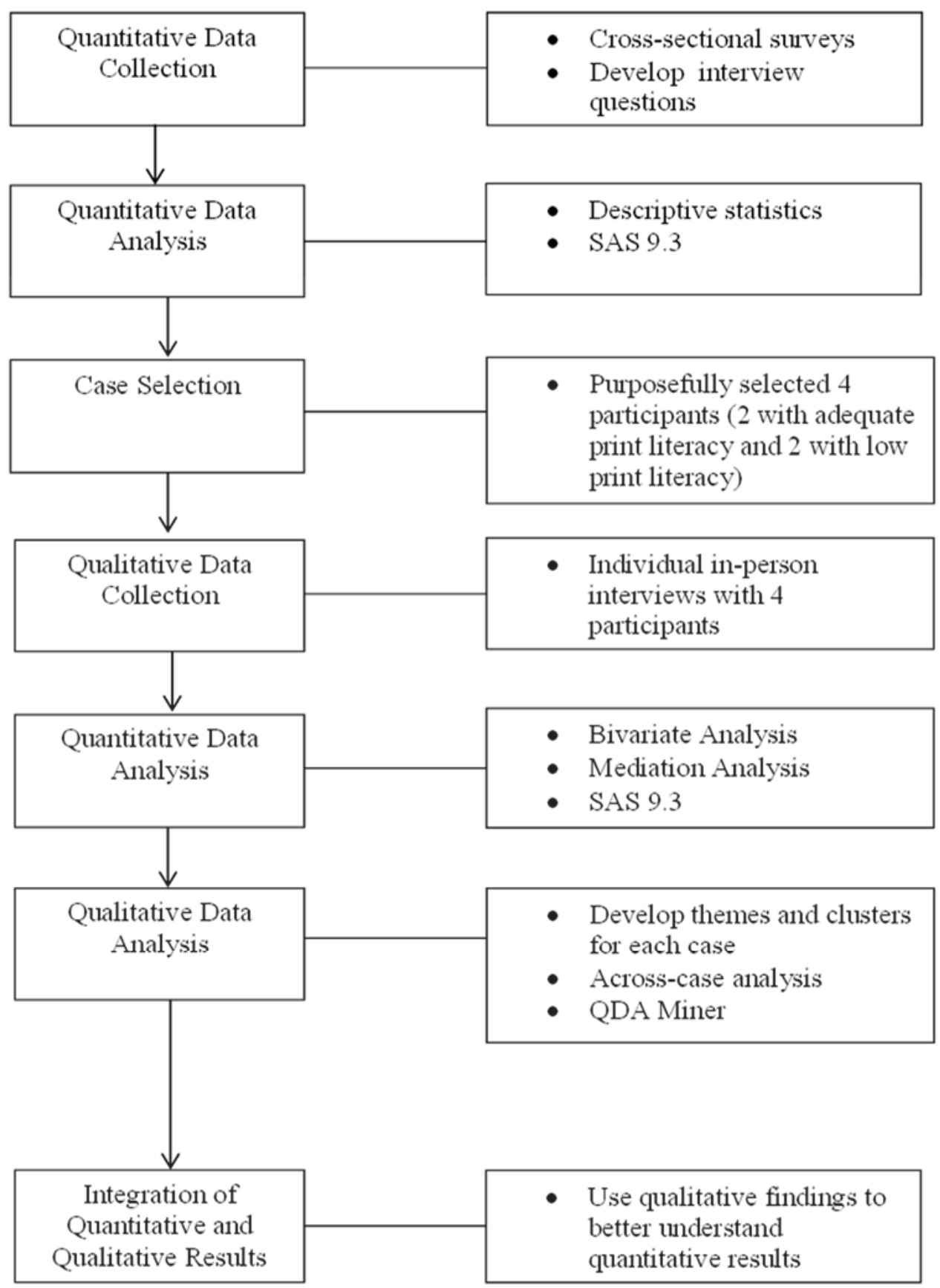

Figure 3-3. Visual model of explanatory sequential design 
quantitative data diverged. Lastly, the data were integrated to make inferences based on both the qualitative and quantitative results.

\section{Consideration of Human Subjects}

The study was granted exempt status from the Institutional Review Board (IRB) at The University of Tennessee Health Science Center's and the Office of Medical Research at the Regional Medical Center at Memphis. A consent cover statement (Appendix C) was used in lieu of a traditional informed consent to consent patients for the study. A unique identifier was used for data analysis and appropriate measures were taken to ensure confidentially of all data. 


\section{CHAPTER 4. RESULTS}

This chapter presents the results of the quantitative analysis which included: descriptive statistics of the study population; bivariate analysis of variables across print literacy and numeracy levels; and mediation analysis examining self-efficacy and asthma knowledge as mediators between health literacy and asthma outcomes. Following the quantitative results, qualitative analysis results will be presented to describe the information seeking behaviors, self-management, and patient-provider communication of participants.

\section{Quantitative Results}

\section{Sample Characteristics}

Sample characteristics are presented in Table 4-1. Ninety-nine subjects were included in the analysis. The mean age was 46 years old, and the majority of subjects $(72 \%)$ were women. Seventy-two percent of subjects had at least a high school education. The majority of subjects were publicly insured (63\%), and $27 \%$ of subjects had no insurance. Seventy one percent of subjects had adequate print literacy, while only $29 \%$ of subjects had adequate numeracy. The mean $\%$ FEV1 was $73 \%$ indicating that on average, subjects would be classified as having moderate asthma. The mean number of years with diagnosed asthma was 21 years. Over the last 12 months, subjects selfreported an average of 1.6 inpatient hospitalizations for asthma and 2.7 emergency room visits for asthma. The mean score on the ASE was 53, and the mean score for the Asthma knowledge Questionnaire was $72 \%$ correct. The mean score on the ACQ was 2.11 indicating that on average, subjects had poorly controlled asthma. The mean score on the AQLQ-s was 3.86.

\section{Health Literacy}

Demographic, mediating, and outcome variables were stratified by print literacy and numeracy skills. Table 4-2 presents the sample characteristics stratified by print literacy, and Table 4-3 presents sample characteristics stratified by numeracy.

\section{Print Literacy}

There were no observed differences between individuals with adequate print literacy and low health literacy across age, sex, education, $\% \mathrm{FEV} 1$, number of years with diagnosed asthma, number of comorbidities, number of hospitalizations in the last 12 months, number of emergency department visits in the last 12 months, Asthma 
Table 4-1. Study sample characteristics

\begin{tabular}{lc}
\hline Characteristics & M \pm SD or n (\%) \\
\hline $\mathrm{N}$ & 99 \\
Age & $46 \pm 11.37$ \\
Sex & $28(28)$ \\
$\quad$ Male & $71(72)$ \\
Female & \\
Education & $28(28.3)$ \\
$\quad$ High school & $31(31.3)$ \\
$\quad$ High school & $32(32.3)$ \\
$\quad$ Some College & $8(8.1)$ \\
College Graduate & \\
Insurance & $10(10.1)$ \\
Private Insurance & $62(62.6)$ \\
$\quad$ Public Insurance & $27(27.3)$ \\
Uninsured & $73.3 \pm 18.61$ \\
FEV1\% & $22 \pm 14.48$ \\
Disease duration(years) & $1.11 \pm 1.03$ \\
Comorbidities & $0.28 \pm 0.78$ \\
Hospitalizations & $1.26 \pm 2.49$ \\
ED visits & $52.9 \pm 8.58$ \\
ASE & $72.18 \pm 11.76$ \\
Asthma Knowledge & $2.11 \pm 1.21$ \\
ACQ & $3.86 \pm 1.3$ \\
AQLQ-S & \\
Print Literacy & $70(71)$ \\
Adequate & $29(29)$ \\
Low & \\
Numeracy & $29(29)$ \\
Adequate & $70(71)$ \\
Limited & \\
\hline &
\end{tabular}

Notes: ED: emergency department, ASE: Asthma Self-efficacy Scale, ACQ: Asthma Control Questionnaire, AQLQ-S: Standardized Asthma Quality of Life. 
Table 4-2. Characteristics of population stratified by print literacy

\begin{tabular}{lccc}
\hline & \multicolumn{2}{c}{ Print Literacy } & \\
\cline { 2 - 3 } Characteristics & Adequate & Low & p-Value \\
\hline N $(\%)$ & $70(71)$ & $29(29)$ & \\
Age** & $45.62 \pm 11.29$ & $46.69 \pm 11.71$ & 0.67 \\
Sex* & & & 0.55 \\
$\quad$ Male & $21(75)$ & $7(25)$ & \\
$\quad$ Female & $49(69)$ & $22(31)$ & \\
Education* & & & 0.17 \\
$\quad$ < High school & $17(61)$ & $11(39)$ & \\
$\quad$ High school & $21(68)$ & $10(32)$ & \\
$\quad$ Some College & $24(75)$ & $8(25)$ & \\
$\quad$ College Graduate & $8(100)$ & $0(0)$ & \\
Insurance* & & & 0.63 \\
$\quad$ Private Insurance & $7(70)$ & $3(30)$ & \\
$\quad$ Public Insurance & $42(68)$ & $20(32)$ & \\
$\quad$ Uninsured & $21(78)$ & $6(22)$ & \\
\%FEV1** & $74.14 \pm 18.32$ & $71.28 \pm 19.48$ & 0.49 \\
Disease duration(years)** & $21.69 \pm 14.45$ & $22.69 \pm 14.78$ & 0.75 \\
Comorbidities** & $1.00 \pm 0.99$ & $1.37 \pm 1.08$ & 0.10 \\
Hospitalizations** & $0.21 \pm 0.74$ & $0.44 \pm 0.87$ & 0.18 \\
ED visits** & $1.3 \pm 2.75$ & $1.17 \pm 1.75$ & 0.78 \\
ASE** & $54.13 \pm 8.65$ & $49.79 \pm 7.71$ & 0.02 \\
Asthma Knowledge** & $73.02 \pm 11.64$ & $70.15 \pm 12.01$ & 0.27 \\
ACQ** & $2.02 \pm 1.27$ & $2.32 \pm 1.05$ & 0.26 \\
AQLQ-S & $3.94 \pm 1.33$ & $3.68 \pm 1.20$ & 0.25 \\
\hline
\end{tabular}

Notes: ASE: Asthma Self-efficacy Scale, ACQ: Asthma Control Questionnaire, AQLQS: Standardized Asthma Quality of Life Questionnaire, ED: Emergency department $\%$ FEV1: Forced expiratory volume in 1 second. Age, sex, education, insurance status, disease duration, and number of comorbidities were all self-reported. Hospitalizations and ED visits are number of self-reported visits in the last 12 months. Asthma knowledge is scored as percent of correct answers. Private insurance includes employer sponsored, individual plans, or insurance through a spouse's or parent's employer. Public insurance includes Medicaid and Medicare.

* Chi-square

** Independent t-tests

£ Wilcoxon Mann-Whitney 
Table 4-3. Characteristics of population stratified by numeracy

\begin{tabular}{lccc}
\hline & \multicolumn{2}{c}{ Numeracy } & \\
\cline { 2 - 3 } Characteristics & Adequate & Low & p-Value \\
\hline N (\%) & $29(29)$ & $70(71)$ & \\
Age** & $43.3 \pm 12.45$ & $47.02 \pm 10.79$ & 0.14 \\
Sex* & & & 0.56 \\
$\quad$ Male & $7(25)$ & $21(75)$ & \\
$\quad$ Female & $22(31)$ & $49(69)$ & \\
Education** & & & $<0.001$ \\
$\quad<$ High school & $4(14)$ & $24(86)$ & \\
$\quad$ High school & $5(16)$ & $26(84)$ & \\
$\quad$ Some College & $14(44)$ & $18(56)$ & \\
$\quad$ College Graduate & $6(75)$ & $2(25)$ & \\
Insurance** & & & 0.30 \\
$\quad$ Private Insurance & $5(50)$ & $5(50)$ & \\
$\quad$ Public Insurance & $16(26)$ & $46(74)$ & \\
$\quad$ Uninsured & $8(30)$ & $19(70)$ & \\
\%FEV1** & $74.24 \pm 16.13$ & $72.91 \pm 19.64$ & 0.75 \\
Disease duration(years)** & $19.52 \pm 13.34$ & $23 \pm 14.90$ & 0.28 \\
Comorbidities** & $0.76 \pm 0.69$ & $1.26 \pm 1.11$ & 0.008 \\
Hospitalizations** & 0 & $0.4 \pm 0.90$ & $<0.001$ \\
ED visits** & $0.86 \pm 1.66$ & $1.43 \pm 2.78$ & 0.21 \\
ASE** & $56 \pm 8.39$ & $51.56 \pm 8.37$ & 0.02 \\
Asthma Knowledge** & $76.33 \pm 11.03$ & $70.45 \pm 11.7$ & 0.02 \\
ACQ** & $1.77 \pm 1.07$ & $2.25 \pm 1.24$ & 0.07 \\
AQLQ-S & $4.54 \pm 1.33$ & $3.58 \pm 1.18$ & 0.001 \\
\hline
\end{tabular}

Notes: ASE: Asthma Self-efficacy Scale, ACQ: Asthma Control Questionnaire, AQLQS: Standardized Asthma Quality of Life Questionnaire, ED: Emergency department $\%$ FEV1: Forced expiratory volume in 1 second. Age, sex, education, insurance status, disease duration, and number of comorbidities were all self-reported. Hospitalizations and ED visits are number of self-reported visits in the last 12 months. Asthma knowledge is scored as percent of correct answers. Private insurance includes employer sponsored, individual plans, or insurance through a spouse's or parent's employer. Public insurance includes Medicaid and Medicare.

* Chi-square

** Independent t-tests

£ Wilcoxon Mann-Whitney 
Knowledge Questionnaire scores, ACQ scores, or overall AQLQ-S scores. Individuals with adequate print literacy did have significantly higher ASE scores $(p=0.02)$ compared to individuals with low print literacy indicating that print literacy was associated with increased self-efficacy.

\section{Numeracy}

There were no observed differences between individuals with adequate numeracy and limited numeracy across age, sex, insurance status, \% FEV1, number of years with diagnosed asthma, and number of emergency department visit in the last 12 months. More education was significantly associated $(\mathrm{p}=<0.001)$ with having adequate numeracy. Individuals with adequate numeracy had fewer comorbidities $(p=0.08)$ and fewer hospitalizations in the last 12 months $(\mathrm{p}=<0.001)$. Note that individuals with adequate numeracy reported no hospitalizations for asthma in the last 12 months. Adequate numeracy was also associated with higher self-efficacy $(\mathrm{p}=0.02)$ and increased asthma knowledge $(p=0.02)$ compared to individuals with limited numeracy. Individuals with adequate numeracy had lower ACQ scores compared to individuals with limited numeracy $(\mathrm{p}=0.07)$. Although this association was not statistically significant, the difference in scores is clinically relevant (Juniper, Svensson, Mörk, \& Ståhl, 2005). Lastly, individuals with adequate numeracy had better asthma related quality of life compared to individuals with limited numeracy $(\mathrm{p}=0.001)$.

\section{Association between Numeracy and Print Literacy}

Print literacy and numeracy are different skill sets. Adequacy in one area does not indicate adequacy in the other. Chi square analysis was done to examine the association between numeracy and print literacy in this population. Results showed that adequate numeracy was significantly associated with having adequate health literacy $(p=0.03)$. Individuals with adequate numeracy have 3.5 higher odds of having adequate print literacy than individuals with limited numeracy.

\section{Intrinsic Bias}

The current study was a sub-study of a larger study with a follow up period from 6 to 18 months. Sub-study data was collected at different times throughout the follow up period. Because subjects were enrolled in a larger study, they may have been more likely to take medications as prescribed due to follow-up visits and frequent interactions with study staff. There was concern that individuals who were in the study for a longer period of time would have improved asthma outcomes compared to individuals who were in the study for shorter periods of time.

Eighty percent of sub-study data was collected during the first month (visit 1 or visit 2) of being enrolled in the BELT study. Ten percent of participants completed the 
sub-study after 6 months of enrollment, and 9\% of subjects completed the sub-study after 14-18 months of enrollment in the BELT study. Analysis was also done to examine differences in asthma outcomes by the length of time subjects were enrolled in the larger study. Individuals who completed the sub-study during visit 1 or visit 2 had significantly higher ACQ scores $(\mathrm{p}=0.01)$ compared to all other participants. Individuals who completed the sub-study at their 6 month visit had significantly lower ACQ scores $(\mathrm{p}=<$ .0001) than individuals who completed the sub-study at any other time period. There were no differences in AQLQ-S scores across sub-study completion times $(p=0.05)$. Based on this analysis, time of visit will be controlled in mediation analyses with ACQ as the outcome variable.

\section{Mediation Analysis}

The analysis was completed using a SAS macro developed by Preacher and Hayes (2008). A total of four multiple mediator models were run. In model 1, print was the independent variable and asthma control was the dependent variable. In model 2, print literacy was the independent variable and asthma quality of life was the dependent variable. In model 3, numeracy was the independent variable and asthma control was the dependent variable. In model 4, numeracy was the independent variable and asthma quality of life was the dependent variable. All models included both self-efficacy and asthma knowledge as mediators and controlled for age, sex, education, insurance status, $\% \mathrm{FEV} 1$, number of years with diagnosed asthma, number of comorbidities, and number of hospitalizations and emergency department visits in the last 12 months. All covariates were included in the analysis regardless of being significantly associated in bivariate analysis. Many of these covariates have been found to be significantly associated with print literacy and numeracy in previous research (Kutner et al., 2006). Secondly, the focus of this analysis is on the mediating effects of self-efficacy and asthma knowledge not predictors of asthma outcomes or health literacy. Controlling for other factors emphasizes the relationship being examined and not extraneous variables that are not the focus of this study. Because $\mathrm{X}$ was dichotomous (binary), the analysis is testing the difference in mean of $\mathrm{Y}$ through M1 and M2.

\section{Model 1}

Figure 4-1 displays the relationship between print literacy and asthma control. The total effect of print literacy on asthma control was $0.7039(\mathrm{p}=0.13)$ indicating no difference in asthma control based on print literacy. The direct effect of print literacy on asthma control was $0.35(\mathrm{p}=0.18)$ indicating no difference in asthma control resulting from print literacy's influence on self-efficacy and asthma knowledge. The model had an adjusted $R^{2}$ of $0.20(p=0.001)$ indicating that the print literacy, self-efficacy, and asthma knowledge explained $20 \%$ of the variance in asthma control. Table 4-4 displays the partial effects of the control variables. The number of emergency department visits in the last 12 months was the only significant covariate. 


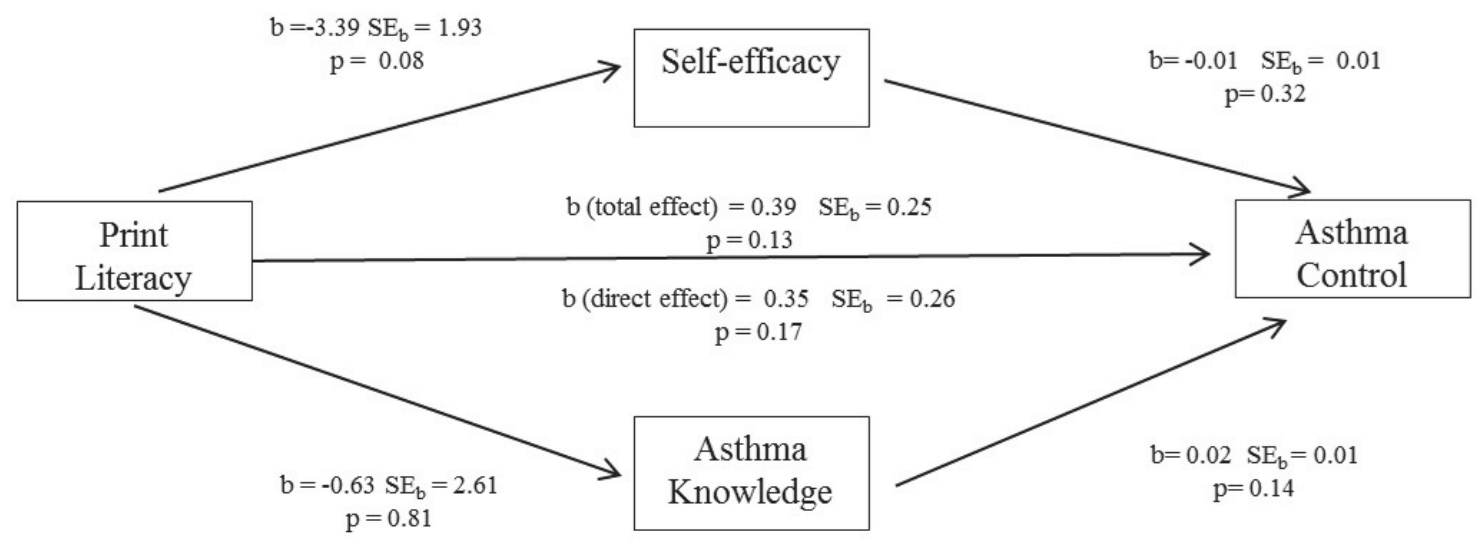

Figure 4-1. Associations among print literacy, self-efficacy, asthma knowledge, and asthma control

Notes: SE: standard error, b: unstandardized path coefficient. Results of mediation analysis model showing associations among print literacy, the proposed mediating variables (self-efficacy and asthma knowledge) and asthma control. Unstandardized path coefficients, standard errors, and p-values are reported. The total effect is the effect of print literacy on asthma control. The direct effect is the effect of print literacy on asthma control when accounting for self-efficacy and asthma knowledge. 
Table 4-4. Model 1: Partial effect of control variables on asthma control

\begin{tabular}{lrcc}
\hline Variable & Coefficient & Standard Error & p-Value \\
\hline Age & -0.0158 & 0.0106 & 0.14 \\
Sex & -0.0646 & 0.2714 & 0.81 \\
Education & 0.0582 & 0.1330 & 0.66 \\
Insurance Status & 0.3660 & 0.1902 & 0.06 \\
\%FEV 1 & -0.0085 & 0.0065 & 0.19 \\
Disease Duration & 0.0042 & 0.0081 & 0.60 \\
Comorbidities & 0.1607 & 0.1176 & 0.18 \\
Hospitalizations & 0.0087 & 0.1548 & 0.96 \\
ED visits & 0.1633 & 0.0461 & $<0.001$ \\
Time of Visit & -0.2001 & 0.1020 & 0.05 \\
\hline
\end{tabular}

Notes: \%FEV1: Forced expiratory volume in 1 second; ED: emergency department. 
The indirect effects were not significant (Table 4-5). The total indirect effect of the mediators combined had a point estimate of $0.0015(-0.1032,0.2495)$. The independent indirect effect of self-efficacy $[0.0017(-0.0311,0.2873)$ and knowledge $[-0.0002(-0.2061,0.0817)$ were both insignificant as well. Although the significant direct effect indicated partial mediation, significance tests for the specific indirect effects were not significant. This discrepancy may be due to the model's low power for detecting mediating effects.

\section{Model 2}

Figure 4-2 displays the relationship between print literacy and asthma related quality of life. The total effect of print literacy on quality of life was $-0.21(p=0.47)$ indicating that print literacy was not associated with quality of life. The direct effect of print literacy on quality of life was $-0.16(\mathrm{p}=0.59)$ indicating no difference in quality of life resulting from print literacy's influence on self-efficacy and asthma knowledge. The overall model was not significant with an adjusted $\mathrm{R}^{2}$ of $0.04(\mathrm{p}=0.18)$. Table 4-6 displays the partial effects of the control variables. Number of emergency department visits in the last 12 months was the only significant covariate $(p=0.007)$.

The indirect effects were not significant (Table 4-7). The total indirect effect of the mediators combined had a point estimate of $-0.0092(-0.2992,0.0822)$. The independent indirect effect of self-efficacy $[-0.0027(-0.3823,0.0214)$ and knowledge $[-0.0065(-0.0540,0.1945)$ were both insignificant as well. Print literacy was not associated with quality of life and that relationship was not mediated by self-efficacy or asthma knowledge.

\section{Model 3}

Figure 4-3 displays the relationship between numeracy and asthma control. The total effect of numeracy on asthma control was $0.50(p=0.07)$ indicating no difference in asthma control based on numeracy. The direct effect of numeracy on asthma control was $0.50(\mathrm{p}=0.08)$ indicating no difference in asthma control resulting from numeracy's influence on self-efficacy and asthma knowledge. The model had an adjusted $\mathrm{R}^{2}$ of 0.21 $(\mathrm{p}=0.001)$ indicating that numeracy, self-efficacy, and asthma knowledge explained $21 \%$ of the variance in asthma control. Table 4-8 displays the partial effects of the control variables. Number of emergency department visits in the last 12 months was the only significant covariate $(\mathrm{p}=0.001)$.

The indirect effects were not significant (Table 4-9). The total indirect effect of the mediators combined had a point estimate of $0.0012(-0.1889,0.2056)$. The independent indirect effect of self-efficacy $[0.0053(-0.0465,0.2908)$ and knowledge $[-0.0041(-0.2583,0.0341)$ were both insignificant as well. 
Table 4-5. Indirect effects of print literacy on asthma control through selfefficacy and asthma knowledge

\begin{tabular}{lcccc}
\hline & & & \multicolumn{2}{c}{ BCa 95\% CI } \\
\cline { 4 - 5 } Indirect Effect & Point Estimate & Standard Error & Lower & Upper \\
\hline Total & 0.0015 & 0.0839 & -0.1032 & 0.2495 \\
Self-efficacy & 0.0017 & 0.0699 & -0.0311 & 0.2873 \\
Knowledge & -0.0002 & 0.0639 & -0.2061 & 0.0817 \\
\hline
\end{tabular}

Notes: BCa 95\% CI: Bias-corrected and accelerated confidence intervals. Independent variable (print literacy); dependent variable (asthma control); Total indirect effect represents the sum of indirect effects for self-efficacy and asthma knowledge. Model controlled for age, sex, education, insurance status, \%FEV 1, number of years with diagnosed asthma, number of comorbidities, and number of hospitalizations, time of visit, and emergency department visits in the last 12 months. 


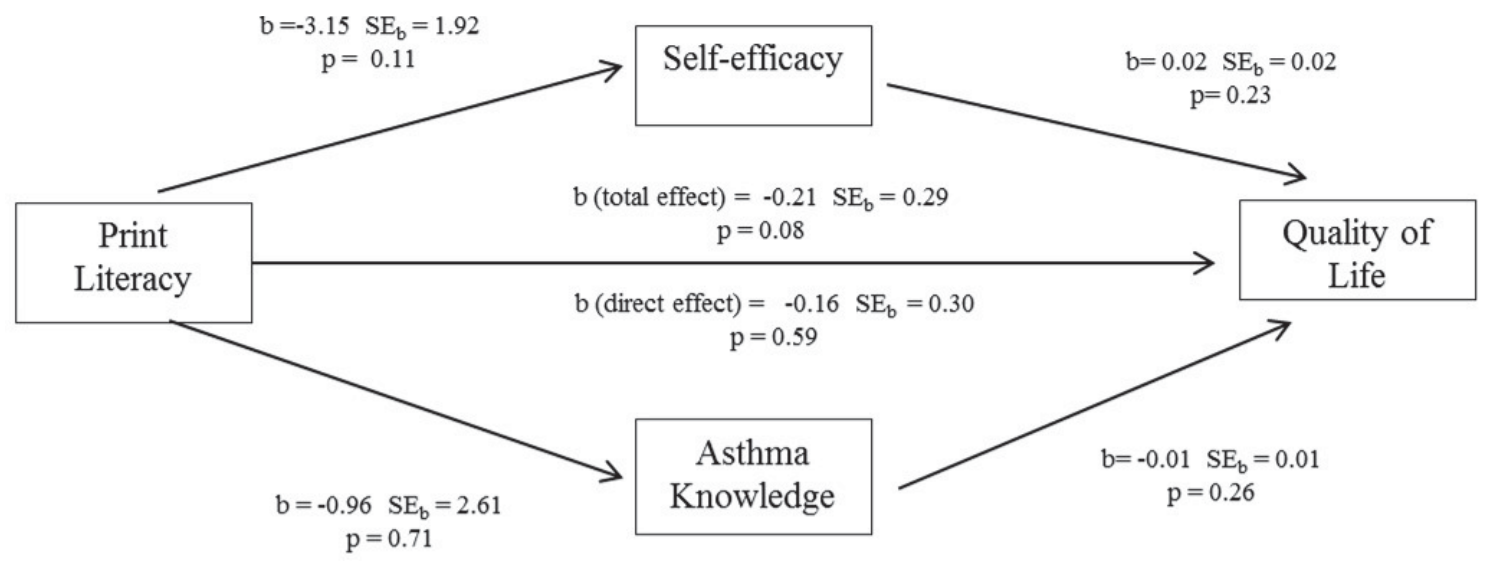

Figure 4-2. Associations among print literacy, self-efficacy, asthma knowledge, and asthma related quality of life

Notes: SE: standard error, b: unstandardized path coefficients. Results of mediation analysis model showing associations among print literacy, the proposed mediating variables (self-efficacy and asthma knowledge) and asthma related quality of life. Unstandardized path coefficients, standard errors, and p-values are reported. The total effect is the effect of print literacy on quality of life. The direct effect is the effect of print literacy on quality of life when accounting for self-efficacy and asthma knowledge. 
Table 4-6. Model 2: Partial effect of control variables on asthma related quality of life

\begin{tabular}{lccc}
\hline Variable & Coefficient & Standard Error & p-Value \\
\hline Age & 0.0081 & 0.0124 & 0.52 \\
Sex & -0.2575 & 0.3087 & 0.41 \\
Education & 0.0414 & 0.1554 & 0.79 \\
Insurance Status & -0.3381 & 0.2221 & 0.13 \\
\%FEV 1 & 0.0020 & 0.0073 & 0.79 \\
Disease Duration & -0.0021 & 0.0094 & 0.83 \\
Comorbidities & -0.1510 & 0.1369 & 0.27 \\
Hospitalizations & -0.0834 & 0.1774 & 0.64 \\
ED visits & -0.0834 & 0.0535 & 0.01 \\
\hline
\end{tabular}

Notes: \%FEV1: Forced expiratory volume in 1 second; ED: emergency department. 
Table 4-7. Indirect effects of print literacy on asthma related quality of life through self-efficacy and asthma knowledge

\begin{tabular}{lcccc}
\hline & Point & & \multicolumn{2}{c}{ BCa 95\% CI } \\
\cline { 4 - 5 } Indirect Effect & Estimate & SE & Lower & Upper \\
\hline Total & -0.0092 & 0.0905 & -0.2992 & 0.0822 \\
Self-efficacy & -0.0027 & 0.0844 & -0.3823 & 0.0214 \\
Knowledge & -0.0065 & 0.0538 & -0.0540 & 0.1945 \\
\hline
\end{tabular}

Notes: BCa 95\% CI: Bias-corrected and accelerated confidence intervals, independent variable (print literacy); dependent variable (asthma related quality of life); Total indirect effect represents the sum of indirect effects for self-efficacy and asthma knowledge. Model controlled for age, sex, education, insurance status, $\% \mathrm{FEV} 1$, number of years with diagnosed asthma, number of comorbidities, and number of hospitalizations and emergency department visits in the last 12 months. 


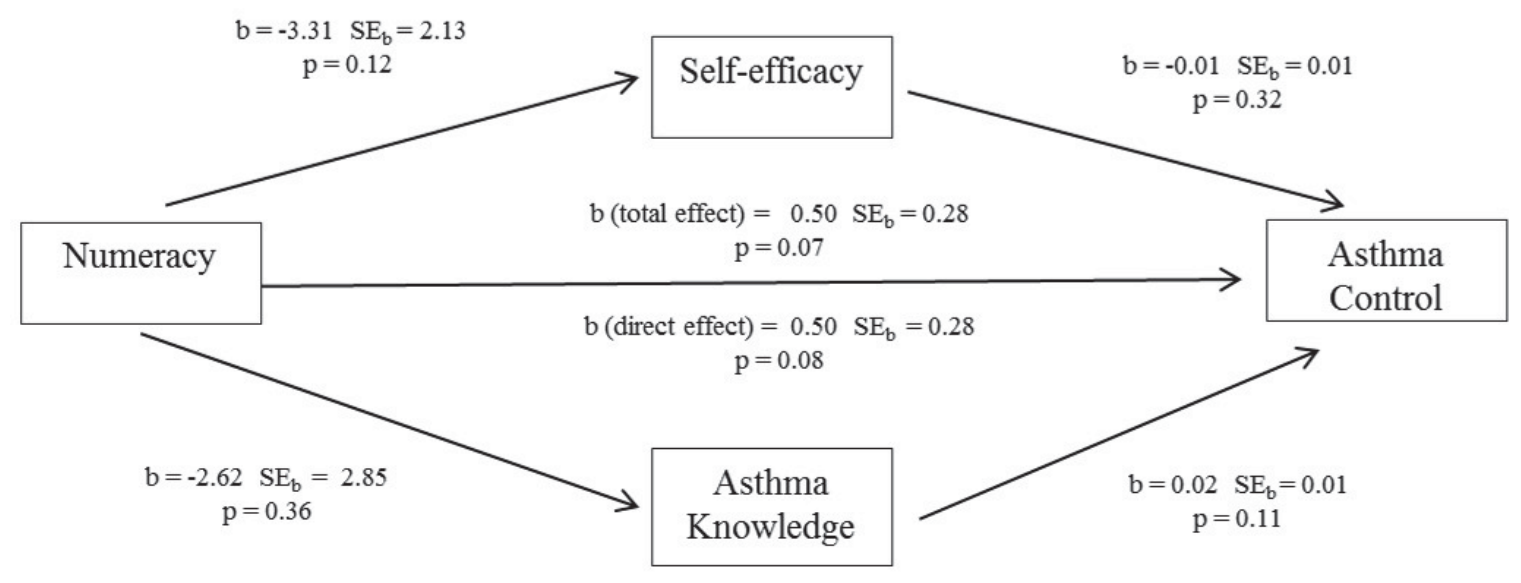

Figure 4-3. Associations among numeracy, self-efficacy, asthma knowledge, and asthma control

Notes: SE: standard error, b: unstandardized path coefficient. Results of mediation analysis model showing associations among numeracy, the proposed mediating variables (self-efficacy and asthma knowledge) and asthma control. Unstandardized path coefficients, standard errors, and p-values are reported. The total effect is the effect of numeracy on asthma control. The direct effect is the effect of numeracy on asthma control when accounting for self-efficacy and asthma knowledge. 
Table 4-8. Model 3: Partial effect of control variables on asthma control

\begin{tabular}{lccc}
\hline Variables & Coefficient & Standard Error & p-Value \\
\hline Age & -0.0178 & 0.0105 & 0.10 \\
Sex & -0.0079 & 0.2692 & 0.98 \\
Education & 0.1070 & 0.1373 & 0.44 \\
Insurance Status & 0.3069 & 0.1906 & 0.11 \\
\%FEV 1 & -0.0099 & 0.0064 & 0.13 \\
Disease & 0.0031 & 0.0081 & 0.70 \\
Duration & & & \\
Comorbidities & 0.1466 & 0.1173 & 0.22 \\
Hospitalizations & -0.0271 & 0.1560 & 0.86 \\
ED visits & 0.1543 & 0.0458 & 0.001 \\
Time of Visit & -0.1841 & 0.1006 & 0.07 \\
\hline
\end{tabular}

Notes: \%FEV1: Forced expiratory volume in 1 second; ED: emergency department. 
Table 4-9. Indirect effects of numeracy on asthma control through self-efficacy and asthma knowledge

\begin{tabular}{lcccc}
\hline & & & \multicolumn{2}{c}{ BCa 95\% CI } \\
\cline { 4 - 5 } Indirect Effect & Point Estimate & SE & Lower & Upper \\
\hline Total & 0.0012 & 0.0942 & -0.1889 & 0.2056 \\
Self-efficacy & 0.0053 & 0.0805 & -0.0465 & 0.2908 \\
Knowledge & -0.0041 & 0.0688 & -0.2583 & 0.0341 \\
\hline
\end{tabular}

Notes: BCa 95\% CI: bias-corrected and accelerated confidence intervals SE: standard error. Independent variable (numeracy); dependent variable (asthma control); Total indirect effect represents the sum of indirect effects for self-efficacy and asthma knowledge. Model controlled for age, sex, education, insurance status, \%FEV 1, number of years with diagnosed asthma, number of comorbidities, and number of hospitalizations, time of visit, and emergency department visits in the last 12 months. 


\section{Model 4}

Figure 4-4 displays the relationship between numeracy and asthma related quality of life. The total effect of numeracy on asthma quality of life was $-0.99(p=0.002)$ indicating a significant one point difference in asthma quality of life based on numeracy. The direct effect of numeracy on asthma quality of life was $-0.98(\mathrm{p}=0.0002)$ indicating a difference in asthma quality of life resulting from numeracy's influence on self-efficacy and asthma knowledge. Individuals with adequate numeracy had better asthma related quality of life compared to individuals with limited numeracy, and this was partially mediated by self-efficacy and asthma knowledge. However the effect of these mediators is likely small due to the small size of the indirect effect coefficients. The model was significant with an adjusted $\mathrm{R}^{2}$ of $0.14(\mathrm{p}=0.01)$ indicating that numeracy, self-efficacy, and asthma knowledge explained $14 \%$ of the variance in asthma related quality of life. Table 4-10 displays the partial effect of control variables on asthma related quality of life. Number of emergency room visits in the last 12 months was the only significant covariate $(\mathrm{p}=0.009)$.

The indirect effects were not significant (Table 4-11). The total indirect effect of the mediators combined had a point estimate of $0.0018(-0.2530,0.1849)$. The independent indirect effect of self-efficacy $[-0.0093(-0.3249,0.0424)]$ and knowledge $[0.0111(-0.0310,0.2674)]$ were both insignificant as well.

\section{Post-Hoc Power Analysis}

This study used bootstrapped accelerated bias-corrected confidence intervals to test for statistical significance of the indirect effects. This method was chosen over other methods for testing significance because it has the greatest power for detecting mediation, particularly in complex models with small sample sizes (Briggs, 2006; Mallinckrodt, Abraham, Wei, \& Russell; Preacher \& Hayes, 2008; Shrout \& Bolger, 2002; Williams \& MacKinnon, 2008). Previous studies using the methods used in this study typically did not perform or report power analyses (Buffardi \& Campbell, 2008; Danaher, Smolkowski, Seeley, \& Severson, 2008; Day et al., 2013; Lynch, Johnson, Kable, Carroll, \& Coles, 2011; Molloy et al., 2012; Parisi et al., 2012; Wittman, Arce, \& Santisteban, 2008;), but relied on previously documented power determined through simulation studies (Briggs, 2006; Williams \& MacKinnon, 2008). This lack of discussion regarding power analysis is likely due to the paucity of literature in this area. Two papers offering guidance for power analysis apply only to single mediator models (Fritz \& MacKinnon, 2007; Preacher \& Kelly, 2011). Thoemmes, MacKinnon, \& Reiser (2010) recommend using Monte Carlo methods for power analysis in multiple mediator models. This approach was developed by Muthén and Muthén (2002). Steps for the Monte Carlo approach include: defining the model by setting all parameters to fixed values based on previous research, drawing a large number of samples based on the previously defined model; fitting the sample to the proposed model; producing a power estimate based on empirical rate statistical significance averaged across all the replications (Thoemmes et al., 2010). 


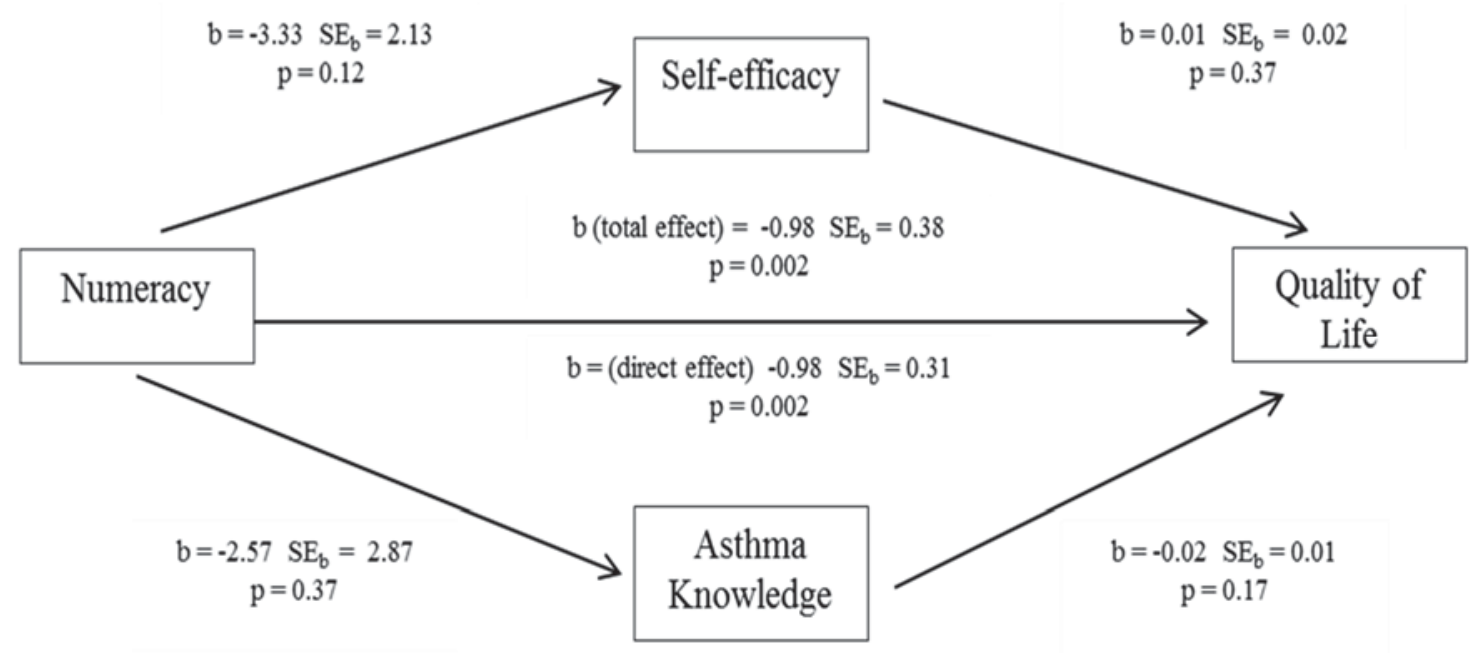

Figure 4-4. Associations among numeracy, self-efficacy, asthma knowledge, and quality of life

Notes: SE: standard error, $b=$ unstandardized path coefficients. Results of mediation analysis model showing associations among numeracy, the proposed mediating variables (self-efficacy and asthma knowledge) and asthma related quality of life. Unstandardized path coefficients, standard errors, and p-values are reported. The total effect is the effect of numeracy on quality of life. The direct effect is the effect of numeracy on quality of life when accounting for self-efficacy and asthma knowledge. 
Table 4-10. Model 4: Partial effect of control variables on asthma related quality of life

\begin{tabular}{clrc}
\hline p-Value & \multicolumn{1}{c}{ Variables } & Coefficient & Standard Error \\
\hline 0.36 & Age & 0.0109 & 0.0118 \\
0.27 & Sex & -0.3247 & 0.2931 \\
0.54 & Education & -0.0951 & 0.1533 \\
0.27 & Insurance Status & -0.2373 & 0.2127 \\
0.69 & \%FEV 1 & 0.0028 & 0.0069 \\
0.86 & Disease Duration & 0.0016 & 0.0090 \\
0.43 & Comorbidities & -0.1039 & 0.1304 \\
0.95 & Hospitalizations & 0.0100 & 0.1706 \\
0.009 & ED visits & -0.1348 & 0.0507 \\
\hline
\end{tabular}

Notes: \%FEV1: forced expiratory volume in 1 second; ED: emergency department. 
Table 4-11. Indirect effects of numeracy on asthma related quality of life through self-efficacy and asthma knowledge

\begin{tabular}{lcccc}
\hline & & & \multicolumn{2}{c}{ BCa 95\% CI } \\
\cline { 4 - 5 } Indirect Effect & Point Estimate & Standard Error & Lower & Upper \\
\hline Total & 0.0018 & 0.1027 & -0.253 & 0.1849 \\
Self-efficacy & -0.00093 & 0.087 & -0.3249 & 0.0424 \\
Knowledge & 0.0111 & 0.0721 & -0.03 & 0.2674 \\
\hline
\end{tabular}

Notes: BCa 95\% CI: bias-corrected and accelerated confidence intervals, SE: standard error. Independent variable (numeracy); dependent variable (asthma quality of life). Total indirect effect represents the sum of indirect effects for self-efficacy and asthma knowledge. Model controlled for age, sex, education, insurance status, \%FEV 1, number of years with diagnosed asthma, number of comorbidities, and number of hospitalizations and emergency department visits in the last 12 months. 
This Monte Carlo approach is usually done a priori to determine an adequate sample size or for post-hoc analysis, as it was used in the current study. In addition to the Monte Carlo analysis, estimated power from simulation studies will be reported as well. Mplus was used to conduct the Monte Carlo analysis. In model 1, the power to detect the total effect and direct effect was 0.998 and 0.64 respectively. Power to detect the total mediating effect of self-efficacy and asthma knowledge was very low at 0.06 . Power to detect individual effects of self-efficacy and asthma knowledge was 0.06 and 0.02 respectively. In model 2 , the power to detect the total effect and direct effect was 0.28 and 0.09 respectively. Power to detect the total mediating effect of self-efficacy and asthma knowledge was very low at 0.06 . Power to detect individual effects of selfefficacy and asthma knowledge was 0.07 and 0.04 respectively. In model 3, the power to detect the total effect and direct effect was 0.80 and 0.23 respectively. Power to detect the total and individual mediating effects of self-efficacy and asthma knowledge was very low at 0.06. 0.003 In model 4, the power to detect the total effect and direct effect were 0.96 and 0.72 respectively. Power to detect the total mediating effect of self-efficacy and asthma knowledge was 0.05 . Power to detect the individual mediating effects of selfefficacy and asthma knowledge was very low at 0.004 and 0.06 respectively.

The estimates from the Monte Carlo approach power analysis were much lower than simulation study estimates previously reported by Briggs (2006). For multiple mediator models with a sample size of 100, power to detect the total indirect effect ranged from 0.825-0.958. Power to detect the first indirect effect ranged from 09170.9537 , and power to detect a second indirect effect ranged from 0.171-0.532. Briggs (2006) simulated multiple populations with varying path coefficients and found that the $\mathrm{BCa}$ confidence intervals were the most powerful.

It is unclear why the Monte Carlo results were significantly lower than the estimates by Briggs (2006). One factor that may have contributed to the discrepancy is Monte Carlo approach requirement for population parameter estimates from prior research and theory. Because there were no parameter values of mediators of asthma outcomes from previous literature, parameter values from the current study were used instead. Also, simulation studies use predetermined path coefficients, and those coefficients may differ from actual real world data. The findings also suggest that much larger sample sizes for adequate power are needed when there are weak relationships between some variables. In the current study, the $a$ coefficients were much larger than the $b$ coefficients indicating weak relationships between the mediating variables and the outcome variables. Although the current study may have been underpowered due to a small sample size and weak relationships between some variables, the most powerful method was used to detect a mediating effect.

\section{Qualitative Results}

The qualitative results revealed the experiences of information seeking, selfmanagement, and patient provider communication among African-American adults with asthma. All participants in the qualitative phase of the study were women. While 
participants' print literacy skills varied, all participants had limited numeracy skills. Sample characteristics are presented in Table 4-12. Three overall themes emerged from the analysis of the interview data. The clusters and emerging themes from each separate case analysis are presented in Table 4-13.

\section{Information Desired vs. Information Received}

Participants in this study acquired information about asthma from various sources and through different mediums. However, all noted discordance between the content, depth, and amount of information that they were actually given and the information that they desired to successfully manage their asthma. Participants were given basic information about the pathophysiology of asthma and how to take asthma medications properly. Some participants only received oral information from their providers while others attended asthma education classes. All participants expressed a desire to learn about their disease and suggested formal educational opportunities to get information. This was demonstrated by Participant 1 who said, "If you got asthma, why not have a class and let people come there and get educated about asthma you know?" Participant 2 said:

No they never sent me to an educational class, but that probably would be good for someone like me that has the determination that they decide that "I'm not gonna use that pump." Ok so a person like me should have already been in a class. It should have been something set out. You need to go to this class and see what happen to people when they don't use that pump every day.

Participants also had ideas about the content that these classes should cover. When discussing class content, Participant 2 said:

What is asthma? What medications that they have on the market for asthma. Uh, what uh triggers. What can trigger asthma? And what you need to do once you realize that you're having a asthma attack because I'm telling you, a lot of people don't know they havin' a asthma attack.

The need for more information about what triggers one's asthma was important to all the participants. Participant 1 who had previously attended an asthma education class suggested changes to the content saying, "In 2004, they didn't really say how serious (asthma was). They let us know it (asthma) could get serious whereas everybody should know it's a serious thing...I mean people die have died from having asthma attack. It could get that bad."

In addition to an educational class, participants also had other suggestions to help patients to learn about asthma. Participant 2 said:

I think it should be a pamphlet in every asthma doctor's office; that if you goin' to specialist, they need to have to give you so that you can read up on it... and um, 
Table 4-12. Characteristics of interview participants

\begin{tabular}{|c|c|c|c|c|c|c|c|c|c|}
\hline Participant & Age & Education & Insurance & $\begin{array}{c}\text { Print } \\
\text { Literacy }\end{array}$ & Numeracy & ASE & $\begin{array}{c}\text { Asthma } \\
\text { Knowledge }\end{array}$ & $\begin{array}{c}\text { AQLQ- } \\
\text { S }\end{array}$ & ACQ \\
\hline 1 & 57 & Some college & Public & Low & Limited & 56 & $67 \%$ & 4.59 & 1 \\
\hline 2 & 64 & High school & Uninsured & Adequate & Limited & 54 & $59 \%$ & 5.03 & 1 \\
\hline 3 & 68 & $\begin{array}{l}<\text { High } \\
\text { school }\end{array}$ & Public & Adequate & Limited & 57 & $63 \%$ & 5.16 & 1 \\
\hline 4 & 59 & Some college & Public & Low & Limited & 57 & $71 \%$ & 3.16 & 2.83 \\
\hline
\end{tabular}

Notes: ASE (Asthma Self-efficacy Scale) measured asthma self-efficacy with higher scores indicating higher self-efficacy. Asthma knowledge scored as percent correct. AQLQ-S (Standardized Asthma Quality of Life Questionnaire) measured asthma related quality of life with higher scores indicating better quality of life. ACQ (Asthma Control Questionnaire) measured asthma control with lower scores indicating better asthma control. 
Table 4-13. Individual participant clusters and emerging themes

\begin{tabular}{|c|c|c|c|c|}
\hline Participant & Cluster 1 & Cluster 2 & Cluster 3 & Cluster 4 \\
\hline $1 *$ & $\begin{array}{l}\text { Doctor knows best } \\
\text {-expectations of } \\
\text { relationship } \\
\text {-growing process } \\
\text {-time and comfort } \\
\text {-impact of comfort/trust }\end{array}$ & $\begin{array}{l}\text { Trial and Error } \\
\text {-intentional self- } \\
\text { monitoring } \\
\text {-self-consciousness }\end{array}$ & $\begin{array}{l}\text { Information received vs. } \\
\text { information wanted } \\
\text {-provider initiated } \\
\text {-patient preference or initiated }\end{array}$ & $\begin{array}{l}\text { Asthma is in control } \\
\text {-inevitable } \\
\text {-fear and anxiety } \\
\text {-personal experience of } \\
\text { helplessness }\end{array}$ \\
\hline 2 & $\begin{array}{l}\text { Doctors as partners } \\
\text {-mistrust } \\
\text {-expectations } \\
\text {-patient responsibility }\end{array}$ & $\begin{array}{l}\text { Trial and error } \\
\text {-self-management as a } \\
\text { process } \\
\text {-intentional self- } \\
\text { monitoring }\end{array}$ & $\begin{array}{l}\text { Information received. information } \\
\text { wanted } \\
\text {-provider initiated } \\
\text {-patient preference or initiated }\end{array}$ & $\begin{array}{l}\text { Patient as an } \\
\text { expert/consumer } \\
\text {-ownership of } \\
\text { body/disease } \\
\text {-medical care as a service } \\
\text {-development of } \\
\text { knowledge base }\end{array}$ \\
\hline 3 & $\begin{array}{l}\text { Doctor as a partner } \\
\text {-patient responsibilities } \\
\text {-influence of } \\
\text { culture/race } \\
\text {-expectations of doctor } \\
\text { partnership development }\end{array}$ & $\begin{array}{l}\text { Trial and error } \\
\text {-asthma is emotional } \\
\text {-self-management as a } \\
\text { process }\end{array}$ & $\begin{array}{l}\text { Information as power } \\
\text {-information yields confidence } \\
\text {-information yields better self- } \\
\text { management } \\
\text {-the more the better }\end{array}$ & $\begin{array}{l}\text { Patient as an } \\
\text { expert/consumer } \\
\text {-shops for acceptable care } \\
\text {-ownership/expert of } \\
\text { body/disease }\end{array}$ \\
\hline $4 *$ & $\begin{array}{l}\text { Patient as the doctor } \\
\text {-mistrust of doctor } \\
\text {-influence of } \\
\text { race/culture } \\
\text {-educated by experience } \\
\text {-process to control }\end{array}$ & $\begin{array}{l}\text { Role of the doctor } \\
\text {-attentive listener } \\
\text {-treats the whole person }\end{array}$ & $\begin{array}{l}\text { Information received vs. } \\
\text { information wanted } \\
\text {-provider initiated } \\
\text {-patient preference } \\
\text {-"mad scientist" }\end{array}$ & \\
\hline
\end{tabular}

Notes: Clusters are in italics followed by emerging themes.

* Denotes a participant with low health literacy 
I think they need to have in that pamphlet some foods that you need to avoid uh, when you have asthma.

While all participants had a desire to learn about their asthma and wanted structured opportunities, participants with adequate print literacy were more proactive than participants with low health literacy in obtaining the information that they needed. Both of these participants reported using computers to learn about asthma. Participant 3 said:

I have become computer literate. So I go down and look on the computer about asthma. And with me having it from '95 up until now, I uh, didn't really have a source of information unless I got sick...but now if there's something new that I need to know, I keep in touch with what asthma is on the computer.

Participant 2 said, "When I really learned about asthma, I learned it from going into the computer and pullin' stuff out." Although both participants relied heavily on computer information, neither of them knew how to determine if the information was from a reliable source. Participant 2 reported, "If I'm reading something, and it's some of the side effects I'm having, I believe it. And if it's not, then I go back and ask my doctor." When asked how she determined if the information she found on the computer was true, Participant 3 reported:

Well to tell you the truth, I don't cause it's so much going on on the computer. And with me being the age I am, I am thankful that I can go in and put it on the uh on the website, and type in asthma uh asthma related, and they will go to the source.

Both participants also noted that they take internet information with them to their doctor's appointment to continue to discuss what they learn. Participant 2 noted, "Most of the time I bring a paper and say this is what I got off the internet." Participant 3 said, "The more information you receive or however you receive it. TV-computer, book, or whatever you um try to see which one is more helpful to you when you get to your doctor's office."

Although individuals with low print literacy did not mention using computers to learn about their asthma, they did try to use whatever information was given to them to learn about their asthma. In reference to information available at the doctor's office, Participant 4 said, "I would find pamphlets that they had and I would read up about the disease that I have." This same participant also took it upon herself to read the medication inserts that came with her asthma medications but found the information hard to understand. She said:

I try to learn by reading what's inside of the package when I open it. You have to be a mad scientist to really understand. But some of it, I kind of you know, you know, get the idea what they're saying, you know...look like they writing to the doctor. 
Another participant with low print literacy, Participant 4, reported that she made a doctor's appointment when she had questions about her asthma.

All of the participants believed that knowledge of asthma was important and beneficial for individuals with asthma to manage their disease. It is important to note that none of the patients with adequate print literacy mentioned any difficulties understanding the information they received from their doctors or information they found on the internet. Regardless of print literacy skills, all participants stated that they had enough information to successfully manage their asthma.

\section{Trial and Error}

The participants described asthma self-management as a learning process. This theme was best described by Participant 3 who said, "I see that it's a trial and error which you can't really afford to have errors." The participants also described how they started to monitor themselves in an effort to better control their asthma. Participant 1 said: "I kind a started watching what I'm doing when I start wheezing. What cause me to wheeze? Uh does exertion?" Participant 2 echoed this process saying, "I pay more attention to what trigger(s) my asthma, what doesn't trigger it. How far can I go before I can get to that pump, and all of that."

Participants also mentioned that their doctor's influence on their self-management practices has limitations. This was demonstrated by Participant 3 who said, "I would only go by what the doctors tell me, which is good. But some things you have to learn to do on your own." Participant 2 said:

So now people with asthma, they gonna have to learn if they don't listen to what the doctor say, you can't do no more. Once they (doctors) tell and they emphasize on how important it is for you to breathe, okay you gotta get up here. It's a mindset thing.

When discussing self-management, the impact of emotions on taking care of asthma was discussed. Participant 3 said, "So your emotion, how you feel emotionally will trigger your asthma. Yeah and the reason I know I lost my mother since I had it. And let me tell you Courtnee, it wasn't nothing nice." Participant 4 said:

Uh when I get upset or want to get ahold of someone. You get to breathin' too hard and and you'll have stirred it up you know. So most of the times, I have to take a spray to calm myself.

In addition to emotions triggering asthma, the confusion between asthma symptoms and emotional episodes was discussed. Participant 1 said, "I don't know what to say. Sometimes I get I can sometimes my anxiety attack; or what, what kind a trigger 
it. And I had to learn the difference between anxiety attacks and my asthma, cause I gets them mixed up sometimes."

Participants had different feelings about being in control of their asthma. Both of the participants with adequate print literacy felt that they were in control of their asthma. However, feeling in control of one's asthma did not mean that an individual exercised complete control in every situation. This was demonstrated by Participant 2 who said, "Um most of the time, I feel like I'm in control. But when you have that bad asthma attack, no you're not in control anymore. Asthma can kill you if you don't manage it right." Unlike the participants with adequate literacy, participants with low health literacy did not give a definitive yes about being in control of their asthma. Participant 1 said, "I mean I do what I'm supposed to do, and it's been working pretty good. When it [asthma] wants to cut up, it's gon' cut up, and there's no way I can uh stop it." Another participant with low health literacy tied her ability to her beliefs about her asthma medication and felt that her asthma had been out of control until recently. Participant 4 said:

Yeah I have better control of my asthma now. I would say from when I was uh I say my early twenties until I say well about 2 or 3 years ago; I felt like my asthma was still out of control.

When asked about the years when she felt her asthma was out of control, Participant 4 said:

The sprays that will really help me for my condition, and I'm going I still feel like I don't have control of it you know. And it didn't do me like that you know they way they say it supposed to have done. This is what I'm afraid of. I'm not taking this medication, and it seem like to me I'm hooked on it, cause you know... if I don't take my medicine, I can tell the difference. I'm out of control. But when I take my medicine, I'm more in control. And see they uh the other times I uh took my medicine like I should, but it was still out of control.

\section{Expectations of the Patient-Provider Relationship}

When discussing the relationship between patient and providers, participants reported the expectations they had of their providers. In addition to provider expectations, participants discussed their roles in the relationship and different factors that affect their interactions with their providers.

\section{Provider Expectations}

All participants expected their provider to listen to them and expressed dissatisfaction when they felt that their providers were not listening to them. Participant 2 reported, "I would just tell him [doctor]; I just want you to listen to me about what's 
going on with my body instead of writing while I'm talking to you. Look at me. Then I know that you listening to me." Participant 4 said, "I didn't feel like they were really interested. They were just talking. This is what they supposed to do, just talk. It wasn't really concern." In addition to being good listeners, participants expected their doctor to treat them as a whole person and not just treat their asthma. Participant 4 reported, "I just want my doctor to recognize who I am... and they say "well let's see how you doin'," you know." Participant 1 reported, "She [participant's doctor] know pretty much what's going on with me period. She know with my body."

Participants also acknowledged that their providers knew more than they did, but they still had something to contribute and wanted their providers to recognize their contributions. Participant 2 said, "They're in charge. I do what they say, but we have a good relationship. And I don't care how long it takes. He knows he has other patients, but I will talk to him." Participant 1 said, "If they [doctors] don't agree with me, they'll listen to me or whatever...they're going to run some tests to confirm what they think or to rule out what I think."

Participants with adequate print literacy reported seeking care elsewhere when their expectations were not met. Participant 2 said, "You gonna talk to me or you gonna put me on out, and I'm gonna go find me another doctor." Standards of acceptable care extended not only to the provider, but to the entire experience. Participant 3 said, "Except the last time I called to make an appointment, and then the receptionist was really awful. Well the heck with that. So I went to another doctor. They were good." The participants with low health literacy did not report changing doctors because they were not satisfied with the care they were receiving.

\section{Patient Responsibility}

As previously discussed, participants want their providers to listen to them. All of the participants reported that they were responsible for telling their providers all of their symptoms. Participant 3 said, "I'm gonna tell them everything." Participant 2 said, "It is my responsibility to tell the doctor the truth." Participants with adequate print literacy were more engaged as patients than participants with low health literacy. They believed it was important to bring information to their providers. Participant 2 said, "I think today, they really look for you to go into the computer and come back and say something." Participant 3 reported:

I know they know more than I do, but I share this information with them. What I have seen, and uh I tell them, "You know she gave me flovent, and she gave me this, and she gave me that, but I find one of them to be very helpful."

Participants with adequate print literacy also reported taking ownership of their disease and their bodies. Participant 3 said, "I'm tellin' them what's going on with me cause I know my body." Participant 2 said, "It's my health. It's not theirs." These

participants also treated the patient-provider relationship as a partnership. Participant 2 
said, "You got to have some uh uh focus on what you want to happen to you with this asthma other than waitin' on your doctor, takin' your hand, walkin' us." Participants with adequate health literacy also believed that a good relationship with their providers was necessary for taking care of their asthma. Participant 2 reported, "You have to build rapport with your doctor. It come from building." Participant 3 said, "The best thing to do is to have good communication with your doctor." These ideas of rapport and bringing information to your doctor's visits were not reported by individuals with low print literacy. Although participants with low print literacy did not discuss building rapport with their providers, one participant noted the impact of good rapport on her selfmanagement. Participant 1 reported, 'I'm comfortable to the point where I don't have a problem taking my medicines. If I'm not comfortable with my doctor, I'm not going to take the medicine."

\section{Factors That Influence the Patient-Provider Relationship}

Participants discussed several factors that impacted their relationships with their providers. These factors included mistrust, comfort, and race. Participants reported their mistrust of doctors regarding the medications that they were prescribed for their asthma. Participant 1 said, "...My actual feeling about doctors are that they are in with the pharmacies... and it may not be something that you really need, but they got a contract or whatever." Another participant recalled a time where she felt her doctor was not upfront with her about the side effects of one of her asthma medications. Participant 4 said:

They tried something different and say we got something good for you and that was prednisone... If I had known about the prednisone that I could have took it another way, I wouldn't have took the prednisone like I did because they never did tell us that uh, the prednisone would do all the things that it did do.

In addition to mistrust about providers' prescribing habits, participants recalled experiences of being an African-American in the health care system. Participant 4 reported, "You hear how others they have done people in the past. You know, specially our people, you know. And uh, it make you weary. That's the reason a lot of Blacks are weary about doctors." This patient also recalled an experience where she felt the provider did not want to touch her because she was African-American. She reported:

I have went to the doctor and he say "You got asthma?" Mmhmm that's right. Uh pull that coat and then he got a ink pen and did something like he didn't want to touch me... Maybe it's a phobia or maybe you don't like brown skin mmhmm.

Another participant also had negative experiences with providers. Participant 3 reported, "I think when I first got pregnant and went to the doctor I was really timid...you still had some of these prejudice white folks." It is important to note that the participant whispered when she said "white folks" and would often touch and point to her skin instead of saying "black." In addition to perceived racism in the health care system, 
a participant recalled other experiences that have continued to stick with her. Participant 3 said:

I went to the drugstore to get an ice cream because it was hot and it wasn't but a nickel. That lady looked at me, "ma'am Negroes have to go out to the back." That hurt me so bad... and it's still sticking with me. Stuck with me.

Interestingly, the topic of race was not introduced by the interviewer. The influence of race evolved from discussing patient-provider communication. In addition to race, a participant also felt discriminated against for being overweight, and she felt that providers have looked at her like she was "just disgusting" and attributed her asthma to her being overweight. Participant 4 said, "Yeah, yeah, suppose to it's a lot of things they do behind closed doors, and what nobody there to witness, you know. You know, they say I never done that. I never said that, but you know deep down inside."

Both of the participants with adequate print literacy discussed ways to overcome mistrust and discrimination. Participant 2 emphasized the importance of building rapport with her doctor saying:

You shouldn't just have to build a rapport. It should be one when you get there, but in this society people look at the way you dress, your mannerisms. They look at your hair. They look at your eyes. They look at your everything, and that's what they judge you by. They look at you don't have no money. They look at your insurance. They look at everything. So you have to build rapport with your doctor.

Participant 3 used information to combat negative experiences saying:

All you wanna do is learn how to take care of yourself without asking anyone to help and I got to the point where I was real smart... so I just started to researching a lot of stuff and that built up my confidence...

\section{Integration of Qualitative and Quantitative Results}

The results of the mediation analysis and IPA were used to make meta-inferences about the relationship between health literacy and asthma outcomes. Table 4-14 presents major conclusions from both phases of the study. These conclusions were integrated to make meta-inferences for the overall study. These inferences are discussed in the next chapter. 


\section{Table 4-14. Linking survey results to interview results}

\begin{tabular}{|c|c|c|c|}
\hline \multirow[b]{2}{*}{ Quantitative Results } & \multicolumn{3}{|c|}{ Qualitative Themes } \\
\hline & $\begin{array}{c}\text { Information Received vs. } \\
\text { Information Wanted }\end{array}$ & Trial and Error & $\begin{array}{c}\text { Expectations of Patient- } \\
\text { Provider Relationship } \\
\end{array}$ \\
\hline $\begin{array}{l}\text { Print literacy, self-efficacy, and } \\
\text { asthma knowledge explain } 20 \% \text { of } \\
\text { variance in asthma control. }\end{array}$ & $\begin{array}{l}\text { Participants wanted a } \\
\text { greater amount and more } \\
\text { detailed information about } \\
\text { asthma than their providers } \\
\text { gave them. }\end{array}$ & $\begin{array}{l}\text { Participants described asthma } \\
\text { self-management as a learning } \\
\text { process. }\end{array}$ & $\begin{array}{l}\text { All participants expected their } \\
\text { provider to listen to them and } \\
\text { treat them as a whole person, not } \\
\text { just treat their asthma. }\end{array}$ \\
\hline $\begin{array}{l}\text { Numeracy, self-efficacy, and } \\
\text { asthma knowledge explain } 21 \% \text { of } \\
\text { variance in asthma control and } \\
14 \% \text { of variance in quality of life. }\end{array}$ & $\begin{array}{l}\text { Participants with adequate } \\
\text { print literacy used } \\
\text { information from the } \\
\text { internet and books to fill in } \\
\text { the information gap. }\end{array}$ & $\begin{array}{l}\text { Participants reported that the } \\
\text { providers give information and } \\
\text { advice, but the responsibility of } \\
\text { self-management ultimately lies } \\
\text { with the patient. }\end{array}$ & $\begin{array}{l}\text { All participants wanted to } \\
\text { contribute to the relationship, but } \\
\text { participants with adequate print } \\
\text { literacy felt obligated to bring } \\
\text { asthma information to their } \\
\text { medical encounters. }\end{array}$ \\
\hline $\begin{array}{l}\text { Self-efficacy and asthma } \\
\text { knowledge did not mediate the } \\
\text { relationship between print literacy } \\
\text { and asthma control or print literacy } \\
\text { and quality of life. }\end{array}$ & & $\begin{array}{l}\text { Participants with adequate print } \\
\text { literacy reported that they had } \\
\text { more control of their asthma } \\
\text { than participants with low print } \\
\text { literacy. }\end{array}$ & $\begin{array}{l}\text { Participants with adequate print } \\
\text { literacy were health care } \\
\text { consumers and pursued care } \\
\text { elsewhere when they were not } \\
\text { satisfied with the care they } \\
\text { received }\end{array}$ \\
\hline $\begin{array}{l}\text { Self-efficacy and asthma } \\
\text { knowledge partially mediate the } \\
\text { relationship between numeracy and } \\
\text { asthma control but do no mediate } \\
\text { the relationship between numeracy } \\
\text { and asthma control. }\end{array}$ & & & $\begin{array}{l}\text { Personal experiences of } \\
\text { discrimination as well as others' } \\
\text { experiences of discrimination } \\
\text { caused participants to be } \\
\text { mistrustful of the health care } \\
\text { system and doctors. }\end{array}$ \\
\hline & & & $\begin{array}{l}\text { Participants with adequate print } \\
\text { literacy reported strategies for } \\
\text { overcoming mistrust of the } \\
\text { health care system. }\end{array}$ \\
\hline
\end{tabular}




\section{CHAPTER 5. DISCUSSION}

This study examined the relationship between health literacy and asthma outcomes among African-American adults using a mixed methods approach. Quantitative results will be discussed in the first section followed by a discussion of the qualitative results. Next, conclusions drawn from integrating the quantitative and qualitative phases will be discussed. This chapter will conclude with the strengths and limitations of the study, implications of the findings, recommendations for future research, and conclusions.

\section{Demographic Findings}

Asthma prevalence is higher among women compared to men, and higher among African-Americans compared to Non-Hispanic Whites (Akinbamai et al., 2011). The study population was $70 \%$ women, and all of the participants were African-American. The average ACQ score was 2.11 indicating that on average, study participants did not have well controlled asthma. The average $\% \mathrm{FEV} 1$ of $73 \%$ indicated that the participants had moderate disease severity. Approximately $29 \%$ of participants had low health literacy compared to national estimates of health literacy showing that $36 \%$ of adults have basic or below basic health literacy (Kutner et al., 2006). Previous research has shown that African-Americans are more likely to have low health literacy compared to non-Hispanic Whites (Canino et al., 2009; Kutner et al., 2006). Seventy one percent of the study population had limited numeracy skills. This is consistent with previous studies who found that $26 \%$ to $71 \%$ of adults have inadequate numeracy skills (Donelle et al., 2007).

\section{Relationship between Health Literacy and Health Outcomes}

The first specific aim of the study was to determine the relationship between health literacy and health outcomes. Previous research has found that health literacy is associated with decreased asthma knowledge (Gazmararian et al., 2003; Manusco \& Rincon, 2006; Williams et al., 1998). The present study found no association between print literacy and asthma knowledge. The reason for the lack of association between print literacy and asthma knowledge is unclear. The study by Williams et al. (1998) had a primarily African-American population and used a true or false measure of asthma knowledge similar to the tool used in this study.

The literature regarding the relationship between health literacy and other outcomes is conflicting. Williams et al. (1998) found that low health literacy was correlated with decreased self-efficacy; whereas, Manusco and Rincon (2006) found no association between health literacy and self-efficacy. The present study supports the findings of Williams et al. (1998) that low print literacy is associated with decreased self- 
efficacy. Perhaps health literacy influences self-efficacy in certain populations (i.e. urban African-Americans), but not in others.

Health literacy has also been associated with decreased quality of life and increased emergency department visits and hospitalizations (Apter et al., 2009; Manusco $\&$ Rincon, 2006). However, the relationship between health literacy and quality of life was diminished in the presence of other covariates (Manusco \& Rincon, 2006). The present study found no association between health literacy and quality of life, emergency department visits, or hospitalizations. Hospitalizations and emergency department visits in the current study were self-reported and the absence of an association may be due to recall bias.

To our knowledge, no study has examined the relationship between health literacy and asthma control. Although we found no association between print literacy and asthma control, more research is needed to determine if print literacy is associated with asthma control.

Previous research has focused on print literacy skills and the relationship between numeracy and health outcomes has not been well studied. Low numeracy but not print literacy has been associated with a history of asthma-related hospitalizations and emergency department visits (Apter et al., 2006). In a later study, Apter et al. (2009) found that numeracy but not print literacy was associated with quality of life. The current study supports the previous research in this area. We found that low numeracy, but not print literacy, was associated with decreased quality of life, decreased asthma control, decreased asthma knowledge, and an increased number of asthma-related hospitalizations. The numeracy burden of asthma lies in the use of peak flow meters, understanding spirometry readings, and medication dosing (Apter et al., 2006). This study provides further evidence for the independent association of numeracy on asthma outcomes.

\section{Self-Efficacy and Asthma Knowledge as Mediators}

Although the relationship between health literacy and health outcomes has been established, the mechanisms linking the two are unclear. The second and third specific aims of this study were to determine if self-efficacy and asthma knowledge mediated the relationship between health literacy and asthma outcomes. Osborn et al., (2011) examined if self-efficacy, knowledge linked health literacy to physical activity and selfreported health status. Their findings suggest that health literacy influences knowledge, knowledge influences self-efficacy, and self-efficacy influences physical activity. Macabasco-O'Connell et al. (2010) found that low health literacy was associated with worse quality of life among individuals with heart failure, but that relationship was not mediated by self-efficacy or knowledge. In the current study, we found no association between print literacy and health outcomes, and neither self-efficacy nor asthma knowledge mediated the relationship. Although none of the pathways were significant, print literacy, asthma knowledge, and self-efficacy explained $20 \%$ of the variance in 
asthma control scores (adjusted $\mathrm{R}^{2}=0.20, \mathrm{p}=0.001$ ). Those three factors do influence asthma control, but they may be working through other factors or different pathways that were not examined during this study. Also, to our knowledge, this is the first time selfefficacy and disease knowledge have been studied as mediators of health literacy and health outcomes in the context of asthma.

Apter et al. (2009) examined the relationship between numeracy and quality of life and found that self-efficacy partially mediated the relationship. Osborn et al. (2010) found that self-efficacy mediated the relationship between glycemic control and numeracy and health literacy skills, but numeracy had a stronger association with selfefficacy than health literacy. The current study found that numeracy was associated with asthma-related quality of life but not asthma control. Self-efficacy and asthma knowledge partially mediated the relationship between numeracy and quality of life, but had no influence on the relationship between numeracy and asthma control. These findings support the previous literature showing that self-efficacy does partially mediate the relationship between numeracy and health outcomes. It is unclear why numeracy but not print literacy was associated with asthma outcomes. The greater impact of numeracy on asthma outcomes may also be related to how print literacy and numeracy were measured in this study. Numeracy was measured using the NVS. The NVS is a more objective analysis than the single item print literacy screening question, and may have represented functional literacy ; whereas, the print literacy measurement was a subjective assessment. Differences in associations with outcomes may in reality be differences between objective health literacy versus subjective health literacy. The quantitative burden of managing asthma should be assessed to better determine how numeracy affects asthma outcomes, and if it indeed it is more important for asthma self-management than print literacy.

\section{Patients' Experiences Managing Asthma}

The fourth specific aim of this study was to use the experiences of individuals with asthma to better understand the relationship between health literacy and asthma outcomes. Interviews revealed that all participants, regardless of health literacy skills, felt a disparity between the information that they received from their providers and the information that they felt was important for them to take care of their asthma. However, participants with adequate health literacy were more likely to supplement the information they received from their providers with other sources of information. This was evidenced by their reports of using the internet and books to learn about their asthma. Because individuals with adequate health literacy were seemingly more proactive about acquiring information about their disease, they may have greater disease knowledge or be more confident about taking care of their asthma. These findings may offer insight into the results of Osborn et al. (2011) who found that knowledge, not health literacy, was a significant predictor of self-efficacy. A participant in the current study reported that the more information she learned about her asthma, the more confident she felt taking care of her asthma. 
In addition to seeking more information from outside sources, participants with adequate health literacy were also more active patients. They felt it was their responsibility to bring information from the internet to their doctors. Katz, Jacobson, Veledar, and Kripalani (2007) found that patients with low health literacy were less likely to ask questions and participate during a medical counter. A previous qualitative study by Baker et al. (1996) found that patients with low health literacy felt that their providers did not listen to them or explain medical problems in a way that they could understand, but these patients were less likely to ask questions or admit that they did not understand. Increased information seeking by patients with adequate health literacy may give patients more confidence, willingness, and tools to interact with their providers. Although the current study and previous research found a relationship between patient activation and health literacy, other research has reported no association between the two (Greene, Hibbard, \& Tusler, 2005), and health literacy and patient activation were associated with different aspects of disease management. Health literacy influenced decision making, while patient activation influenced self-management behaviors.

Participants with adequate health literacy also navigated the health care system as consumers. They reported finding new doctors and/or clinics when they were not satisfied with the care their doctor provided or the temperament of the staff who worked at the clinic. Although participants with adequate health literacy were more active, all participants had similar expectations from their providers. They all desired to be respected, listened to, and treated as whole person and not just their disease. Participants with adequate health literacy may be more empowered to make sure they receive the type of care that they desire. It is necessary to help individuals with low health literacy be informed consumers as well.

Participants also reported general mistrust of providers and concerns about being treated differently by providers because they were African-American. Both of these factors negatively influenced the patient-provider relationship. These findings support previous research showing that African-Americans have greater distrust of the health care system (Cegala \& Post, 2006). In the current study, perceptions of racial discrimination were based on historical knowledge of racism and personal experiences of perceived racism in health care. Participants in this study also reported that if they did not trust their provider, they were less likely to take their asthma medications as they were prescribed. This finding supports previous research demonstrating that poor patient-provider communication had a negative impact on medication adherence (Apter et al., 1998; Schoenthaer et al., 2009). Adequate patient-provider communication is important for all patients, but may be particularly important for African-American patients and patients with low health literacy. It is important for providers to be cognizant of the concerns of minority patients and work to build rapport with these patients.

\section{Mixed Methods Meta-Inferences}

The fifth specific aim of this study was to examine the extent to which patient experiences of self-management enhance the understanding of the relationship between 
health literacy skills and asthma outcomes. The quantitative findings of this study indicated that print literacy was not associated with asthma outcomes, but print literacy, asthma knowledge, and self-efficacy did explain some of the variance in asthma control and asthma-related quality of life. On the other hand, low numeracy was associated with decreased asthma-related quality of life, and this relationship was partially mediated by self-efficacy and asthma knowledge. Interestingly, all of the participants who completed interviews had limited numeracy skills, yet there were still differences among the participants based on their print literacy skills. Print literacy skills influenced patientprovider communication and level of patient activation regardless of numeracy skills. These findings suggest that the combination of low numeracy and low print literacy is more detrimental to self-management, than low numeracy alone. Adequate patientprovider communication and increased patient activation may also mitigate the negative impact of limited numeracy skills.

Findings also suggest that health literacy may not be directly related to knowledge and self-efficacy. Health literacy may affect the quality and substance of patient-provider communication, resulting in increased knowledge and self-efficacy, and subsequently, better asthma outcomes. In this study, participants with adequate health literacy researched their asthma on their own and brought that information to the doctors. These patients may have had more in-depth conversations about their asthma than individuals with low health literacy. Katz et al. (2007) found that patients with adequate health literacy asked more questions, were more likely to use medical terms, and discuss alternative treatment options compared to patients with low health literacy. We propose that increased information seeking by patients with adequate health literacy may contribute to increased patient activation among individuals with adequate health literacy. Subsequently, increased patient activation influences the quality of patient- provider communication. Previous research has shown that providers respond positively to active patients and involve these patients more during the decision making process (Arnold et al., 2012; Cegala \& Post, 2009).

Culture is an integral part of health literacy and influences how people define health and illness, health behaviors, perception of medical treatments, and how symptoms are described (Andrulis \& Brach, 2007; Kreuter \& Haughton, 2006). Health communication takes place within a larger society. Societal norms and realities in the larger society are present in health care as well. Both patients and providers bring their attitudes, beliefs, experiences, and culture into patient-provider communication (Perloff et al., 2006). In the current study, participants recalled perceived discrimination inside and outside of the health care system. They also introduced the topics of race and culture when discussing patient-provider communication which indicated that their experiences of managing their asthma could not be understood apart from their racial and cultural background. Experiences of perceived discrimination negatively influenced how all participants interacted with their health care providers, yet participants with adequate print literacy used strategies such as actively building rapport with their doctors and learning about their disease to overcome their mistrust of doctors and negative experiences due to race. However, participants with low print literacy did not report any of these strategies. Consequently, cultural factors may exacerbate or contribute to low 
health literacy by negatively influencing patient-provider communication. Both parties are influenced by the communication style of the other, and both patients and providers contribute to the success of the interaction. If a patient has previous experiences or knowledge of racial discrimination in the health care system, they are less trusting of the provider and information they receive from the provider and may be less willing to engage with their provider. A lack of contribution by the patient can result poorer patient-provider communication. Results of this study suggest that individuals with adequate print literacy may have more success overcoming negative experiences, and have quality patient-provider communication than individuals with low print literacy. Because of the observed relationship between health literacy, patient-provider communication, and race and culture, culture must also be included in any efforts to improve health literacy among African-Americans.

\section{Implication of Findings}

\section{Theoretical Implications}

The results of this study support the model (Figure 2-3) of causal pathways linking limited health literacy and health outcomes proposed by Paasche-Orlow and Wolf (2007). In this model, patient-provider interaction and self-care are major domains through which health literacy influences health outcomes. In the present study, participants with adequate print literacy were more engaged with their providers and used multiple sources to learn about and take care of their asthma. The Paasche-Orlow and Wolf (2007) model also recognizes that race/ethnicity and culture influence health literacy. Issues regarding race and perceived discrimination were reported when participants discussed their medical encounters.

The Baker (2006) model, which was used as the conceptual framework for this study, may have simplified the relationship between health literacy and health outcomes in this population. That model did not include factors (i.e., patient-provider communication, patient activation) that were relevant to the relationship between health literacy and health outcomes in this study. The Baker (2006) model also did not include numeracy. Yet, numeracy but not print literacy was significantly associated with asthma outcomes in this study. Numeracy is a separate and important aspect of health literacy, and conceptual frameworks should acknowledge its unique influence on health outcomes.

\section{Practical and Clinical Implications}

This study provides several clinical implications. First, the NVS can be used to screen patients who are at increased risk for adverse asthma outcomes. The NVS takes less than 5 minutes to administer and can be administered by anyone. Secondly, providers should provide their patients with standardized disease information. Participants had different opportunities for learning about their asthma, and all of them 
desired more information than their doctors provided. Using standardized videos, pamphlets, or handouts would insure that all participants at a given clinic had the same knowledge base. If providers do not have the time or resources to distribute these types of materials, they could give patients a list of reliable sources to obtain information about their disease. Participants in this study were very eager to learn about their disease, but participants with adequate health literacy were more adept at finding other sources beyond their providers to learn about their asthma. A list of sources given by a provider would also help patients who are not able to determine if an information source is valid and reliable. Giving patients encouragement and directions for acquiring information would be beneficial for all patients and particularly those with low health literacy. Lastly, $70 \%$ of participants in the study had limited numeracy and $29 \%$ of the participants had low print literacy. These findings should serve as a reminder to providers to use plain language during medical encounters, encourage patients to ask questions, and make sure that patients understand their treatment plans before they leave the office.

\section{Limitations and Strengths}

This study had several limitations including sample size, power, and the crosssectional design. Strengths include using a mixed methods approach and inclusion of a vulnerable population. Limitations are discussed first followed by the study strengths.

This study had a sample of 99 African-Americans, and all were located in the southeastern part of the United States. Generalizations to other racial/ethnic groups and/or other regions of the country should be made with caution. Larger sample sizes are also needed to make generalizations to other African-American adults with asthma. The sampling for the qualitative phase of the study also presented limitations. Only print literacy skill was used to identify participants for interviews. Consequently, all of the participants who completed interviews had limited numeracy skills. The perspective of individuals with both adequate print literacy and adequate numeracy was not included in this study. Exclusion of these individuals may have resulted in decreased insight into the impact of adequate numeracy.

All of the interviewees were women who lived in Memphis. The homogenous gender and location of the individuals who completed the interview may be seen as a limitation. However, asthma is more prevalent among women, and insight into women's unique experiences with asthma is valuable. Secondly, the purpose of the interviews was to receive insight into the experience of African-American adults living with asthma. These women were not expected to be representative of all adults with asthma, but their experiences were used to offer insight into the relationship between health literacy and asthma outcomes. The researcher does not believe that having all women or women from a single city are true limitations.

Secondly, the study had low power to detect a second mediated effect. Previous studies using the Preacher and Hayes (2008) method of bootstrapping did not conduct post hoc power analysis and relied on the values derived from previous simulation 
studies. Consequently, the values from this study cannot be compared to other studies that used the same statistical method employed in this study. The post hoc power calculations from this sample were lower than the values from simulation studies (Briggs, 2006). Although the post hoc analysis indicated low power for detecting a second mediated effect, the bootstrapping method is the most powerful and the recommended method for multiple mediator analysis (Briggs, 2006; Preacher \& Hayes, 2008; Williams \& MacKinnon, 2008).

A third limitation of the study was the cross-sectional design. Health literacy, self-efficacy, and knowledge change over time, and a cross-sectional analysis captures only a snapshot in time. The results of this study have no bearing on the relationship between the observed variables over time. Also, mediation analysis is only testing associations between variables. Therefore, the results do not implicate a causal relationship between health literacy and asthma outcomes.

The strengths of this study included the study population and the use of a mixed methods approach. African-Americans have a higher prevalence of asthma and are more likely to have low health literacy. The current study included only African-Americans in an effort to better understand the factors that mediate the relationship between health literacy and health outcomes in this vulnerable population. There was divergence among the qualitative and quantitative results that provided areas for further research and other possible mechanisms that link health literacy and health outcomes. The qualitative phase of the study highlighted key issues such as patient-provider communication, patient activation, and culture that were not addressed by the quantitative phase alone. The original purpose of using mixed methods was to provide completeness, diversity of views, and enhancement. The meta-inferences made from this study achieved the original purpose for mixing quantitative and qualitative data and a more comprehensive picture was achieved that was not possible by using either method alone.

\section{Recommendations for Future Research}

Several recommendations for future research emerged from this study. This study found that numeracy, but not print literacy, was associated with asthma outcomes. Future research should examine the numerical burden of asthma to better understand the role of numeracy in asthma self-management. Participants with adequate health literacy and limited numeracy differed from participants with low print literacy and limited numeracy when discussing how they communicate with providers and their information seeking habits. The study also found that individuals with adequate numeracy had higher odds of having adequate print literacy compared to individuals with limited numeracy. Future research should examine the interaction and relationship between numeracy and print literacy.

The present study only examined self-efficacy and asthma knowledge as mediators and found that self-efficacy and knowledge only partially mediated the relationship between numeracy and asthma-related quality of life. Future research should 
examine other mediating factors such as patient-provider communication and patient activation.

Lastly, research on the influence of culture on health literacy should also be conducted. Health literacy and cultural issues are usually researched and addressed separately (Andrulis \& Brach, 2007), yet both of them are needed to improve patientprovider communication. In the present study participants recalled experiences of perceived discrimination that negatively impacted how they interacted with the health care system and their providers. Addressing health literacy issues without acknowledging cultural experiences that may exacerbate or contribute to low health literacy is not expedient.

\section{Conclusions}

Health literacy is one of many factors that contribute to health disparities among African-Americans. The relationship between health literacy and health outcomes is complex with multiple pathways. Research is needed to identify factors that link health literacy and health outcomes to create evidence based interventions to mitigate the impact of low health literacy. The current study used a mixed methods approach to identify these connections. This study design allowed for a more in-depth understanding of health literacy, health outcomes, and asthma self-management. The majority of participants had either low health literacy or limited numeracy which emphasizes the importance of health literacy research among African-American adults with asthma. Based on the results, knowledge and self-efficacy are not the primary mediators of the relationship, and factors such as patient-provider communication and patient activation may have a stronger influence on the relationship between health literacy and health outcomes. The combined influence of culture and health literacy is also important for the study population. This study also stressed the unique contribution of numeracy to health outcomes, and further research is needed in this area. Understanding factors that mediate and the relationship between health literacy and health outcomes are necessary to create targeted interventions to mitigate the impact of low health literacy. 


\section{LIST OF REFERENCES}

Adams, R.L., Appleton, S.L., Hill, C.L., Ruffin, R.E., \& Wilson, D.H. (2009). Inadequate health literacy is associated with increased asthma morbidity in a population sample. Journal of Allergy and Clinical Immunology, 124, 601-603.

Akinbami, L.J., Moorman, J.E., \& Xiang, L. (2011). Asthma prevalence, health care use, and mortality: United States, 2005-2009. National Health Statistics.

Ancker, J.S., \& Kaufman, D. (2007). Rethinking health numeracy: a multidisciplinary literature review. Journal of the American Medical Informatics Association, 14(6), 713-721.doi 10.1197/jamia.M2464.

Andrulis, D.P., \& Brach, C. (2007). Integrating literacy, culture, and language to improve health care quality for diverse populations, American Journal of Health Behavior, 31, S122-S133.

Apter, A.J., Reisine, S.T., Affleck, G., Barrows, E., \& ZuWallack, R.L. (1998). Adherence with twice-daily dosing of inhaled steroids socioeconomic and healthbelief differences. American Journal of Respiratory and Critical Care Medicine, 157(6), 1810-1817.

Apter, A.J., Reisine, S.T., Affleck, G., Barrows, E., \& ZuWallack, R.L. (1999). The influence of demographic and socioeconomic factors on health-related quality of life in asthma. Journal of Allergy and Clinical Immunolgy, 103, 72-78.

Apter, A.J., Boston, R.C., George, M., Norfleet, A.L., Tenhave, T., Coyne, J.C.,...Feldman, H.I. (2003). Modifiable barriers to adherence to inhaled steroids among adults with asthma: it's not just black and white. Journal of Allergy and Clinical Immunology, 111, 1219-1226. doi: 10.1067/mai.2003.1479

Apter, A.J., Cheng, J., Small, D., Bennett, I.M., Albert, C., Fein, D.G., George, M.,...Van Horne, S. (2006). Asthma numeracy skill and health literacy. Journal of Asthma, 43,705-710. doi:10.1080/02770900600925585

Apter, A.J., Paasche-Orlow, M.K., Remillard, J.T., Bennett, I.A., Ben-Joseph, E.P., Batista,R.M.,... Rudd, R.E. (2008). Numeracy and communication with patients: they are counting on us. Journal of General Internal Medicine, 23(12), 21172124. doi: 10.1007/s11606-008-0803-x

Apter, A.J., Wang, X., Bogen, D., Bennett, I.M., Jennings, R.M., Garcia, L.,...Have, T.T. (2009). Linking numeracy and asthma related quality of life. Patient and Education Counseling, 75, 386-391. 
Arnold, C.L., Coran, J.J., \& Hagen, M.G. (2012). Revisiting patient communication training: an updated needs assessment and the AGENDA model. Patient Education and Counseling, 88, 399-405

Baker, D.W., Parker, R.M., Williams, M.V., Pitkin, K., Parikh, N.S., Coates, W., \& Imara, M. (1996). The health care experience of patients with low literacy. Archives of Family Medicine, 5, 329-334.

Baker, D.W. (2006). The meaning and the measure of health literacy. Journal of General Internal Medicine, 21, 878-883. doi: 10.111/j.1525-1497.2006.00540.x

Bandura, A. (1977). Self-efficacy: toward a unifying theory of behavioral change. Psychological Review, 84(2), 191-215.

Baron, R.M., \& Kenny, D.A. (1986). The moderator-mediator variable distinction in social psychological research: conceptual, strategic, and statistical considerations. Journal of Personality and Social Psychology, 51(6), 1173-1182.

Berkman, N.D., Sheridan, S.L., Donahue, K.E., Halpern, D.J., \& Crotty, K. (2011). Low health literacy and health outcomes: an updated systematic review. Annals of Internal Medicine, 155, 97-107.

Bernard, H.R. (2006). Research methods in anthropology: qualitative and quantitative approaches, 4th ed. Oxford, UK: AltaMira Press.

Black, W. C., Nease, R. F., \& Tosteson, A. N. (1995). Perceptions of breast cancer risk and screening effectiveness in women younger than 50 years of age. Journal of the National Cancer Institute, 87, 720-731.

Briggs, N. (2006). Estimation of the standard error and confidence interval of the indirect effect in multiple mediator models. Dissertation Abstracts International, 37, 4755B.

Brigham and Women's Hospital. Blacks and Exacerbations on Long Acting Beta Agonists (LABA) vs. Tiotropium (BELT). IN: ClinicalTrials.gov [Internet]. Bethesda (MD): National Library of Medicine (US).2000-[cited 2013 May 30]. Available from http://clinicaltrials.gov/ct2/show/NCT01290874 NLM Identifier: NCT01290874.

Brocki, J.A. \& Wearden, A.J. (2006). A critical evaluation of the use of interpretative phenomenological analysis (IPA) in health psychology. Psychology and Health, 21(1), 87-108.

Bryman (2006). Integrating quantitative and qualitative research: how is it done? Qualitative Research, 6(1), 97-113. 
Buffardi, L.E., \& Campbell, W.K. (2008). Narcissism and social networking web sites. Personality and Social Psychology Bulletin, 34, 1303-1314.

Canino, G., McQuaid, E.L., \& Rand, C.S. (2009). Addressing asthma health disparities: a multilevel challenge. Journal of Allergy and Clinical Immunology, 123(6), 12091219. doi:10.1016/j/jaci.2009.02.043

Cegala, D. J. \& Post, D.M. (2006). On addressing racial and ethnic health disparities: the potential role of patient communication skills interventions. American Behavioral Scientist, 49, 853-867.

Cegala, D.J., \& Post, D.M. (2009). The impact of patients' participation on physicians' patient centered communication. Patient Education and Counseling, 202-208.

Chew, L.D., Bradley, K.A., \& Boyko, E.J. (2004). Brief questions to identify patients with inadequate health literacy. Family Medicine, 36(8), 588-94.

Cloutier, M.M., Schatz, M., Castro, M., Clark, N., Kelly, H.W.,Mangione-Smith, R.,... Gergen, P. (2012). Asthma outcomes: Composite scores of asthma control. Journal of Allergy and Clinical Immunology, 129, S24-S33.

Cornett, S. (2009). Assessing and addressing health literacy. Online Journal of Issues in Nursing, 14(3).

Creswell, J.W., \& Plano Clark, V.L. (2011). Designing and conducting mixed methods research, 2nd ed. Los Angeles, CA: SAGE.

Danaher, B.G., Smolkowski, K., Seeley, J.R., \& Severson, H.H. (2008). Mediators of successful web-based smokeless tobacco cessation program. Addiction, 103, 1706-1712.

Day, D.M., Hart, T.A., Wanklyn, S.G., McCay, E., MacPherson, A., \& Burnier, N. (2013). Potential mediators between child abuse and both violence victimization in juvenile offenders. Psychological Services, 10(1), 1-11.

Diette, G.B., \& Rand, C. (2007). The contributing role of health-care communication to health disparities for minority patients with asthma. Chest, 132, 802S-809S. doi:10.1378/chest.07-1909

Donelle, L. Hoffman-Goetx, L., \& Arocha, J.F. (2007). Assessing health numeracy among community-dwelling older adults. Journal of Health Communication, 12, 651-655.doi: 10.1080/10810730701619919

Effron, B., \& Tibshirani, T.J. (1993) An Introduction to the Bootstrap. New York: Chapman \& Hall. 
Fade, S. (2004). Using interpretative phenomenological analysis for public health nutrition and dietetic research: a practical guide. Proceedings of the Nutrition Society, 63, 647-653.

Federman, A.D., Wisnivesky, J.P., Wolf, M.S., Leventhal, H., \& Halm, E.A. (2010). Inadequate health literacy is associated with suboptimal health beliefs in older asthmatics. Journal of Asthma, 47, 620-626.

Ferguson, W.J., \& Candib, L.M. (2002). Culture, language, and the doctor-patient relationship. Family Medicine and Community Health, 34(5), 353-361.

Ford, E.S., Mannimo, D.M., Homa, D.M., Gwynn, C., Redd, S.C., Moriarty, D.G., \& Mokdad, A.H. (2003). Self-reported asthma and health-related quality of life: Findings from the behavioral risk factor surveillance system. CHEST, 123, 119127.

Fritz, M.S. \& MacKinnon, D.P. (2007). Required sample size to detect the mediated effect. Psychological Science, 18(3), 233-239.

Garg, V.K., Bidani, R., Rich, E.P., Hershey, E., \& Hershey, C.O. (2005). Asthma patients' knowledge, perception, and adherence to the asthma guidelines. Journal of Asthma, 42,633-638. doi: 10.1080/027770900500263806

Gazmararian, J.A., Williams, M.V., Peel, J., \& Baker, D.W. (2003). Health literacy and knowledge of chronic disease. Patient Education and Counseling, 51, 267-275.

George, M., Campbell, J., \& Rand, C. (2009). Self-management of acute asthma among low income urban adults. Journal of Asthma, 46, 618-624.

doi:10.1080/02770900903029788

Golbeck, A.L., Ahlers-Schmidt, C.R., Paschal, A.M., \& Dismuke, S.E. (2005). A definition and operational framework for health numeracy. American Journal of Preventive Medicine, 29, 375-376.

Green, J.C., Caracelli, V.J., \& Graham, W.F. (1989). Toward a conceptual framework for mixed-method evaluation designs. Educational Evaluation and Policy Analysis, $11(3), 255-274$.

Greene, J., Hibbard, J., \& Tusler, M. (2005). How much do health literacy and patient activation contribute to older adults' ability to manage their health? AARP Public Policy Institute.

Halm, E.A., Wisnivesky, J.P., \& Leventhal, H. (2005). Quality and access to care among a cohort of inner-city adults with asthma: who gets guideline concordant care? Chest, 128, 1943-1950. 
Hardie, G.E., Janson, S., Gold, W.M., Carrieri-Kohlman, V., \& Boushey, H.A. (2000). Word descriptors used by African-American and White asthma patients during induced bronchoconstriction. Chest, 117(4), 935-943.

Howard, D.H., Gazmararian, J., \& Parker, R.M. (2005). The impact of low health literacy on the medical costs of Medicare managed enrollees. The American Journal of Medicine, 118, 371-377.

Johnson, R.L., Roter, D., Powe, N.R., \& Cooper, L.A. (2004). Patient race/ethnicity and quality of patient-physician communication during medical visits. American Journal of Public Health, 94(12), 2084-2090).

Johnson, S.E., Baur, C., \& Meissner, H.I. (2011). Back to basics: why basic research is needed to create effective health literacy interventions. Journal of Health Communication: International Perspectives, 16, 22-29.

Juniper, E. F., Guyatt, G.H., Epstein, R.S., Ferrie, P.J., Jaeschke, R., \& Hiller, T.K. (1992). Evaluation of impairment of health related quality of life in asthma: development of a questionnaire for use in clinical trials. Thorax, 47, 76-83.

Juniper, E.F., Buist, S., Cox, F.M., Ferrie P.J., \& King, D.R. (1999). Validation of a standardized version of the asthma quality of life questionnaire. Chest, 115, 12651270 .

Juniper, E.F., O’Byrne, P.M., Guyatt, G.H., Ferrie, P.J., \& King, D.R. (1999). Development and validation of a questionnaire to measure asthma control. European Respiratory Journal, 14, 902-907.

Juniper, E.F., Svensson, K., Mörk, \& Ståhl, E. (2005). Measurement properties and interpretation of three shortened versions of the asthma control questionnaire. Respiratory Medicine, 99, 553-558.

Juniper, E.F., Bousquet, J., Abetz, L., Bateman, E.D., \& The GOAL Committee (2006). Identifying 'well-controlled' and 'not well-controlled' asthma using the Asthma Control Questionnaire. Respiratory Medicine, 100, 616-621.

Kamble. S., \& Bharmal, M. (2009). Incremental direct expenditure of treating asthma in the United States. Journal of Asthma, 46, 73-80. doi:10.1080/02770900802503107

Katz, M.G., Jacobson, T.A., Veledar, E., \& Kripalani, S. (2007). Patient literacy and question-asking behavior during the medical encounter: A mixed-methods analysis. Journal of General Internal Medicine, 22, 782-786.

Kreuter, M.W., \& Haughton, L.T. (2006). Integrating culture into health information for African American Women. American Behavioral Scientist, 49 (6), 794-811. 
Krishnan, J.A., Diette, G.B., Skinner, E.A., Clark, B.D., Steinwachs, D., \& Wu, A.W. (2001). Race and sex differences in consistency of care with national asthma guidelines in managed care organizations. Archives of Internal Medicine, 161, 1660-1668.

Kutner, M., Greenberg, E., Jin, Y., Paulsen, C., \& White, S. (2006). The Health Literacy of America's Adults: Results from the 2003 National Assessment of Adult Literacy (NCES 2006-483). U.S. Department of Education. Washington, DC: National Center for Education Statistics.

Larkin, M., Watts, S., \& Clifton, E. (2006). Giving voice and making sense in interpretative phenomenological analysis. Qualitative Research in Psychology, 3, 102-120.

Lavoie, K.L., Bouchard, A., Joseph, M., Campbell, T.S., Favreau, H., \& Bacon, S.L. (2008). Association of asthma self-efficacy to asthma control and quality of life. Annals of Behavioral Medicine, 36, 100-106. doi: 10.1007/s12160-008-9053-8

Le, T.T., Bilderback, A., Bender, B., Wamboldt, F.S., Turner, C.F., Rands, C.S., \& Bartlett, S.J. (2008). Do asthma medication beliefs mediate the relationship between minority status and adherence to therapy? Journal of Asthma, 45, 33-37. doi:10.1080/027709000701815552

Lee, S.D., Arozullah, A.M., \& Cho, Y.I. (2004). Health literacy, social support, and health: a research agenda. Social Science and Medicine, 58, 1309-1321. doi:10.1016/S02779536(03)00329-0

Leidy, N.K., Chan, K.S., \& Coughlin, C. (1998). Is the asthma quality of life questionnaire a useful measure for low-income asthmatics? American Journal of Respiratory Critical Care Medicine, 158, 1082-1090.

Lynch, M.E., Johnson, K.C., Kable, J.A., Carroll, J., \& Coles, C.D. (2011). Smoking in pregnancy and parenting stress: Maternal psychological symptoms and socioeconomic status as potential mediating variables. Nicotine \& Tobacco Research, 13 (7), 532-539.

Macabasco-O’Connell, A., DeWalt, D.A., Broucksou, K.A., Hawk, V., Baker, D.W., Schillinger, D.,... Pignone, M. (2011). Relationship between literacy, knowledge, self-care behaviors, and heart failure-related quality of life among patients with heart failure. Journal of General Internal Medicine, 26(9), 979-986. doi: 10.1007/s1 1606-011-1668-y

MacKinnon, D.P., Lockwood, C.M., Hoffman, J.M., West, S.G., \& Sheets, V. (2002). A comparison of methods to test mediation and other intervening variable effects. Psychological Methods, 7(1), 1-35. 
Mallinckrodt, B., Abraham, W.T., Wei, M., \& Russell, D.W. (2006). Advances in testing the statistical significance of mediation effects. Journal of Counseling Psychology, 53 (3), 372-378.

Manusco, C.A., \& Rincon, M. (2006). Asthma patients' assessments of health care and medical decision making: the role of health literacy. Journal of Asthma, 43, 4144. doi:10.1080/ 02770900500447052

Manusco, C.A., \& Rincon, M. (2006). Impact of health literacy on longitudinal asthma outcomes. Journal of General Internal Medicine, 21, 813-817. doi: 10.111/j.1525-1497.2006.00528.x

Manusco, C.A., Sayles, W., \& Allengrante, J.P. (2010). Knowledge, attitude and selfefficacy in asthma self-management and quality of life. Journal of Asthma, 47(80), 883-888.

McLeish, A.C. \& Zvolensky, M.J. (2010). Asthma and cigarette smoking: a review of the empirical literature. Journal of Asthma, 47, 345-361.

Molloy, G.J., Randall, G., Wilkman, A., Perkins-Porras, L., Messerli-Bürgy, N., \& Steptoe, A. (2012). Type D personality, self-efficacy, and medication adherence following an acute coronary syndrome. Psychosomatic Medicine, 74, 100-106.

Morrow D., Clark, D., Wanzhu, T., Jingwei, W., Weiner, M., Steinley, D., \& Murray, M.D. (2006). Correlates of health literacy in patients with chronic heart failure. The Gerontologist, 46(5), 669-676. doi:10.1093/geront/46.5.669

Muthén, L.K., \& Muthén, B.O. (2002). How to use a Monte Carlo study to decide on sample size and determine power. Structural Equation Modeling, 4, 599-620.

Nielsen-Bohlman, L., Panzer, A. M., \& Kindig, D. A. (Eds.). (2004). Health literacy: a prescription to end confusion. National Academies Press.

Onwuegbuzie, A.J., \& Teddlie, C. (2003). A framework for analyzing data in mixed methods research. In A. Tashakkori \& C. Teddlie (Eds.), Handbook of mixed methods in social and behavioral research (pp.351-383). Thousand Oaks, CA: SAGE.

Osborn, C.Y., Weiss, B.D., Davis, T.C., Skripkauskas, S., Rodrigue, C., Bass, P.F., Wolf, M.S. (2007). Measuring adult literacy in health care: performance of the newest vital sign. American Journal of Health Behavior, 31, Supplement 3, S36-S46.

Osborn, C.Y., Cavanaugh, K., Wallston, K.A., \& Rothman, R.L. (2010). Self-efficacy links health literacy and numeracy to glycemic control. Journal of Health Communication, 15(Suppl 2), 146-158. 
Osborn, C.Y., Paasche-Orlow, M.K., Bailey, S.C., \& Wolf, M.S (2011). The mechanisms linking health literacy to behavior and health status. American Journal of Health Behavior, 35 (1), 118-128.

Paasche-Orlow, M.K., Riekert, K.A., Bilderback, A., Chanmugam, A., Hill, P., Rand, C.S.,...Krishnan, J.A. (2005). Tailored education may reduce health disparities in asthma self-management. American Journal of Respiratory and Critical Care Medicine, 172, 980-986.

Paasche-Orlow, M.K. \& Wolf, M.S. (2007). The causal pathways linking health literacy to health outcomes. American Journal of Behavioral Health, 31, S19-S26.

Paasche-Orlow, M.K., \& Wolf, M.S. (2008). Evidence does not support clinical screening of literacy. Journal of General Internal Medicine, 23, 100-102. doi: 10.1007/s11606-007-0447-2

Parikh, N.S., Parker, R.M., Nurss, J.R., Baker, D.W., \& Williams, M.V. (1996). Shame and health literacy: the unspoken connection. Patient and Education Counseling, 27, 33-39.

Parisi, J.M., Rebok, G.W., Xue, Q., Fried, L.P., Seeman, T.E., Tanner, E.K.,...Carlson. M.C. (2012). The role of education and intellectual activity on cognition. Journal of Aging Research, 2012, 1-9.

Perloff, R.M., Bonder, B., Ray, G.B., Ray, E.B., \& Siminoff, L.A. (2006). Doctor-patient communication, cultural competence, and minority health: theoretical and empirical perspectives. American Behavioral Scientist, 49, 835-852.

Powers, B.J., Trinh, J.V., \& Bosworth, H.B. (2010). Can this patient read and understand health information? Journal of American Medical Association, 304, 76-84.

Preacher, K.J., \& Hayes, A.F. (2008). Asymptotic and resampling strategies for assessing and comparing indirect effects in multiple mediator models. Behavior Research Methods, 40(3), 879-891. doi:10.3758/BRM.40.3.879

Preacher, K.J., \& Kelley, K. (2011). Effect size measurements for mediation models: Quantitative strategies for communicating indirect effects. Psychological Methods, 16 (2), 93-115.

Rosas-Salazar, C., Apter, A.J., Canino, G., \& Celedón, J.C. (2012). Health literacy and asthma. Journal of Allergy and Clinical Immunology, 129 (4) 935-942.

Rosenfeld, L., Rudd, R., Emmons, K.M., Acevedo-Garcia, D., Martin, L., \& Buka, S. (2011). Beyond reading alone: the relationship between aural literacy and asthma management. Patient Education and Counseling, 82, 110-116. doi: 10.1016/j.pec.2010.02.023 
Rucker, D.D., Preacher, K.J., Tormala, \& Petty, R.E. (2011). Mediation analysis in social psychology: Current practices and new recommendations. Social and Personality Psychology Compass, 5/6, 359-371.

Schaffer, S.D. \& Yarandi, H.N. (2007). Measuring asthma self-management knowledge in adults. Journal of the American Academy of Nurse Practitioners, 19, 530-535.

Scherer, Y.K., \& Bruce, S. (2001). Knowledge, attitudes, and self-efficacy and compliance with medical regimen, number of emergency department visits, and hospitalizations in adults with asthma. Heart \& Lung, 30, 250-257.

Schillinger, D., Grumbach, K., Piette, J., Wang, F., Osmond, D., Daher, C.,...Bindman, A.B. (2002). Association of health literacy with diabetes outcomes. Journal of the American Medical Association, 288 (4), 475-482.

Schoenthaler, A., Chaplin, W.F., Allegrante, J.P., Fernande, S., Diaz-Gloster, M., Tobin, J.N., \& Ogedegbe, G. (2009). Provider communication effects medication adherence in hypertensive African Americans. Patient Education and Counseling, 75(2), 185-191.

Shah, L.C., West, P., Bremmeyr, K., \& Savoy-Moore, R.T. (2010). Health literacy instrument in family medicine: the "newest vital sign" ease of use and correlates. Journal of American Board of Family Physicians, 23, 195-203.

Shrout, P.E., \& Bolger, N. (2002). Mediation in experimental and nonexperimental studies: New procedures and recommendations. Psychological Methods, 7(4), 422-445.

Silvers, S.K., \& Lang, D.M. (2012). Asthma in African Americans: what can we do about the higher rates of disease? Cleveland Clinic Journal of Medicine, 79(3), 193-201.

Smith.J.A. (1996). Beyond the divide between cognition and discourse: using interpretative phenomenological analysis in health psychology. Psychology and Health, 11, 261-267.

Smith, J.A., \& Osborn, M. (2003). Interpretative Phenomenological Analysis. In, Smith, J.A. (Ed.), Qualitative Psychology: A Practical Guide to Research Methods (pp.53-80). London: SAGE Publications. 201.doi: 10.3949/ccjm.79a.11016

Sobel, M.E. (1982). Asymptotic confidence intervals for indirect effects in structural equation models. In: Leinhardt, S. (Ed.), Sociological Methodology (pp. 290-312). Washington, DC: American Sociological Association. 
Sobel, R.M., Paasche-Orlow, M.K., Waite, K.R., Rittner. S.S., Wilson, E.A.H., \& Wolf, M.S. (2009). Asthma 1-2-3: a low literacy multimedia tool to educate African American adults about asthma. Journal of Community Health, 34, 321-327.

Thai, A.L., \& George, M. (2010). The effects of health literacy on asthma selfmanagement. Journal of Asthma and Allergy Educators, 1(2), 50-55. doi: $10.1177 / 2150129710368850$

Thoemmes, F., MacKinnon, D.P., \& Reiser, M.R. (2010). Power analysis for complex mediational designs using Monte Carlo methods. Structural Equation Modeling, $17,510-534$.

Teddlie, C., \& Tashakkori, A. (2009). Foundations of mixed methods research: Integrating quantitative and qualitative approaches in social and behavioral sciences. Los Angeles, CA: SAGE.

Trochtenberg, D.S., \& BeLue, R. (2007). Descriptors and perceptions of dyspnea in African American asthmatics. Journal of Asthma, 44(10), 811-815. doi: 10.1080/02770900701645769

U.S. Department of Health and Human Services, National Institutes of Health (2007).National Heart, Lung, and Blood Institute, National Asthma Education and Prevention Program. Expert Panel Report 3: Guidelines for the diagnosis and management of asthma. Full report 2007. Bethesda, MD: NIH Publication No. 074051 Available at: http://www.nhlbi.nih.gov/guidelines/asthma/asthgdln.pdf.

U.S. Department of Health, and Human Services, Office of Disease Prevention, and Health Promotion. (2010). National action plan to improve health literacy. Washington, DC.

Vangeest, J.B., Welch, V.L., \& Weiner, S.J. (2010). Patients' perceptions of screening for health literacy: reactions to the newest vital sign. Journal of Health Communication, 15, 402-412. doi: 10.1080/10810731003753117

Wallace, L.S., Rogers, E.S., Roskos, S.E., Holiday, D.B., \& Weiss, B.D. (2006). Brief report: screening items to identify patients with limited health literacy skills. Journal of General Internal Medicine, 21, 874-877. doi: 10.1111/j.15251497.2006.00532.x

Weiss, B.D., Mays, M.Z., Martz, W., Castro, K.M., DeWalt, D.A., Pignone, M.P.,...Hale, F.A. (2005). Quick assessment of literacy in primary care: the newest vital sign. Annals of Family Medicine, 3, 514-522. doi: 10.1370/afm.405.

Wigal, J.K., Stout, C., Brandon, M., Winder, J.A., McConnaughy, K., Creer, T.L., \& Kotses, H. (1993). The knowledge, attitude, and self-efficacy asthma questionnaire. Chest, 104, 1144-1148. 
Williams, M.V., Baker, D. W., Honig, E.G., Lee, T.M., \& Nowlan, A. (1998). Inadequate literacy is a barrier to asthma knowledge and self-care. Chest, 114, 10081015.doi: 10.1378/chest.114.4.

Williams, M.V., Davis, T., Parker, R.M., \& Weiss, B.D. (2002). The role of health literacy in patient-physician communication. Family Medicine, 34(5) 383- 389.

Williams, L.K., Joseph, C.L., Peterson, E.L., Moon, C., Xi, H., Krajenta, R.,...Pladevall, M. (2007). Race-ethnicity, crime, and other factors associated with adherence to inhaled corticosteroids. Journal of Allergy and Clinical Immunology, 119, 168175.doi: 10.1016/j.jaci.2006.09.029

Williams, J. \& MacKinnon, D.P. (2008). Resampling and distribution of the product methods for testing indirect effects in complex models. Structural Equation Models, 15(1), 23-51. doi:10.1080/10705510701758166.

Wilson, S.R., Rand, C.S., Cabana, M.D., Foggs, M.B., Halterman, Olson, L.,...Taggart, V.T. (2012). Asthma outcomes: Quality of Life. Journal of Allergy and Clinical Immunology, 129, S88-S123.

Wittman, M., Arce, E., \& Santisteban, C. (2008). How impulsiveness, trait anger, and extracurricular activities might affect aggression in school children. Personality and Individual Differences, 45, 618-623.

Wolf, M.S., Williams, M.V., Parker, R.M., Parikh, N.S., Nowlan, A.W., \& Baker, D.W. (2007). Patients' shame and attitudes toward discussing the results of literacy screening. Journal of Health Communication, 12(8), 721-732.

Zarcadoolas, C., Pleasant, A. \& Greer, D.S. (2006.) Advancing health literacy: A Framework for Understanding and Action. San Francisco, CA: Jossey-Bass 


\section{APPENDIX A. PRINT LITERACY QUESTIONNAIRE}

Patient ID\#

Age

Sex

Female

Male

Educational attainment

Never attended school or only kindergarten

_ Grades 1 through 8 (Elementary)

_ Grades 9 through 11 (Some high school)

Grade 12 or GED (High school graduate)

_College 1 year to 3 years (Some college or technical school)

_College 4 years or more (College graduate)

Health insurance coverage

Private insurance through employer insurance

Medicare/Medicaid

Uninsured

_ Private Insurance not through employer

How often do you have problems learning about your medical condition because of difficulty understanding written information?

always (5)

often (4)

sometimes (3)

occasionally (2)

never

How often do you have someone help you read hospital materials?

always (5)

often (4)

sometimes (3)

occasionally (2)

never (1)

How confident are you filling out medical forms by yourself?

extremely (1)

quite a bit (2)

somewhat (3)

a little bit (4)

not at all (5) 


\section{APPENDIX B. QUALITATIVE INTERVIEW SCHEDULE}

\section{Interview Guide}

Introduction: The purpose of this meeting with you is for you to share your thoughts, ideas, and feelings about asthma and how you learn about asthma. Also, I want to find out how you take care of your asthma and how you talk with your doctor about your asthma. There is no right or wrong answer to the questions I will ask you. Please stop and ask me a question at any time.

1. I will begin by asking you to think about how you have learned about asthma. How did you first learn about asthma?

2. How do you learn about asthma now?

3. What type of information do you need to take care of your asthma?

4. Where is the best place to get information about asthma?

5. Do you have enough information to take care of your asthma?

6. Do you have the right information to take care of your asthma?

7. What helps you take care of your asthma?

8. What are some things that make it difficult for you to take care of your asthma?

9. Do you feel you have control of your asthma? What makes you feel this way?

10. Do you feel that your asthma is out of your control? What makes you feel this way?

11. What do you feel controls your asthma? You or someone else?

12. How do you feel talking with your doctor about your asthma?

13. What does your doctor do to help you take care of your asthma?

14. Is there something else you think that your doctor could do to help you take care of your asthma?

15. Do you think that your doctor works with you to help take care of your asthma?

16. What should your doctor and other health providers be doing to help you with your asthma?

17. What suggestions do you have for other patients who have asthma to help them take care of themselves?

18. What suggestions do you have for other patients who have asthma to help them work with their doctor? 


\section{APPENDIX C. SURVEY CONSENT}

\section{Health Literacy in African-American Adults with Asthma}

You are being invited to take some surveys as part of a research study about health literacy. Health literacy is "The degree to which individuals have the capacity to obtain, process, and understand basic health information and services needed to make appropriate health decisions (Healthy People 2010)." This study is being conducted by Courtnee Melton, M.S. at the University of Tennessee Health Science Center. This study is being conducted as part of a graduate student project.

You were selected as a possible participant in the study because you are participating in the BELT: Blacks and Exacerbations on LABA vs. Tiotropium study. The study involves answering four questionnaires that will take approximately twenty minutes to complete.

There are no known risks if you decide to participate in this research study. There are no costs to you for participating in the study. The information collected for this study will not benefit you directly, but the information learned should provide information that will help health care providers understand how to better communicate with their patients.

Your participation in this study is voluntary, and there is no penalty for not participating in this study. Failure to participate in the study will not adversely affect your medical care.

All your paper research records will be stored in locked file cabinets and will be accessible only to research personnel. All your electronic research records will be computer password protected and accessible only to research personnel. Any information that is obtained in connection with this research study and that can identify you will remain confidential, protected, and will be disclosed only with your permission.

By completing the surveys, you are voluntarily agreeing to participate. You are free to decline to answer any particular question you do not wish to answer for any reason.

If you have any questions about the study, please contact:

Courtnee Melton

956 Court Ave

D220 Coleman College of Medicine Building

Memphis, TN 38163

(901) 448-2435

cmelto11@uthsc.edu\ 


\section{VITA}

Courtnee Erin Melton was born in Memphis, Tennessee, in 1984. She received her Bachelor of Science and Master of Science in Human Movement Science from the University of Memphis in 2006 and 2008, respectively.

She has presented poster presentations at the Kentucky Conference on Health Communication, AcademyHealth, and American Public Health Associations annual meetings. She also presented preliminary results from her dissertation research at the annual National Communication Association Meeting.

Courtnee Melton received a Doctor of Philosophy degree in Health Outcomes and Policy Research from the University of Tennessee Health Science Center in December 2013. Her dissertation research focused on factors that mediate the relationship between health literacy and health outcomes among African-American adults with asthma. 